Key Words:

Jet Mixing,

Turbulence Model

Retention:

Permanent

\title{
ADVANCED MIXING MODELS
}

\author{
R. A. Dimenna, S. Y. Lee, and D. A. Tamburello \\ Savannah River National Laboratory \\ D. Rector \\ Pacific Northwest National Laboratory
}

OCTOBER 2008

Savannah River National Laboratory

Savannah River Nuclear Solutions

Aiken, SC 29808

Prepared for the U.S. Department of Energy Under

Contract Number DE-AC09-08SR22470

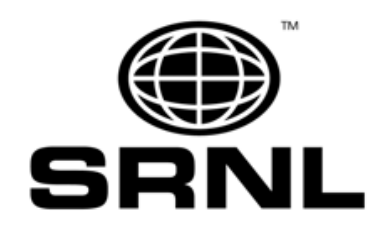


SRNS-TR-2008-00XXX

DISCLAIMER

This work was prepared under an agreement with and funded by the U.S. Government. Neither the U. S. Government or its employees, nor any of its contractors, subcontractors or their employees, makes any express or implied:

1. warranty or assumes any legal liability for the accuracy, completeness, or for the use or results of such use of any information, product, or process disclosed; or

2. representation that such use or results of such use would not infringe privately owned rights; or

3. endorsement or recommendation of any specifically identified commercial product, process, or service.

Any views and opinions of authors expressed in this work do not necessarily state or reflect those of the United States Government, or its contractors, or subcontractors.

Printed in the United States of America

Prepared for

U.S. Department of Energy 
Key Words:

Jet Mixing,

Turbulence Model

Retention:

Permanent

\title{
ADVANCED MIXING MODELS
}

\author{
R. A. Dimenna, S. Y. Lee, and D. A. Tamburello \\ Savannah River National Laboratory \\ D. Rector \\ Pacific Northwest National Laboratory
}

OCTOBER 2008

Savannah River National Laboratory

Savannah River Nuclear Solutions

Savannah River Site

Aiken, SC 29808 


\section{REVIEWS AND APPROVALS}




\section{TABLE OF CONTENTS}

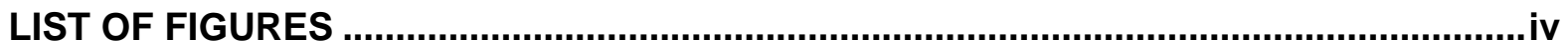

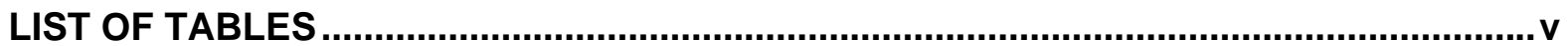

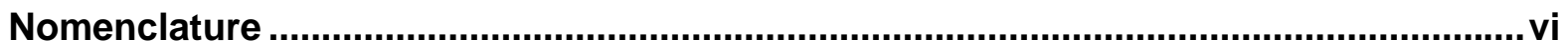

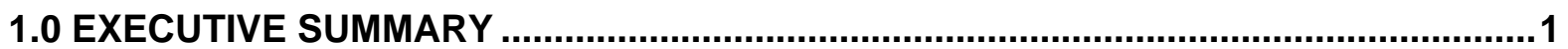

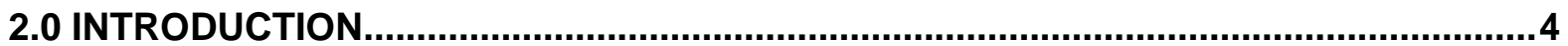

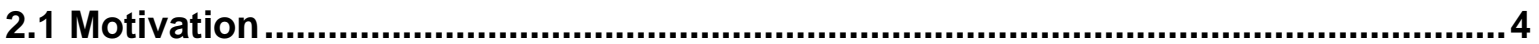

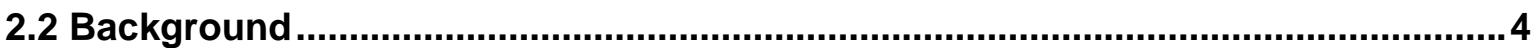

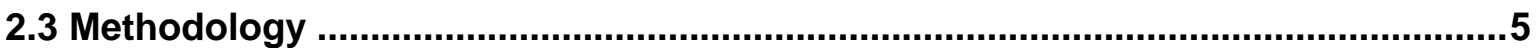

3.0 Literature Review on Jet Mixing Studies ........................................................... 9

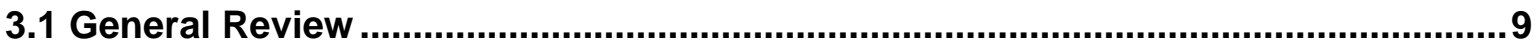

3.2 Hanford Review................................................................................................. 12

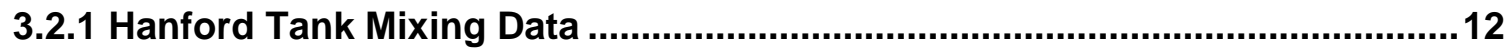

3.2.2 PNNL Computer Programs ...........................................................................13

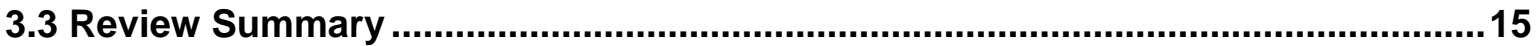

4.0 Basic Characteristics of Turbulent Flow Mixing and Its Indicators .........................17

4.1 Length Scales in Turbulent Flows .....................................................................17

4.2 Energy Cascade ............................................................................................................. 18

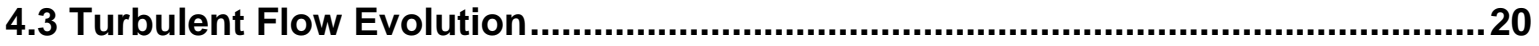

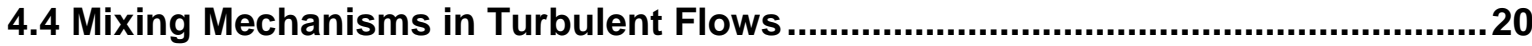

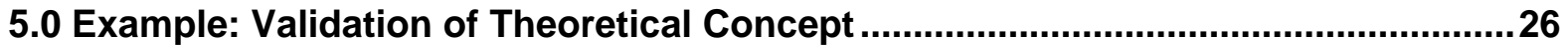

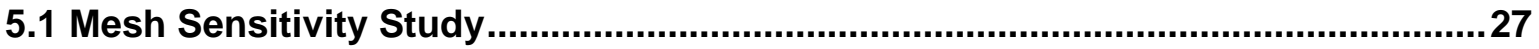

5.2 CFD Results against Grenville-Tilton Correlation for Mixing Time.......................33

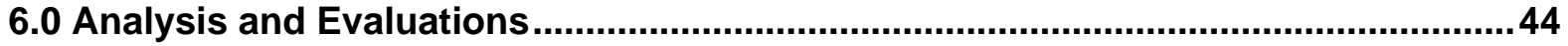

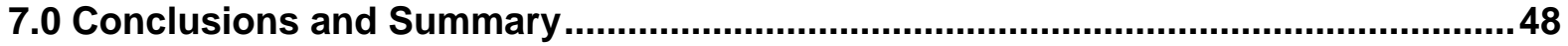

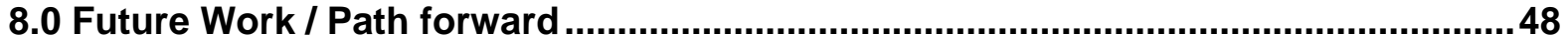

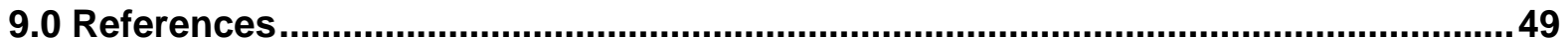

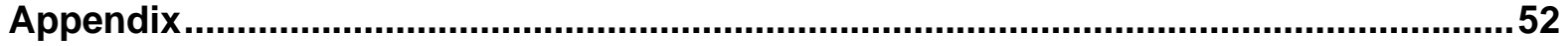

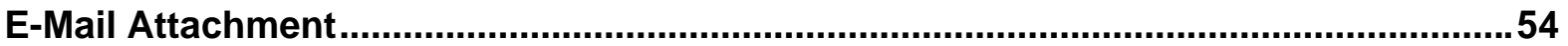




\section{LIST OF FIGURES}

Figure 1. Four different types of high-level radioactive waste storage tanks at SRS ..........6

Figure 2. Schematic of submersible pump with two opposing jets................................... 6

Figure 3. Typical velocity profiles in the direction perpendicular to the free surface from the previous modeling results of large-scale tank mixing simulations [1] ................. 9

Figure 4. Schematic of fluid entrainment into a turbulent jet via the formation of turbulent eddies at the jet boundary

Figure 5. Water entrainment due to turbulent diffusion in three-dimensional turbulent jet under steady-state flow conditions

Figure 6. Locations of nine monitoring points in the flow field domain driven by jet mixer inside the tank

Figure 7. Mesh sensitivity results for transient nondimensionalized velocity magnitudes at two monitoring locations point 4 and point 8 inside Tank B

Figure 8. Mesh sensitivity results for transient kinetic energies at two monitoring locations point 4 and point 8 inside Tank $B$

Figure 9. Mesh sensitivity results for transient eddy viscosities at two monitoring locations point 4 and point 8 inside Tank $B$

Figure 10. Mesh sensitivity results for transient nondimensionalized velocity magnitudes at two monitoring locations point 4 and point 8 inside Tank $C$

Figure 11. Mesh sensitivity results for transient kinetic energies at two monitoring locations point 4 and point 8 inside Tank $C$

Figure 12. Mesh sensitivity results for transient turbulent viscosities at two monitoring locations point 4 and point 8 inside Tank $C$.

Figure 13. Transient turbulent flow evolutions along the principal direction of jet discharge in tank B

Figure 14. Transient flow evolutions at the plane of jet discharge in tank B using RKE turbulence model.

Figure 15. Transient snapshots of flow evolutions at the horizontal planes at two different tank elevations of $0.2 \mathrm{~m}$ and $1.2 \mathrm{~m}$ in tank $\mathrm{B}$ using RKE turbulence model ........36

Figure 16. Transient local velocity magnitudes at two monitoring locations on the principal discharge direction inside Tank $B$

Figure 17. Transient turbulent kinetic energies at two monitoring locations on the principal discharge direction inside Tank $B$....

Figure 18. Transient turbulent energy dissipation rates at two monitoring locations on the principal discharge direction inside Tank B

Figure 19. Transient turbulent viscosities at two monitoring locations on the principal discharge direction inside Tank B

Figure 20. Transient local velocity magnitudes at two monitoring locations far away from the principal discharge line inside Tank B ....

Figure 21. Transient turbulent kinetic energies at two monitoring locations far away from the principal discharge line inside Tank B

Figure 22. Transient turbulent energy dissipation rates at two monitoring locations far away from the principal discharge line inside Tank $B$

Figure 23. Transient turbulent eddy viscosities at two monitoring locations far away from the principal discharge line inside Tank B

Figure 24. Comparison of transient velocity magnitudes at a monitoring location 4 on the principal discharge line for three different operating conditions (RKE turbulence model) 
Figure 25. Comparison of transient turbulent kinetic energies at a monitoring location 4 on the principal discharge line for three different operating conditions (RKE turbulence model).

Figure 26. Comparison of transient turbulent eddy viscosities at a monitoring location 4 on the principal discharge line for three different operating conditions (RKE turbulence model)

Figure 27. Comparison of transient velocity magnitudes at a monitoring location 8 far away from the principal discharge line for three different operating conditions (RKE turbulence model)

Figure 28. Comparison of transient turbulent kinetic energies at a monitoring location 8 far away from the principal discharge line for three different operating conditions (RKE turbulence model)

Figure 29. Comparison of transient turbulent eddy viscosities at a monitoring location 8 far away from the principal discharge line for three different operating conditions (RKE turbulence model)

Figure 30. Comparison of transient jet flow evolutions with steady-state literature data along the principal discharge line inside Tank B (RKE model)

Figure 31. Transient turbulence intensity at remote monitoring point 8 far away from the principal discharge line inside Tank B and Tank C (RKE model)....

Figure 32. Transient turbulence eddy viscosity at remote monitoring point 8 far away from the principal discharge line inside Tank $B$ and Tank $C$ (RKE model)....

Figure 33. Transient turbulent mixing length scales at remote monitoring locations Point 6 and Point 8 far away from the principal discharge line inside Tank B (RKE model)

\section{LIST OF TABLES}

Table 1. Pump design parameters for quad volute and standard slurry pumps used for jet mixing operations at SRS.

Table 2. Models and correlations for mixing time

Table 3. Modeling conditions and G-T mixing times for transient CFD calculations ............27

Table 4. Number of mesh nodes used in grid sensitivity study for Tank B and Tank C......29

Table 5. Test conditions of turbulent jets used in the present and literature 


\section{NOMENCLATURE}

\begin{tabular}{|c|c|}
\hline A & Area \\
\hline C & Concentarion or constant for equation \\
\hline $\mathrm{C}_{\mathrm{a}}$ & Constant used in Eq. (23) \\
\hline $\mathrm{C}_{\mathrm{eq}}$ & Equilbrium concentarion \\
\hline $\mathrm{C}_{\mathrm{o}}$ & Constant used in Eq. (1) \\
\hline $\mathrm{C}_{v}$ & Constant in Eq. (18) \\
\hline $\mathrm{D}$ & Tank diameter \\
\hline$D_{m}$ & Mass diffusion coefficient \\
\hline$d_{0}$ & Jet nozzle diameter \\
\hline $\mathrm{E}$ & Kinetic energy \\
\hline $\mathrm{F}$ & Correlation constant used in Table 2. \\
\hline$f_{\text {jet }}$ & Jet mixing time factor used in Table 2 \\
\hline g & Gravitational acceleration \\
\hline$h_{1}$ & Liquid heght \\
\hline$k$ & Turbulent kinetic energy per unit mass \\
\hline$k_{v}$ & Wave number at lower bound limit of viscous disspitation \\
\hline$k_{w}$ & Wave number used in Eq. (9) \\
\hline $\mathrm{L}$ & Jet length or maximum integral length scale \\
\hline M & Fluid momentum \\
\hline $\mathrm{m}$ & Total mass flow rate \\
\hline $\mathrm{m}_{\mathrm{o}}$ & Mass flow rate at jet inlet \\
\hline $\mathrm{m}_{1}$ & Entrained mass flow rate \\
\hline $\mathrm{p}$ & Pressure \\
\hline$\Delta p$ & Pressure drop \\
\hline Q & Volumetric flow rate \\
\hline$Q_{j}$ & Jet volumetric flow rate \\
\hline $\mathrm{R}$ & Tank or pipe radius \\
\hline$r$ & Local radial distance of turbulent jet region \\
\hline$r_{a}$ & Local radius of turbulent jet flow boundary in Eq. (20) \\
\hline $\mathrm{T}$ & Time interval used in Eq. (4) \\
\hline $\mathrm{t}$ & Time \\
\hline$t_{d}$ & Kolmogorov time \\
\hline$t_{m}$ & Mixing time in Eq. (2) \\
\hline$U_{0}$ & Velocity at jet inlet \\
\hline U & Local velocity along the jet discharge direction \\
\hline u & Transient velocity or local velocity along the $\mathrm{x}$-axis \\
\hline $\mathrm{u}_{\mathrm{i}}$ & Local velocity ( $\mathrm{i}=1$ for $\mathrm{x}$-axis, $\mathrm{i}=2$ for $\mathrm{y}$-axis, $\mathrm{i}=3$ for $\mathrm{z}$-axis ) \\
\hline $\mathrm{u}_{\mathrm{i}}^{\prime}$ & Turbulent fluctuating velocity ( $\mathrm{i}=1$ for $\mathrm{x}$-axis, $\mathrm{i}=2$ for $\mathrm{y}$-axis, $\mathrm{i}=3$ for $\mathrm{z}$-axis) \\
\hline $\mathrm{u}_{\mathrm{j}}$ & Local velocity ( $\mathrm{j}=1$ for $\mathrm{x}$-axis, $\mathrm{j}=2$ for $\mathrm{y}$-axis, $\mathrm{j}=3$ for $\mathrm{z}$-axis) \\
\hline$u_{j}^{\prime}$ & Turbulent fluctuating velocity $(j=1$ for $x$-axis, $j=2$ for $y$-axis, $j=3$ for $z$-axis) \\
\hline $\mathrm{u}_{\mathrm{x}}$ & Local velocity along the $x$-axis \\
\hline $\mathrm{u}_{\mathrm{y}}$ & Local velocity along the $y$-axis \\
\hline$<>$ & Time-averaging symbol for a parameter inside a sharp bracket \\
\hline $\mathrm{v}(\mathrm{x})$ & Local velocity at a point $x$ \\
\hline $\mathrm{V}_{\mathrm{rms}}$ & Root-mean-square velocity \\
\hline $\mathrm{x}$ & Local distance along the $x$-axis \\
\hline$\varepsilon$ & Turbulent energy dissipation rate per unit mass \\
\hline
\end{tabular}




$\begin{array}{ll}\varepsilon_{v} & \text { Turbulent energy dissipation rate per unit volume } \\ \rho & \text { Fluid density } \\ \lambda & \text { Turbulent length scale } \\ \lambda_{B} & \text { Batchelor length scale } \\ \lambda_{d} & \text { Kolmogorov length scale } \\ \lambda_{\text {dif }} & \text { Diffusion length } \\ \mu_{t} & \text { Turbulent dynamic viscosity }\left(=\rho v_{t}\right) \\ v & \text { Kinematic viscosity } \\ v_{t} & \text { Turbulent eddy diffusion coefficient } \\ \varphi_{v} & \text { Non-dimensional velocity distribution } \\ \text { Re } & \text { Reynolds number } \\ \text { Re } & \text { Reynolds number based on jet operating conditions } \\ \text { SRS } & \text { Savannah River Site } \\ \text { CFD } & \text { Computational Fluid Dynamics } \\ \text { DNS } & \text { Direct Numerical Simulation } \\ \text { DOE } & \text { United States Department of Energy } \\ \text { DWPF } & \text { Defense Waste Processing Facility } \\ \text { ECR } & \text { Effective Cleaning Radius } \\ \text { EFRT } & \text { External Flowsheet Review Team } \\ \text { FLUENT } & \text { CFD software code } \\ N-S & \text { Navier-Stokes } \\ \text { PJM } & \text { Pulse Jet Mixer } \\ \text { PNNL } & \text { Pacific Northwest National Laboratory } \\ \text { RANS } & \text { Reynolds-Averaged Navier-Stokes } \\ \text { RKE } & \text { Realizable } k-\varepsilon \\ \text { SMP } & \text { Slurry Mixer Pump } \\ \text { SMP } & \text { Submersible Mixer Pump } \\ \text { SRS } & \text { Savannah River Site } \\ \text { TEMPEST } & \text { CFD code } \\ \text { wt } & \text { weight } \\ \text { WTP } & \text { Waste Treatment Plant (at the DOE Hanford Site) } \\ & \end{array}$




\subsection{EXECUTIVE SUMMARY}

The process of recovering the waste in storage tanks at the Savannah River Site (SRS) typically requires mixing the contents of the tank with one to four dual-nozzle jet mixers located within the tank. The typical criteria to establish a mixed condition in a tank are based on the number of pumps in operation and the time duration of operation. To ensure that a mixed condition is achieved, operating times are set conservatively long. This approach results in high operational costs because of the long mixing times and high maintenance and repair costs for the same reason. A significant reduction in both of these costs might be realized by reducing the required mixing time based on calculating a reliable indicator of mixing with a suitably validated computer code.

The work described in this report establishes the basis for further development of the theory leading to the identified mixing indicators, the benchmark analyses demonstrating their consistency with widely accepted correlations, and the application of those indicators to SRS waste tanks to provide a better, physically based estimate of the required mixing time.

Waste storage tanks at SRS contain settled sludge which varies in height from zero to $10 \mathrm{ft}$. The sludge has been characterized and modeled as micron-sized solids, typically 1 to 5 microns, at weight fractions as high as 20 to $30 \mathrm{wt} \%$, specific gravities to 1.4, and viscosities up to $64 \mathrm{cp}$ during motion. The sludge is suspended and mixed through the use of submersible slurry jet pumps. To suspend settled sludge, water is added to the tank as a slurry medium and stirred with the jet pump. Although there is considerable technical literature on mixing and solid suspension in agitated tanks, very little literature has been published on jet mixing in a large-scale tank. If shorter mixing times can be shown to support Defense Waste Processing Facility (DWPF) or other feed requirements, longer pump lifetimes can be achieved with associated operational cost and schedule savings.

The focus of the present work is to establish mixing criteria associated with the waste processing at SRS and to quantify the mixing time required to suspend sludge particles with the submersible jet pump. Literature results for a turbulent jet flow are reviewed briefly, since the decay of the axial jet velocity and the evolution of the jet flow patterns are important phenomena affecting sludge suspension and mixing operations.

One of the main objectives in the waste processing is to provide the DWPF a uniform slurry composition at a certain weight percentage (typically $\sim 13 \mathrm{wt} \%$ ) over an extended period of time. In preparation of the sludge for slurrying to DWPF, several important questions have been raised with regard to sludge suspension and mixing of the solid suspension in the bulk of the tank:

- How much time is required to prepare a slurry with a uniform solid composition for DWPF?

- How long will it take to suspend and mix the sludge for uniform composition in any particular waste tank?

- What are good mixing indicators to answer the questions concerning sludge mixing stated above in a general fashion applicable to any waste tank / slurry pump geometry and fluid / sludge combination?

Grenville and Tilton (1996) investigated the mixing process by giving a pulse of tracer (electrolyte) through the submersible jet nozzle and by monitoring the conductivity at three 
locations within the cylindrical tank. They proposed that the mixing process was controlled by the turbulent kinetic energy dissipation rate in the region far away from the jet entrance. They took the energy dissipation rates in the regions remote from the nozzle to be proportional to jet velocity and jet diameter at that location. The reduction in the jet velocity was taken to be proportional to the nozzle velocity and distance from the nozzle. Based on their analysis, a correlation was proposed. The proposed correlation was shown to be valid over a wide range of Reynolds numbers $(50,000$ to 300,000$)$ with a relative standard deviation of $\pm 11.83 \%$.

An improved correlation including the effect of circulation time was proposed by Grenville and Tilton [11] via a better fit of mixing time data for turbulent jet mixing under a wider range of jet Reynolds numbers $(50,000$ to 300,000$)$. The circulation time was defined as the liquid volume divided by the entrained flow rate. They assumed that the mixing rate at the end of the jet length controls the mixing time for the entire tank by estimating the kinetic energy dissipation rate as discussed earlier. They predicted that for a given volume, an optimum geometry exists for a mixing vessel, allowing a desired mixing time to be achieved for a minimum power input. The current work will compare their correlation of the jet mixing time with CFD modeling results for their experimental tanks in an attempt to achieve a fundamental understanding of the turbulent jet mixing and to establish mixing indicators.

The literature reviews on turbulent jet mixing analysis are summarized as follows:

- Jet flow evolution plays a significant role in jet mixing including jet nozzle orientation inside the tank, range of jet Reynolds numbers, and a recirculation effect coupled with the geometrical aspect ratio of liquid depth to tank diameter.

- Mixing time is dependent on Reynolds number and scale ratios. For mixing operations with high Reynolds number, the mixing time is primarily dependent on scale ratios.

- Mixing time for a large volume tank is not affected by the angle of nozzle inclination.

- Most literature results are limited to high depth of liquid above the jet location since no vortex formations were observed at the top liquid surface. Thus, the effect of Froude number referred to the nozzle under high tank liquid level was neglected in correlating the mixing time.

- A number of tank mixing tests performed at Hanford have been identified as potential test applications.

- A Hanford lattice Boltzmann code has been identified to help provide insight into the use and interpretation of turbulence models as applied in a commercial CFD code.

Turbulence parameters identified as potential indicators of mixing within a large tank were identified based on a two-equation turbulence closure model, the RKE model. The parameters selected were the turbulent kinetic energy, the turbulent kinetic energy dissipation rate, and especially the turbulence eddy viscosity. All three were calculated for tank mixing geometries and conditions documented by Grenville and Tilton (1996) and compared against the results of their correlation for mixing time. The results obtained with CFD calculations were qualitatively similar to those observed by Grenville and Tilton, although differences were noted that will require further investigation.

The concept of using the identified mixing indicators to characterize a mixing time was shown to have promise by investigating a range of computational variations including grid sensitivity, time step sensitivity, tank geometries, jet dimensions, and Reynolds number. In 
all cases, qualitatively similar results were obtained between the calculated flow patterns and the Grenville-Tilton correlation.

Based on the results of this work, recommendations for further investigation, including the development of the theory underlying the use of the mixing indicators, are as follows:

1. Identify the most applicable turbulence model to calculate the observable parameters.

2. Characterize the impact of using special near-wall models for flow near walls and internal obstructions.

3. Define the observable parameters to be used as mixing indicators. This will include as part of the definition an evaluation of how those indicators should be observed in the computational output, and the impact of using a rotating pump or pumps as the mixing driver on the calculation of the indicators.

While all parameters affecting the calculation of turbulent flow behavior in a vessel will be considered potential variables, two of the most significant ones are grid density and Reynolds number. Both of these will be addressed as key parameters in the mixing evaluation. 


\subsection{INTRODUCTION}

\subsection{Motivation}

The process of recovering the waste in storage tanks at the Savannah River Site (SRS) typically requires mixing the contents of the tank to ensure uniformity of the discharge stream. Mixing is accomplished with one to four dual-nozzle jet mixers located within the tank. The jet mixers may be fixed in position or they may rotate depending on the specific mixing requirements.

The typical criteria to establish a mixed condition in a tank are based on the number of pumps in operation and the time duration of operation. To ensure that a mixed condition is achieved, operating times are set conservatively long. This approach results in high operational costs because of the long mixing times and high maintenance and repair costs for the same reason. A significant reduction in both of these costs might be realized by reducing the required mixing time based on calculating a reliable indicator of mixing with a suitably validated computer code.

The work described in this report establishes the basis for further development of the theory leading to identifying mixing indicators, the benchmark analyses demonstrating their consistency with widely accepted correlations, and an application of those indicators to SRS waste tanks to provide a better, physically based estimate of the required mixing time.

\subsection{Background}

Waste storage tanks at SRS consist of four types, Types I through IV, in terms of tank structure and capacity as illustrated in Fig. 1. The Type-I tank has about a 0.75-million gallon capacity with a 75-ft diameter; the others have 1- to1.3-million gallon capacities with an $85-\mathrm{ft}$ diameter. Their heights range from $25 \mathrm{ft}$ to $34 \mathrm{ft}$. They contain settled sludge which varies in height from zero to $10 \mathrm{ft}$. The sludge has been characterized and modeled as micron-sized solids, typically 1 to 5 microns, at undissolved solids concentrations, as high as 20 to $30 \mathrm{wt} \%$, specific gravities to 1.4 , and viscosities up to $64 \mathrm{cp}$ during motion.

Settling rates of the sludge suspension vary inversely with the solids weight percent and have been reported to be on the order of $5 \mathrm{inches} / \mathrm{hr}$ at $1.5 \mathrm{wt} \%$ to $0.1 \mathrm{inch} / \mathrm{hr}$ at $13 \mathrm{wt} \%$. The sludge is suspended and mixed through the use of submersible slurry jet pumps. To suspend settled sludge, water is added to the tank as a slurry medium and stirred with the jet pump.

A jet mixer pump has a bottom suction and two opposing discharge nozzles as shown in Fig. 2. Nozzle sizes range from 1.5 to 6 inches in diameter depending on the pump design. The nozzle discharge velocity is typically about $100 \mathrm{ft} / \mathrm{sec}$. The pump is immersed in the sludge layer, allowing a recirculating mixture of sludge and water to serve as the feed flow. The discharge jet entrains waste as it expands into the tank and lifts sedimented waste, or sludge, from the tank bottom. Typically, several pumps can be inserted into the waste tanks through $0.57-\mathrm{m}$ diameter openings and mounted to a rotating turntable located on the tank roof. Pump locations are typically different for every tank because of limited accessibility. Two types of the jet pumps have been typically employed for the mixing and solids suspension of the sludge at SRS. They are quad volute and standard slurry pumps. Their 
jet flow is fully-developed turbulent under typical operating conditions since its Reynolds number has around $10^{6}$ in terms of jet diameter and discharge velocity. Their designs and operating parameters are summarized and compared in Table 1. Both pump designs use a horizontal discharge, and the data in Table 1 provides an indication of the range of jet characteristics typical of the jet mixing to be evaluated as a result of the concepts developed in this project.

Although there is considerable technical literature on mixing and solid suspension in agitated tanks, very little literature has been published on jet mixing in a large-scale tank [Lee et al., 2008]. Current guidelines to ensure a homogeneous feed to the Defense Waste Processing Facility (DWPF) from the waste storage tanks are set to conservatively long mixing times and lead to slurry mixer pump (SMP) failures as a result. If shorter mixing times can be shown to support DWPF or other feed requirements, longer SMP lifetimes can be achieved with associated operational cost and schedule savings. The ultimate goal of the present work is to demonstrate through computational methods and analysis that shorter SMP mixing times can meet DWPF feed composition acceptance requirements and other performance criteria, such as $\mathrm{H}_{2}$ release requirements.

\subsection{Methodology}

Two aspects to mixing the contents of a waste tank containing settled sludge are:

1. Suspending the sludge that may have been settled in the tank for decades.

2. Mixing the suspended sludge once it has been entrained from the bottom of the tank.

Literature data [Lee et al., 2004, 2008] show that large particles are more easily eroded by streams than smaller ones. This phenomenon is more pronounced with small particles since the cohesive forces increase with decreasing size. The literature results show that for a given particle size, a certain velocity can be identified below which the particle will experience sedimentation, and a critical scour velocity, above which it will be eroded. Fluid velocity between these two values will transport solids of that size. The literature data [Lee et al., 2004] show that fluid velocity, particle size, specific gravity of particle, and tank liquid level are key parameters associated with particle suspension. It should be emphasized that the incipient velocity of erosion is actually dependent on the critical shear stress at which settled sediment begins to move. The critical shear stress of the cohesive sludge materials depends on the composition of the sludge material, the particle-size distribution, particle shape, and packing. A minimum fluid velocity for suspending cohesive sludge at SRS has been established and confirmed as $0.7 \mathrm{~m} / \mathrm{sec}(2.27 \mathrm{ft} / \mathrm{sec})$.[Lee et al., 2004] The previous work shows that this velocity, $0.7 \mathrm{~m} / \mathrm{sec}$, will erode the sludge layer for particle sizes larger than clay material (about $5 \mu \mathrm{m}$ ). Establishing this characteristic velocity for SRS sludge allows the local fluid velocity at any distance from the nozzle to be employed as a measure of the slurrying capability of the submersible jet. 

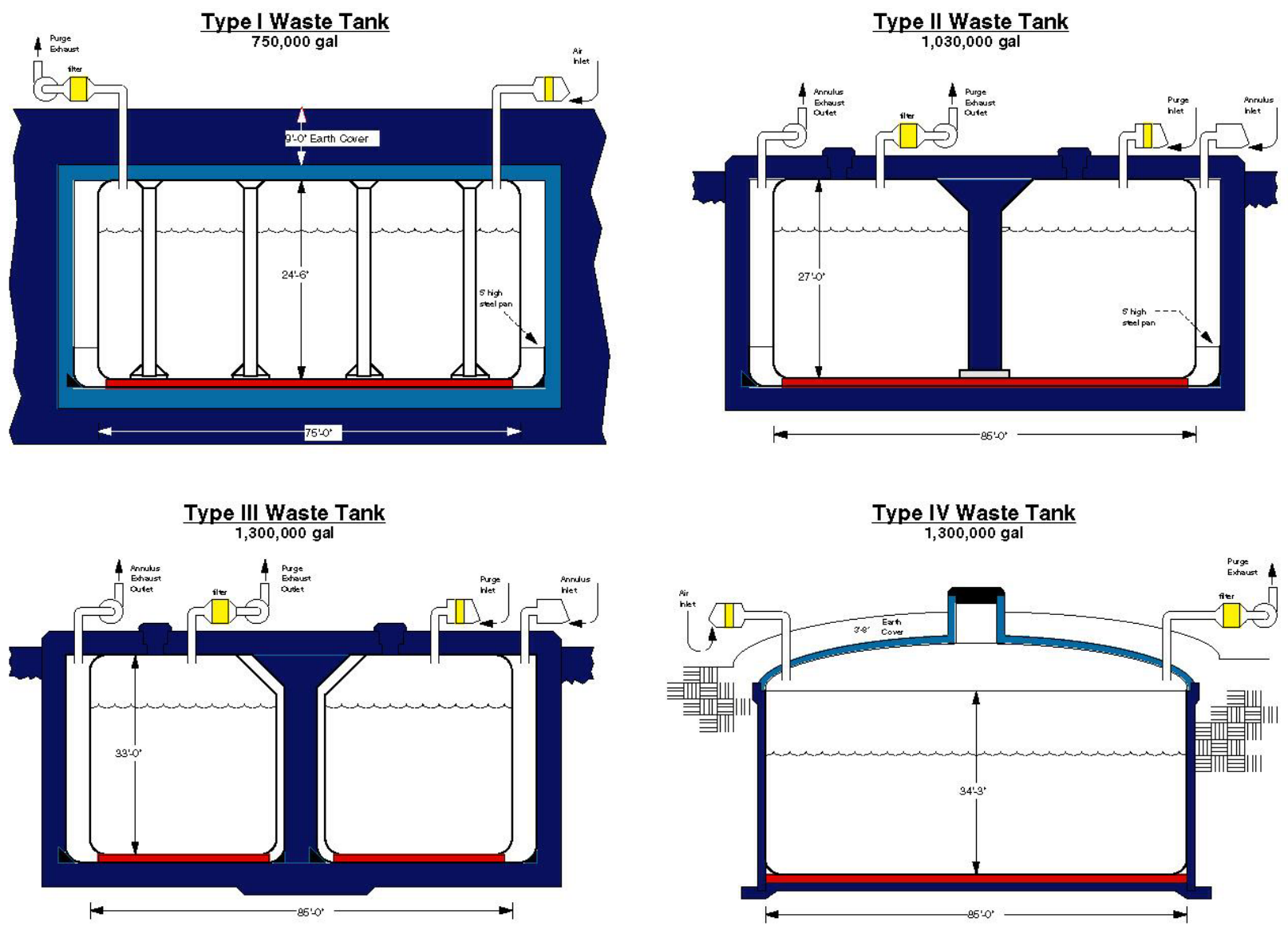

Figure 1. Four different types of high-level radioactive waste storage tanks at SRS

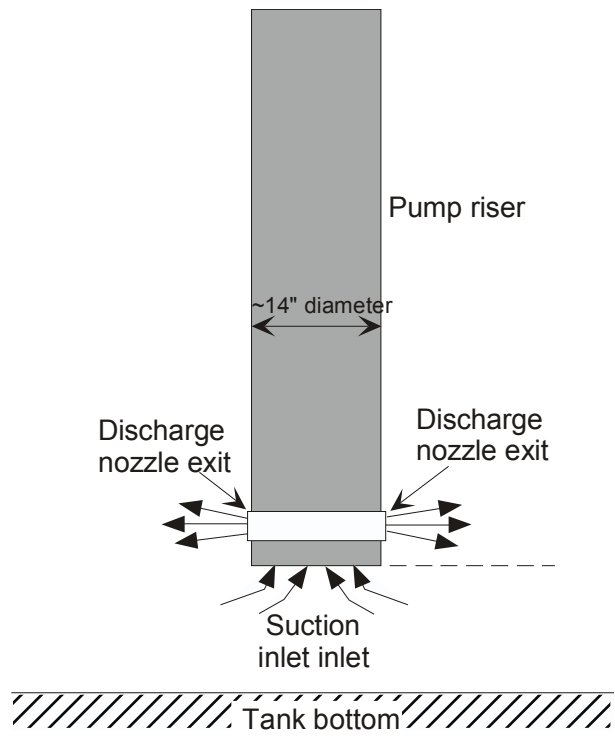

(Vertical view of slurry pump)

Figure 2. Schematic of submersible pump with two opposing jets 
Table 1. Pump design parameters for quad volute and standard slurry pumps used for jet mixing operations at SRS

\begin{tabular}{|c|c|c|}
\hline Submersible jet pumps & Quad volute pump & Standard slurry pump* \\
\hline Power, hp & 300 & 150 \\
\hline Number of nozzles & 2 & 2 \\
\hline Flow rate per nozzle, gpm & 5200 gpm (2 nozzles) & 1200 gpm (2 nozzles) \\
\hline Nozzle diameter, inches & 3.625 & 1.5 \\
\hline $\begin{array}{c}\text { Pump operation mode } \\
\text { Indexed (or fixed position) } \\
\text { or horizontal rotation }\end{array}$ & $\begin{array}{c}\text { Indexed (or fixed position) } \\
\text { or horizontal rotation }\end{array}$ \\
\hline $\begin{array}{c}\text { Pump rotation speed } \\
\text { above tank bottom, inches }\end{array}$ & 0.2 to 0.25 rpm & 0.2 to 0.25 rpm \\
\hline $\begin{array}{c}\text { Velocity at nozzle exit, } \\
\text { ft/sec (m/sec) }\end{array}$ & About 12 & About 12 \\
\hline Rejet & $2 \times 10^{6}$ & 109.0 (33.213) \\
\hline
\end{tabular}

Note:* Nominal operating conditions

The focus of the present work is on both aspects of tank mixing: to establish mixing criteria associated with the waste processing at SRS and to quantify the mixing time required to suspend sludge particles with the submersible jet pump. Prior to discussing the modeling approach, the literature results for a turbulent jet flow are reviewed briefly, since the decay of the axial jet velocity and the evolution of the jet flow patterns are important phenomena affecting sludge suspension and mixing operations.

The literature results [Abramovich, 1963, Lee et al., 2004] show that when a turbulent jet of fluid is discharged from a nozzle into a stagnant fluid medium, it both entrains fluid and expands. The fluid domain for a large-scale tank has both a solid wall boundary and a free surface boundary as the jet expands into the downstream region and ultimately recirculates via the suction on the bottom of the pump as shown in Fig. 2. The spreading fluid is retarded by the interaction with the wall as shown in Fig. 3, and the inner part of the flow may be expected to show a certain structural similarity to a boundary layer. Entrainment of quiescent fluid occurs near the outer edges of the flow, and accordingly resembles a free jet [Abramovich, 1963]. In this case sludge particles near the edge of the jet plume are entrained into a turbulent zone, and they are suspended. Estimations of minimum suspension velocity, particle settling rate, and incipient erosion velocity have been performed to support the use of a computational fluid dynamics (CFD) approach to establish and evaluate a sludge mixing criterion [Lee et al., 2008]. 
Most mixing action and entrainment takes place in the region of fully-developed flow which begins at a distance of approximately eight nozzle diameters from the exit plane [Abramovich, 1963]. From the reference [Abramovich, 1963], when a turbulent jet of fluid is discharged from a nozzle with a diameter $d_{0}$ into a quiescent fluid, the non-dimensional velocity distribution, $\varphi_{v}$, along the jet axis for a homogeneous fluid is approximated by

$\varphi_{v}=\left(\frac{v(x)}{U_{0}}\right)=C_{o}\left[\frac{x}{d_{0}}\right]^{-1}$

In Eq. (1), $C_{0}$ is a constant determined by the turbulence characteristics of the jet, $U_{0}$ the nozzle exit velocity, $v(x)$ the local velocity at a point $x$, and $x$ the distance from the nozzle. Abramovich (1963) correlated experimental data for a free turbulent jet submerged in fluid using the non-dimensional form provided by Eq. (1). From his work for free jet without any flow obstructions, the proportionality constant $C_{o}$ in Eq. (1) was determined to be 6.32 . Since the pump discharge flow inside the large-scale tanks at SRS is affected by the bottom of the tank and internal flow recirculation, the constant $C_{o}$ is evaluated from previous Tank 18 calculations rather than classical free jet theory. It was found to be 4.874 [3]. The maximum axial velocity at any axial position $x$ in an SRS waste tank can then be estimated using Eq. (1). The equation shows that the velocity at any point in the region of established flow is directly proportional to the product, $d_{o} U_{0}$. The axial entraining distance corresponding to the minimum entrainment velocity can be estimated with nozzle diameter and flow rate.

Fluid entrained in the jet region is transported and dispersed across it by motion induced from the largest to the smallest eddies. Eckart (1948) demonstrated that turbulent jet mixing can be viewed as a three-stage process of entrainment, dispersion (or stirring), and diffusion, spanning the full spectrum of space-time scales of the flow. In liquids, where species mass diffusivities are much smaller than kinematic viscosities resulting in a large Schmidt number (ratio of kinematic viscosity to mass diffusion coefficient), it is useful to split the diffusive action into two steps, one in which viscosity acts with acquisition of small-scale vorticity and the second where mass diffusion takes place. A mixed condition is reached at the time when a continuous liquid phase contains a spatially uniform composition of the discontinuous phase over the entire liquid domain of the tank. The current work focuses on the mechanical mixing related to the turbulent dispersion stirred by the jet entrainment. A discussion on turbulent mixing will be provided later.

One of the main objectives in the waste processing is to provide the DWPF a uniform slurry composition at a certain weight percentage (typically $\sim 13 \mathrm{wt} \%$ ) over an extended period of time. In preparation of the sludge for slurrying to DWPF, several important questions have been raised with regard to sludge suspension and mixing of the solid suspension in the bulk of the tank:

- How much time is required to prepare a slurry with a uniform solid composition for DWPF?

- How long will it take to suspend and mix the sludge for uniform composition in any particular waste tank?

- What are good mixing indicators to answer the questions concerning sludge mixing stated above in a general fashion applicable to any waste tank / slurry pump geometry and fluid / sludge combination? 

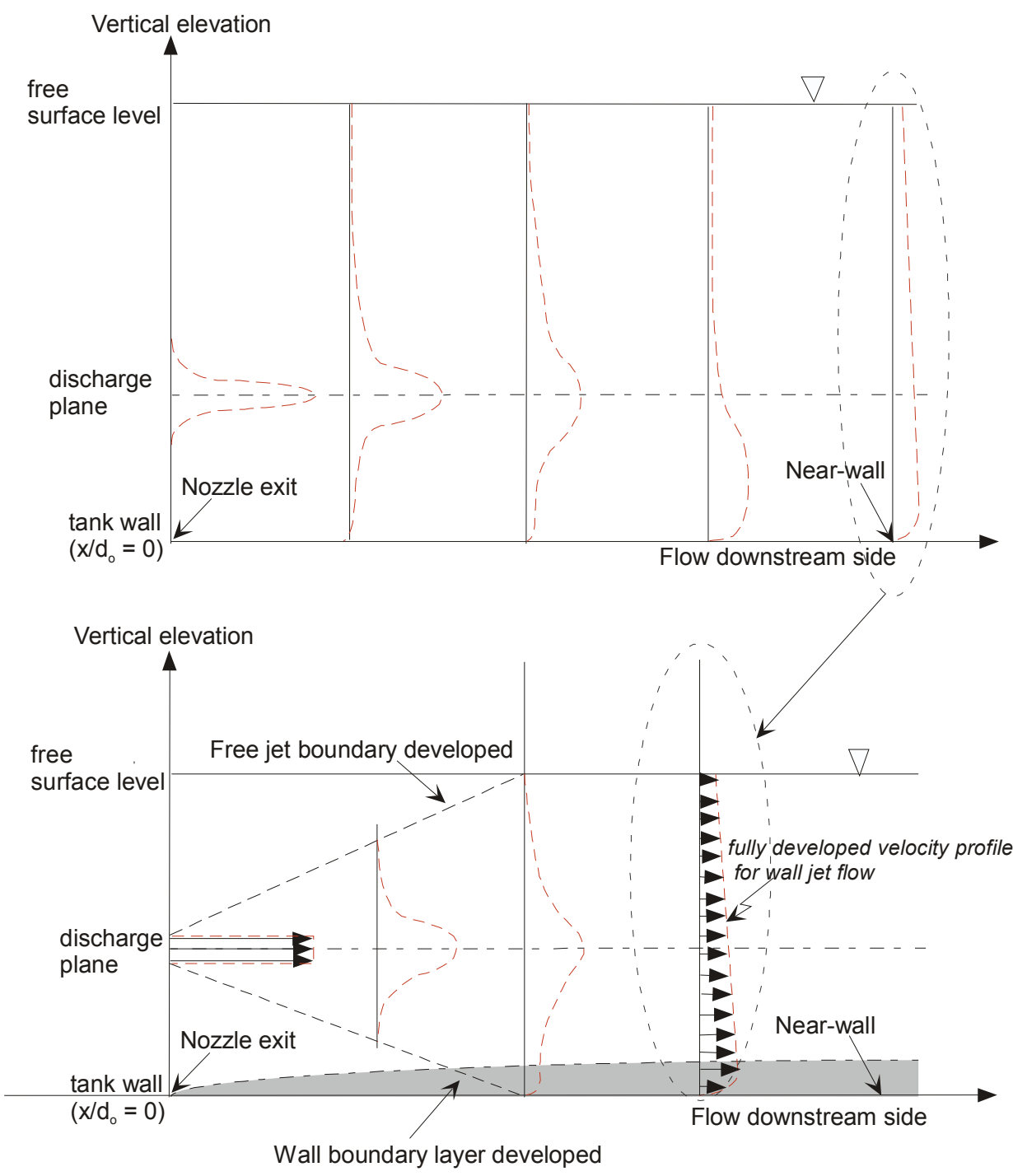

Figure 3. Typical velocity profiles in the direction perpendicular to the free surface from the previous modeling results of large-scale tank mixing simulations [1].

\subsection{LITERATURE REVIEW ON JET MIXING STUDIES}

\subsection{General Review}

Mixing is usually carried out to obtain a uniform mixture, and it can be achieved using mechanical agitators, fluid jet mixers, and static mixers or multiple T-junctions. This work is concerned with the mixing issues driven by a turbulent jet. In jet mixing, a fast stream of liquid is discharged into a stationary bulk liquid. The relative velocity between the jet region and the bulk liquid creates a turbulent mixing layer via the formation of turbulent eddies at the jet boundary as illustrated in Fig. 3. This mixing layer grows in the direction of the jet, entraining and mixing the jet liquid with the stagnant bulk liquid. Based on this concept, it 
has been assumed that longer jet lengths result in better mixing performance. The jet length, $L$, in the literature has been defined as the maximum distance a jet travels before it impinges on the opposite wall. For a cylindrical tank, the longest jet occurs when a jet is discharged at the bottom of the tank diagonally upward toward the opposite side. Thus, most researchers, including Grenville and Tilton (1996, 1997), have considered an inclined injection angle of about $45^{\circ}$ for their experimental investigations to quantify mixing performance and time.

Various techniques have been employed by researchers to examine the mixing behavior of a jet in an attempt to achieve a fundamental understanding of turbulent mixing. These include optical techniques and conductivity measurements. The experimental results for the mixed system have been proposed in the form of correlations to quantify the mixing time for a jet. These mixing correlations can be divided into two main categories. One is dependent on turbulence parameters such as turbulent kinetic energy, energy dissipation rate, and turbulent eddy viscosity, although they are not easily measurable or quantifiable. The other is dependent on measurable quantities such as tank geometrical dimensions and jet flow conditions. However, all of the literature correlations are basically related to two primary parameters, a geometrical length scale and the turbulent eddy viscosity.

Fossett and Prosser (1949) used a conductivity technique to measure mixing time for a turbulent jet. Their correlation contains tank diameter, jet diameter, and jet exit velocity. It is independent of the jet Reynolds number and does not include the effect of kinematic viscosity on the mixing time. It is applicable to the range of jet Reynolds numbers, 4,500 to 80,000. Many other researchers developed a similar correlation as shown in Table 2.

Fox and Gex (1956) indicated that mixing time is dependent on the jet Reynolds number. The Reynolds number is defined in terms of propeller diameter and speed. As jet flow is changed from laminar $(\operatorname{Re}=300)$ to the turbulent flow regime $(\operatorname{Re}=150,000)$, its dependence on the jet Reynolds number becomes weaker.

Lane and Rice (1982) investigated liquid jet mixing employing an inclined side entry jet. In their experimental study, conductivity measurements for tracer concentration were made at a monitoring point at any time to estimate the mixing time. They studied two designs for inclined side entry jet mixing, and they correlated their data to develop a general expression for mixing time in terms of measurable parameters such as jet velocity, tank dimensions, and fluid properties. They proposed a correlation for jet mixing time to predict the time required to achieve a $95 \%$ degree of mixing throughout the tank using an inclined jet located at the side entry near the tank bottom. For $\mathrm{C}_{\mathrm{eq}}$ the equilibrium concentration and $\mathrm{C}$ the transient concentration at a monitoring point, the $95 \%$ mixing time $t_{m}$ was defined by

$t_{m}=\left|\frac{C-C_{e q}}{C}\right|<0.5$

Their correlation has a mixing time factor, $F$, and the factor is a function of the jet Reynolds number, which is similar to the friction factor associated with the momentum dissipation. It is noted that the $\mathrm{F}$ factor exhibits two different trends in the laminar and the turbulent regions as shown in Table 2. As discussed earlier, its dependence on jet Reynolds number is significant in the laminar region and weak in the turbulent regime. 
A number of experimental studies have been carried out to investigate the flow patterns associated with jet mixing. Maruyama et al. (1982) reported mixing times for horizontal jets, inclined jets toward top free surface, and jets vertical to tank floor. In this case, jet was located near the corner of tank floor. They proposed that the mixing time is a function of Reynolds number and jet length, but they emphasized the role of the flow patterns inside the tank on the mixing time behavior.

Perona et al. (1998) performed mixing experiments with water in two different scales of tanks. They are $2 \mathrm{ft}$ in diameter by $10 \mathrm{ft}$ in length ( 230 gallons) and $10 \mathrm{ft}$ in diameter by $40 \mathrm{ft}$ in length (25,000 gallons). The smaller one was about $1 / 6$ linear scale of the actual storage tanks and was made of Plexiglas to permit flow visualization studies. Data were taken with a single jet placed about a quarter tank length from one end pointed horizontally towards the center of the tank. The jet nozzles were straight pieces of pipe, and their diameter and velocity were varied with this configuration. Jet diameters of $0.62,0.87$, and 1.61 inches were tested with the jet located 1.25 inches above the tank bottom for the two smaller diameters and 1.75 inches above the floor for the largest-diameter jet in each of the two tanks. Tests were also made with two-directional opposed jets along the same axis at this location and also at the center of the tank lengthwise. In all cases the jet was positioned close to the bottom of the tank, in the range of 1 to 4 jet diameters from the floor to the jet centerline. They measured jet mixing times for long horizontal tanks with length-to-diameter ratios of 4 and 5 . Mixing times in the 230 gallon tank decreased from 1800 seconds to 300 seconds as the jet Reynolds number was increased from 15,000 to 130,000 . With a single jet in the 25,000 gallon tank, mixing times decreased from 4500 to 840 seconds as the jet Reynolds number was increased from 80,000 to 311,000 . For two-opposing jets of the same diameter and location, mixing times were not significantly different from those of the single jet at the same flow rate. At a given flow rate, mixing times were significantly lower with a 1.38-in double jet than with a 1.93-in double jet. They found that about 28 tank volumes must be recirculated through the entrained jet for good mixing with tanks of this configuration. Their empirical correlation for mixing time is shown in Table 2.

Grenville and Tilton (1996) investigated the mixing process by giving a pulse of tracer (electrolyte) through the jet nozzle and by monitoring the conductivity at three locations within the tank. They proposed that the mixing process was controlled by the turbulent kinetic energy dissipation rate in the region far away from the jet entrance. They took the energy dissipation rates in the regions remote from the nozzle to be proportional to jet velocity and jet diameter at that location. The reduction in the jet velocity was taken to be proportional to the nozzle velocity and distance from the nozzle. Based on this analysis, a correlation was proposed. The proposed correlation was shown to be valid over a wide range of Reynolds numbers with a relative standard deviation of $\pm 11.83 \%$.

An improved correlation including the effect of circulation time was proposed by Grenville and Tilton (1997) via a better fit of mixing time data for turbulent jet mixing under a wider range of jet Reynolds numbers $(50,000$ to 300,000$)$. The circulation time was defined as the liquid volume divided by the entrained flow rate. They assumed that the mixing rate at the end of the jet length controls the mixing time for the entire tank by estimating the kinetic energy dissipation rate as discussed earlier. They predicted that for a given volume, an optimum geometry exists for a mixing vessel, allowing a desired mixing time to be achieved for a minimum power input. This optimum condition occurs when the aspect ratio of the tank height to diameter is $2^{-0.5}$. The current work will compare the Grenville and Tilton (1997) correlation of the jet mixing time with CFD modeling results for their experimental tanks in an 
attempt to achieve a fundamental understanding of the turbulent jet mixing and to establish mixing indicators.

\subsection{Hanford Review}

\subsubsection{Hanford Tank Mixing Data}

A significant fraction of the Hanford tank waste is in the form of solid particulates and the major transport and processing issues include solids mobilization and mixing. Therefore, the tank mixing experiments performed at the Hanford site have been almost exclusively focused on the resuspension and mixing of solid particulates using jet pumps. The early Hanford tank jet mixing experiments have been summarized in Powell et al. (1997).

Several Hanford tank mixing studies were conducted from 1987 to 1994 using either 1/25scale, 1/12-scale or bench-scale tanks. The primary focus of these studies was the extent of mobilization and mixing uniformity of the suspended solids. One metric for solids mobilization is the effective cleaning radius (ECR), which is defined as the distance between the mixer pump nozzle exit and the beginning of the sludge bank following pump operation. The results of these experiments were correlated with system parameters such as jet nozzle diameter and velocity and material properties including sludge shear strength.

The following are summaries of the earlier Hanford tank mixing studies:

- In fiscal year 1987, PNNL conducted a series of ten 1/12-scale sludge mobilization tests. Two scale mixer pumps and a scale model of the 22 air-lift circulators were used. The ECRs were determined as a function of time by probing with a steel bar to locate the sludge band boundary. The simulant consisted of a mixture of silica/soda ash with a shear strength of approximately $1000 \mathrm{~Pa}$ for most of the tests.

- In fiscal year 1988, another series of experiments were conducted using a simulant with a higher shear strength (1500-6000 Pa). The simulant consisted of a mixture of kaolin clay, water, salt, and colloidal silica (Ludox). The results did not correlate well with the 1987 results or the vane shear strength.

- To determine why the anticipated correlation between shear strength and ECR was not observed for the kaolin/Ludox simulant, a series of bench-scale mobilization tests were conducted using three different simulants: kaolin clay, bentonite clay and silica/soda ash (Whyatt et al.).

A series of 1/12-scale tank experiments were conducted in 1992 in support of the tank 241SY-101 hydrogen mitigation issue (Fort et al. 1993). Stationary and rotating mixing jets are used to resuspend settled solids on the tank bottom. Fluid axial velocity profiles were measured at different radial locations from the jet using pitot tubes and electromagnetic probes. The two methods gave comparable results for pure water. The pitot tubes were not usable for suspensions due to the density variation. Other information includes the percent of settled solids that was resuspended, suspended solids concentrations as a function of location within the tank and "breakthrough" times. Data was taken for jet velocities in the range of $15-50 \mathrm{ft} / \mathrm{sec}$. The simulant consisted of a mixture of water, SiO2 flour (Minusil-30), salt and sugar. 
A series of experiments were conducted is fiscal year 1995 to determine the jet pump operating conditions required to maintain solid suspension uniformity once the solids have been suspended (Bamberger et al. 1995). A uniform suspension is defined as one where the solids concentration at all locations in the tank is within $10 \%$ of the mean. The experiments were conducted in a 1/12-scale tank and used four different simulants to cover the different combinations of small/large particle diameters and low/high fluid viscosity. The concentrations were measured using two methods: bottle samples to measure average concentrations and ultrasonic measurements to measure real time concentrations. Tests were performed at flow rates corresponding to $100 \% U_{\circ} d_{o}, 75 \% U_{o} d_{o}, 50 \% U_{\circ} d_{o}$, and $25 \%$ $U_{o} d_{0}$, where the reference product of the exit velocity and nozzle diameter is $14.6 \mathrm{ft}^{2} / \mathrm{sec}$.

The introduction of pulse jet mixers (PJM) prompted a series of experiments to validate the PJM model in the TEMPEST computer program (Bontha et al. 2003). Two different tanks were used: a small-tank test stand with a single pulse tube and a large-tank test stand with four pulse tubes. The fluid velocities were measured by hot film anemometry in the small tank and by electromagnetic flow sensors in the large tank. Other data collected as a function of time included tank level (capacitance probe), pressure (transducer), temperature (thermocouples) and density (Coriolis mass flow meters). The densities and fluid velocity profiles were compared with TEMPEST simulation results as a function of time to validate the PJM model.

Most recently, a series of tank experiments were conducted to determine whether the Waste Treatment Plant (WTP) mixing system designs are adequate to process the solids that will be received by the plant (Meyer et al. 2008). This work was in response to the EFRT (external Flowsheet review team) Issue M3 - Inadequate Design of Mixing System PJM Test Program. Tests were conducted in 34- and 70-inch diameter tanks using pulse jets to determine the extent of solids resuspension and mixing. Four different simulants were used with a variety of particle size distributions and density ratios. The data collected included solids off-bottom using Doppler velocimetry transducers, visual observation of the solids cloud height and solids concentration profiles measured using an ultrasonic attenuation probe. The results were used to develop a correlation for the critical suspension velocity.

\subsubsection{PNNL Computer Programs}

Pacific Northwest National Laboratory has developed two computer programs that may be used to address tank mixing, especially for systems involving suspended solids. The first is TEMPEST (Trent and Eyler 1993), a general purpose finite-volume CFD program that has been applied to a wide variety of tank mixing issues. A summary of TEMPEST features includes the following:

- Cartesian or cylindrical or boundary fitted (orthogonal curvilinear) coordinates

- Turbulence model $(\mathrm{k}-\varepsilon)$

- Scalar transport

- Non-Newtonian viscosity models

- Sludge erosion/deposition

- Translating boundaries

The tank mixing applications addressed using the TEMPEST program include: 
- Numerical simulation of jet mixing concepts in Tank 241-SY-101 (Trent and Michener 1993)

- Tank SY-101 waste retrieval assessment (Onishi et al. 1996)

- Tank 241-AZ-101 criticality assessment resulting from pump jet mixing (Onishi and Recknagle 1997)

- Sludge bed erosion using fluid jets (Onishi and Trent 1998)

- Performance evaluation of rotating pump jet mixing of radioactive wastes in Hanford tanks 241-AP-102 and -104 (Onishi and Recknagle 1998)

- Simulation of Hanford tank 241-C-106 waste release into tank 241-Y-102 (Onishi and Recknagle 1999)

- Pump jet mixing and pipeline transfer assessment for high-activity wastes in Hanford tank 241-AZ-102 (Onishi et al. 2000)

- Optimal elevation and configuration of Hanford's double-shell tank waste mixer pumps (Onishi et al. 2002)

- Feasibility study on using a single mixer pump for tank 241-AN-101 waste retrieval (Onishi et al. 2003)

- Retrieval and pipeline transfer assessment of Hanford tank 241-AN-105 waste (Onishi et al. 2003)

- Assessment of tank 241-S-112 liquid waste mixing in tank 241-SY-101 (Onishi et al. 2003)

- Feasibility study on using two mixer pumps for tank 241-AY-102 waste mixing (Onishi and Wells 2004)

The primary disadvantage of using the TEMPEST program in conducting further mixing studies is that it does not efficiently scale up on parallel computers, and therefore is not able to take advantage of the dramatic increase in computational power.

An alternative computer program for simulation of multiphase tank mixing has been recently developed at PNNL and is based on the lattice Boltzmann/ lattice kinetics methods (Succi 2001). The lattice methods are inherently parallelizable and effectively use the resources of massively parallel computers. Features of the program include:

- A RANS k- $\varepsilon$ turbulence model

- A dynamic sediment bed model based on a phase-field representation. The model includes changes due to deposition and erosion and bed flow based on lithostatic forces.

- A suspended solids field was added that includes hindered settling, turbulent mixing and normal stress contributions to the flow solution.

- Thermodynamic chemistry model (in progress)

- The computer program is currently being validated using data from the M-1 pipe transfer experiments

Note that the solids are represented using two different continuum fields. The suspended solids are treated as passive scalars in the flow field, including terms for hindered settling and Brownian diffusion. The sediment bed interface is represented using a continuum phase field with a diffuse interface. The bed may change with time due to settling, resuspension and deposition through convection. The bed may be permeable with an associated Darcy flow resistance. The erosion rates are calculated using the local shear stress obtained from the turbulence model. The method is demonstrated by modeling the evolution of a sediment bed in a circular pipe under different flow regimes. 


\subsection{REVIEW SUMMARY}

The literature review on the quantitative measurement and evaluation of flow entrainment by a jet stream and the time required to reach a certain degree of homogeneity has been performed to investigate key turbulent parameters for use as mixing performance indicators. The literature reviews on turbulent jet mixing analysis are summarized as follows:

- Jet flow evolution plays a significant role in jet mixing including jet nozzle orientation inside the tank, range of jet Reynolds numbers, and a recirculation effect coupled with the geometrical aspect ratio of liquid depth to tank diameter.

- Mixing time is dependent on Reynolds number and scale ratios. For mixing operations with high Reynolds number, the mixing time is primarily dependent on scale ratios.

- Mixing time for a large volume tank is not affected by the angle of nozzle inclination.

- Most literature results are limited to high depth of liquid above the jet location since no vortex formations were observed at the top liquid surface. Thus, the effect of Froude number referred to the nozzle was neglected in correlating the mixing time.

- A number of tank mixing tests performed at Hanford have been identified as potential test applications.

- A Hanford lattice Boltzmann code has been identified to help provide insight into the use and interpretation of turbulence models as applied in a commercial CFD code. 
Table 2. Models and correlations for mixing time

\begin{tabular}{|c|c|c|c|}
\hline Model & Authors & Mixing time & Validity \\
\hline $\begin{array}{l}\text { Empirical } \\
\text { model }\end{array}$ & $\begin{array}{l}\text { Grenville and } \\
\text { Tilton (1996) }\end{array}$ & $3.0\left(\frac{L}{d_{o}}\right)^{2}\left(\frac{d_{0}}{U_{o}}\right)$ & $\left(50,000<\operatorname{Re}_{\mathrm{jet}}<300,000\right)$ \\
\hline $\begin{array}{l}\text { Empirical } \\
\text { model } \\
\text { including the } \\
\text { effect of } \\
\text { circulation time }\end{array}$ & $\begin{array}{l}\text { Grenville and } \\
\text { Tilton (1997) }\end{array}$ & $\begin{array}{l}S\left(\frac{D^{2}}{U_{o} d_{o}}\right)\left(\frac{h_{l}}{L}\right), \text { where } S=9.34 \text { for } \theta \\
>15^{\circ} \text {, and } S=13.8 \text { for } \theta<15^{\circ} .\end{array}$ & $\begin{array}{l}\quad\left(50,000<\operatorname{Re}_{\text {jet }}<300,000\right) \\
\text { The parameter } \theta \text { in their } \\
\text { correlation is inclination } \\
\text { angle of the jet nozzle and } \\
\text { the horizontal. }\end{array}$ \\
\hline $\begin{array}{l}\text { Empirical } \\
\text { model }\end{array}$ & $\begin{array}{l}\text { Fossett and } \\
\text { Prosser (1949) }\end{array}$ & $\frac{9.0 D^{2}}{U_{o} d_{o}}$ & $\left(4,500<\mathrm{Re}_{\text {jet }}<80,000\right)$ \\
\hline $\begin{array}{l}\text { Empirical } \\
\text { model }\end{array}$ & $\begin{array}{l}\text { Fox and Gex } \\
\quad(1956)\end{array}$ & $\begin{array}{l}\frac{f_{\text {jet }} h_{l}^{0.5} D}{\left(U_{o} d_{o}\right)^{4 / 6} g^{1 / 6}}\left(f_{\text {jet }}=f(R e) \text { for jet }\right. \\
\text { mixing })\end{array}$ & $\left(270<\operatorname{Re}_{\mathrm{jet}}<155,000\right)$ \\
\hline $\begin{array}{l}\text { Empirical } \\
\text { model }\end{array}$ & $\begin{array}{l}\text { Perona et al. } \\
\quad(1998)\end{array}$ & $\begin{array}{l}C\left(\frac{V_{T}}{Q_{j}}\right)\left(\frac{d_{o}}{L}\right), \text { where the constant } C \\
\text { is about } 28 \text { from data. }\end{array}$ & $\begin{array}{l}\text { Long horizontal tank for } d_{o}= \\
0.6 \mathrm{~m}, \mathrm{H}=3 \mathrm{~m}, \mathrm{~d}=16,22,41 \\
\mathrm{~mm} \text { (including two opposing } \\
\text { horizontal jets) }\end{array}$ \\
\hline $\begin{array}{l}\text { Empirical } \\
\text { model }\end{array}$ & $\begin{array}{c}\text { Okita and } \\
\text { Oyama (1963) }\end{array}$ & $5.5\left(\frac{h_{l}}{D}\right)^{0.5}\left(\frac{D}{d_{o}}\right)^{2}\left(\frac{d_{o}}{U_{o}}\right)$ & $\begin{array}{l}\text { Inclined side entry jet }(5,000 \\
\left.\quad<\operatorname{Re}_{\text {jet }}<100,000\right)\end{array}$ \\
\hline $\begin{array}{l}\text { Empirical } \\
\text { model }\end{array}$ & $\begin{array}{l}\text { Lane and Rice } \\
\qquad(1982)\end{array}$ & $\begin{array}{l}F\left(\frac{h_{\ell}^{0.5} D}{\left(U_{o} d_{o}\right)^{0.667} g^{0.166}}\right) \text {, where } F= \\
C_{1}\left(\operatorname{Re}_{j e t}\right)^{-1.133} \text { for laminar flow and } \\
C_{2}\left(\operatorname{Re}_{j e t}\right)^{-0.166} \text { for turbulent flow }\end{array}$ & $\left(200<\operatorname{Re}_{\text {jet }}<100,000\right)$ \\
\hline $\begin{array}{l}\text { Dispersion } \\
\text { model } \\
\text { (G. I. Taylor) }\end{array}$ & Fischer (1973) & $C\left(\frac{\lambda^{2}}{v_{t}}\right)$ & $\begin{array}{l}\text { The constant } C \text { is dependent } \\
\text { on flow conditions. }\end{array}$ \\
\hline $\begin{array}{l}\text { Eddy } \\
\text { dissipation } \\
\text { model }\end{array}$ & Spalding (1971) & & $\begin{array}{c}\text { High } \mathrm{Re} \\
\text { (fully turbulent region) }\end{array}$ \\
\hline $\begin{array}{l}\text { Engulfment } \\
\text { model }\end{array}$ & $\begin{array}{l}\text { Baldyga and } \\
\text { Bourne (1984) }\end{array}$ & $C\left(\frac{v_{t}}{c}\right)^{0.5}$ & $\begin{array}{l}\text { High } \operatorname{Re} \text { (fully turbulent } \\
\text { region) } \\
\text { The constant } C \text { is dependent } \\
\text { on flow conditions. }\end{array}$ \\
\hline
\end{tabular}




\subsection{BASIC CHARACTERISTICS OF TURBULENT FLOW MIXING AND ITS INDICATORS}

A turbulent flow consists of high levels of fluctuating vorticity. At any instant, vortical motion, called eddies, are present in the flow. These eddies range in size from the largest geometric scales of the flow down to small scales where molecular diffusion dominates. The eddies are continuously evolving in time, and the superposition of their induced motions leads to fluctuating waves. Turbulent kinetic energy is passed from the largest eddies to the smallest though a process called the energy cascade. At the smallest scales, the energy is dissipated as heat by a viscous effect. Thus, one of basic characteristics of turbulent flow is dissipation of kinetic energy. To maintain turbulence, a constant supply of energy must be fed to the turbulent fluctuations at the largest scales from the mean motion.

Understanding the turbulent energy dissipation process associated with solids or tracer mixing requires understanding the basic characteristics of turbulent flow. These characteristics include unpredictability, rapid diffusivity, high levels of varying vorticity, and dissipation of kinetic energy. For a stationary velocity record, the instantaneous velocity $u$ can be decomposed into the sum of time-averaged and fluctuating components, which is called Reynolds decomposition.

$u=<u>+u^{\prime}$

In this equation, $<u>$ is the time-averaged quantity denoted as a sharp bracket, and $u$ ' is the fluctuating component corresponding to the deviation from the time-averaged value. The time-averaged fluctuating velocity is zero. Higher order statistical terms such as the variance are used as the magnitude of the fluctuations. For instance, the square root of the variance of the velocity fluctuations $\sqrt{\left\langle u^{\prime 2}\right\rangle}$ is non-zero, and it is defined as the root-meansquare (rms) velocity and denoted as $v_{r m s}$. When $T$ is a time much longer than the longest turbulent fluctuations in the flow, $\mathrm{v}_{\mathrm{rms}}$ is expressed as

$$
v_{r m s}=\sqrt{\left\langle u^{\prime 2}>\right.}=\sqrt{\frac{1}{T} \int_{0}^{T}(u-<u>)^{2} d t}
$$

The velocity $v_{r m s}$ is used in quantifying the degree of local fluctuating velocity and is referred to as turbulent intensity in the literature [Hinze, 1975].

\subsection{Length Scales in Turbulent Flows}

Motions in a turbulent flow exist over a wide range of length and time scales. The largest scales are limited by geometric dimensions such as pipe diameter or the depth of a large scale tank. These large scales are referred to as the integral length scales.

Experimental observations show that eddies lose most of their energy after one or two transits of the integral length scale. The rate of energy transferred from the largest eddies is proportional to their energy times their rotational frequency. The turbulent kinetic energy is proportional to the velocity squared, where the velocity is the fluctuating velocity characterized by the standard deviation. The rotational frequency is proportional to the rms velocity, $v_{r m s}$, divided by the integral length scale $L$. From the Kolmogorov scaling law, the dissipation rate $\varepsilon$ is of the order $\left(v_{\mathrm{rms}}\right)^{3} / L$ in the inertial regime of homogeneous isotropic 
turbulence before it reaches a scale where viscous dissipation becomes dominant. Following this formulation, Tennekes and Lumley (1972) estimated the dissipation length scale in terms of turbulent kinetic energy $k$ and energy dissipation rate $\varepsilon$ as

$$
\lambda \approx k^{1.5} / \varepsilon
$$

It is noted that the rate of dissipation is independent of the fluid viscosity, and it is only dependent on the motion scale. However, the scale at which the energy dissipation occurs is strongly dependent on the fluid viscosity. Hence, the dissipation scale is estimated by combining the dissipation rate and the kinematic viscosity in an expression with dimensions of length, known as the Kolmogorov scale, $\lambda_{\mathrm{d}}$.

$$
\lambda_{d} \sim\left(v^{3} / \varepsilon\right)^{0.25}
$$

Similarly, a time scale $t_{d}$ and velocity scale $v_{d}$ of the smallest eddies can be formed. They are

$$
t_{d} \sim(v / \varepsilon)^{0.5} \text { and } v_{d} \sim(v \varepsilon)^{0.25}
$$

An analogous length scale can be estimated for the range at which molecular diffusion acts on a scalar quantity. This length scale is referred to as the Bachelor length scale, $\lambda_{B}$, and it is estimated as

$$
\lambda_{B} \sim\left(v D_{m}^{2} / \varepsilon\right)^{0.25}
$$

The ratio of the Kolmogorov to Bachelor length scales is equal to the square root of the Schmidt number, Sc. The Schmidt number is the ratio of kinematic viscosity, $v$, to molecular diffusion coefficient, $D_{m}$.

Using SRS waste tank mixing as an example, the local suspension velocity is $0.01 \mathrm{~m} / \mathrm{sec}$ and the integral length scale is roughly 6 inches corresponding to half of loose sludge layer. The fluid is water at room temperature with a kinematic viscosity of $10^{-6} \mathrm{~m}^{2} / \mathrm{sec}$. The Kolmogorov length $\lambda_{d}$ and time $t_{d}$ scales are about $0.6 \mathrm{~mm}(=0.024 \mathrm{in})$ and 0.4 seconds, respectively. When a diffusivity $D_{m}=10^{-9} \mathrm{~m}^{2} / \mathrm{sec}$ for the chemical tracer is used, the Batchelor scale $\lambda_{B}$ is about $0.02 \mathrm{~mm}$, which is about 31 times smaller than the Kolmogorov scale. These results show that the molecular concentration field has a much finer structure than the velocity field.

\subsection{Energy Cascade}

Turbulence causes the formation of eddies of many different length scales which populate the energy spectrum. The energy spectrum characterizes the turbulent kinetic energy distribution as a function of length scale, indicating the amount of turbulent kinetic energy contained in a specific length scale. A fundamental parameter describing the turbulence is the energy dissipation rate. It defines the rate at which energy is generated at the larger scales, cascades through the inertial subrange, and is finally dissipated in the viscous 
subrange of the turbulent spectrum. Most of the kinetic energy of the turbulent motion is contained in the large length scales. The energy cascades from these large scale structures to smaller scale structures by an inertial and essentially inviscid mechanism. This process continues, creating smaller and smaller structures which produces a hierarchy of eddies. Eventually this process creates structures that are small enough that molecular diffusion becomes important and viscous dissipation of energy finally takes place. The scale at which this happens is known as the Kolmogorov length scale, $\lambda_{d}$.

Energy is introduced into the turbulent energy spectrum at the largest length scale, $L$, and cascades down to the smallest eddies, which are on the order of the Kolmogorov length $\lambda_{d}$. When the size of eddies is small enough, molecular diffusion, which smoothes out the concentration gradients of the $2^{\text {nd }}$ phase, is invoked. These two length scales at the extremes of the energy cascade can differ by several orders of magnitude at high Reynolds numbers. In between there is a range with its own characteristic length $\lambda$ that has formed at the expense of the energy of the large ones. These scales are very large compared with the $\lambda_{\mathrm{d}}$, but still very small compared with the large scale of the flow. The range of length scales is then, $\lambda_{d}<\lambda<L$. When a turbulent jet mixer discharges fluid through a nozzle of diameter $d_{o}$, the turbulent wave number $k_{w}$ induced by the jet corresponds to its own characteristic length $\lambda$. The wave number $k_{w}$ of an eddy length scale $\lambda$ is given by

$$
\lambda=2 \pi / k_{w} .
$$

A hypothesis of Kolmogorov was that at very high Reynolds numbers, the statistics of scales in the range $\lambda_{d}<\lambda<d_{o}$ are universally and uniquely determined by the scale $\lambda$ and the rate of energy dissipation $\varepsilon$.

The large turbulent length scales in the flow dictate the rate of energy dissipation. These large length scales draw energy from the mean flow, then transfer the energy to successively smaller scales until it is dissipated at the Kolmogorov microscale. Thus, turbulent mixing transfers energy over the entire range of wave numbers, from the lowest value of $k_{w}$ to the maximum value of $k_{w}$. Over the intermediate range of the wave numbers, say, less than $k_{v}$, the viscous dissipation of energy is not important. This is called as the inertial range. Beyond $k_{v}$ the spectrum is affected by the diffusion process. This entire process is referred to as the energy cascade.

The energy distribution at the largest length scales is generally controlled by the flow geometry and mean flow velocity magnitude. The smallest length scales are many orders of magnitude smaller than the largest scales and hence are isotropic in nature. In between these two bounding scales, $\lambda_{d}<\lambda<L$, the spectrum is only a function of the length scale $\lambda$ and the dissipation rate $\varepsilon$. Hence, the energy cascade spectrum depends on the dissipation rate because the largest length scales set the rate and the energy is transferred through this range. The dissipated energy will contribute to mixing a second component or tracer species into the continuous fluid medium. The large length scales have the most energy and the distribution in that range depends on the boundary conditions. The smallest scales have less energy by several orders of magnitude. As discussed in the previous section, the smallest scale is the Batchelor scale $\lambda_{B}$, more than an order of magnitude smaller than the Kolmogorov scale $\lambda_{d}$. 


\subsection{Turbulent Flow Evolution}

Turbulent flows must satisfy conservation of mass and momentum. Thus, in principle, the incompressible continuity and Navier-Stokes equations can be solved for the instantaneous turbulent flow field via direct numerical simulation (DNS). The difficulty is that an enormous range of scales must be accounted for in the calculation. To accurately simulate the turbulent flow field, the calculation must span the largest geometric scales down to the Kolmogorov and Batchelor length scales as discussed earlier. Even with the fastest, largest modern supercomputers, such a calculation can be achieved only for simple geometries with small computational domains at low Reynolds numbers.

In most situations, engineers are satisfied with an accurate assessment of the timeaveraged flow quantities. To derive the time-averaged flow equations, the instantaneous conservation equations are modified by substituting the Reynolds decomposition, such as representing the instantaneous local velocity by mean and fluctuating velocity components. This results in time averaged equations and a Reynolds stress tensor corresponding to the momentum transport due to the turbulent eddy fluctuations. While the evolution equations for the time-averaged quantities are valid, they can not be solved since several new unknown quantities are introduced, resulting in more unknowns than equations. This is the closure problem of turbulence [Tennekes and Lumley, 1972]. One of the unknown important quantities is related to the addition of the gradient of $\left\langle u_{i}^{\prime} u_{j}^{\prime}\right\rangle$ to the time-averaged momentum equation. It is related to the energy transport due to the turbulent fluctuations. This production term in the turbulence energy equation is identical to the loss to turbulence term in the balance equation for the kinetic energy of the mean motion.

The energy budget for mean kinetic energy indicates that the total change in kinetic energy of the mean flow results from the combined effects of transport, viscous dissipation and loss to turbulence. The mean flow feeds energy to the large turbulence scales as discussed earlier. Viscous dissipation is generally small for the mean flow since the mean velocity gradients are small. The transport terms represents the spatial movement of mean kinetic energy.

The loss to turbulence term in the mean kinetic energy balance is identical to the shear production term, $\rho<u_{i}^{\prime} u_{j}^{\prime}>\frac{\partial<u_{i}>}{\partial x_{j}}$, in the energy budget of turbulent kinetic energy [Hinze, 1975]. These terms correspond to kinetic energy transfer from the mean scales to the turbulent scales. In the balance equation of turbulent kinetic energy, the viscous dissipation is not small. The dissipation of turbulent kinetic energy $\left\langle u_{i}{ }^{\prime} u_{j}{ }^{\prime}\right\rangle$ is an important characteristic of every turbulent flow as discussed in the previous section.

\subsection{Mixing Mechanisms in Turbulent Flows}

The current work is concerned with mechanical mixing related to the formation of a uniform composition when a large scale tank is stirred by a turbulent jet. The turbulent flows contain irregular motions over a wide range of length and time scales. Hence, the major question is how these motions contribute to mixing, resulting in patterns of turbulent jet dissipation and the composition decay of tracer components as a function of distance from the jet exit. 
The turbulent energy dissipation term $\left\langle u_{i}^{\prime} u_{j}^{\prime}\right\rangle$, referred to as the apparent shear stress tensor in the literature, is an important characteristic of turbulent decay when a jet is injected into a stagnant fluid. The mixing length $\lambda$ and the turbulent eddy viscosity $v_{t}$ depend on the relative magnitude of the turbulent shear stress and the mean velocity gradient [Kays and Crawford, 1980]. That is,

$$
\lambda=\frac{\sqrt{\left|\left\langle u_{i}^{\prime} u_{j}^{\prime}\right\rangle\right|}}{\left(\frac{\left.\partial<u_{i}\right\rangle}{\partial x_{i}}\right)}=\sqrt{\frac{v_{t}}{\left(\frac{\left.\partial<u_{i}\right\rangle}{\partial x_{i}}\right)}}
$$

In Eq. (10) the integers, $\mathrm{i}$ and $\mathrm{j}$, represent coordinate indices. For instance, when the integer i value is equal to 1,2 , or 3 , it means $x-, y-$, or $z$-coordinate in a Cartesian coordinate system, respectively. The eddy viscosity $v_{t}$ in the equation, referred to as apparent viscosity in the literature, is dependent on Reynolds number, boundaries, and position in fluid. In contrast, molecular viscosity is independent of Reynolds number and position in the fluid medium. It is a physical viscosity and a transport property of fluid. The eddy viscosity is estimated from spectral quantities of the turbulence data involving turbulent kinetic energy $(k)$ and its dissipation rate $(\varepsilon)$. As discussed in Section 4.1, the spectral information of the velocity fluctuations is used to estimate the length scale, which provides information on the eddy viscosity. The turbulent eddy viscosity is a primary measure of length scale for momentum dissipation, and it is responsible for most of the mixing, as discussed by Tennekes and Lumley (1972).

The turbulent mixing of two fluids or of a fluid and entrained solids to promote chemical reactions or a fluid-solid slurry is a common process in modern industry. Effective use of turbulence can increase interfacial contact of species present in the primary fluid. Fluid or solid entrained in a turbulent region is transported and dispersed across a vessel by motion initiated at the largest eddies and transferred to the smallest eddies, where molecular diffusion has the opportunity to act. At this smallest scale, the ability of a high Reynolds number turbulent flow to generate large interfacial area permits the mixing to proceed effectively. This work will focus on the turbulent mixing process over the inertial range, which is related to fluid dynamical scales of most flows of interest, and is referred to as stirring or suspension mixing. Therefore, the mixing scales considered here are much larger than the ones required to molecularly mix two fluids [P. L. Miller, CIT thesis, 1991].

Large scale tanks at Savannah River Site (SRS) are equipped with submersible mixer pumps (SMP) containing two opposed jets to stir the sludge that is settled on the tank floor. Most fluid regions stirred by the jets may have isotropic turbulence with large Reynolds numbers since the scale size of the fluid domain is much larger than that of nozzle size. Shear at a solid wall is negligibly small so that the turbulence energy created by the jets is dissipated isotropically. Large eddies formed by a jetted fluid near the pump are not isotropic, but as the eddies are dissipated into the fluid domain, the smaller eddies formed by the dissipation process become independent of the original direction and magnitude of the jetted velocity and eventually become nearly isotropic. Larger eddies carry particles across the streamlines, and smaller eddies cause the particles to spread and disperse into the continuous fluid medium.

As shown in Fig. 4, surrounding fluid is entrained into a turbulent jet and mixed with quiescent bulk fluid via turbulent eddies at the boundary of the jet region. As result of this, 
turbulent shear stress increases rapidly due to the sudden increase of the mean velocity gradient. Thus, the turbulent eddy viscosity can be used as a good indicator for bulk mixing.

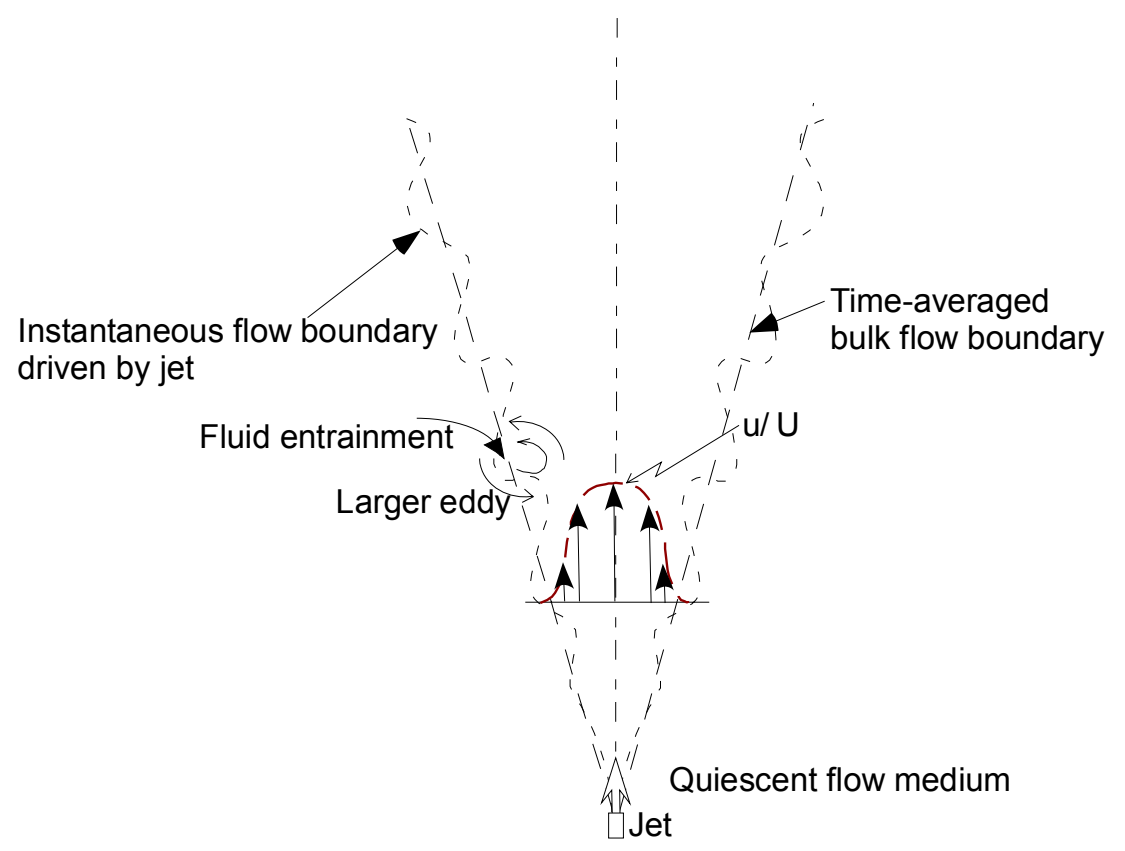

Figure 4. Schematic of fluid entrainment into a turbulent jet via the formation of turbulent eddies at the jet boundary

Most numerical models used to simulate turbulent mixing use time scales defined in terms of local isotropic properties. As shown in Table 2, most mixing times were determined by an empirical approach in terms of geometrical length scales and turbulent parameters. The mixing time is defined by a dissipation time scale for the energy containing eddies in the socalled inertial range. That is

$t=\left(\frac{k}{\varepsilon}\right)$

The kinetic energy per unit mass, $k$, is equal to $0.5 v_{r m s}{ }^{2}$, where $v_{r m s}$ is defined in Eq. (4). The turbulent dissipation rate per unit mass $\varepsilon$ can be estimated by the ratio of the power per unit volume involved in the mixing process. The power consumed by the process is given by the product of volumetric flow and pressure drop required for pumping flow. The pressure drop associated with the mixing flow requirement can be approximated with the Hagen-Poiseuille equation.

From the equations derived in Appendix, turbulent energy dissipation rate per unit volume $\varepsilon_{V}$ is calculated by Eq. (12).

$\varepsilon_{v} \approx\left(\frac{Q \Delta p}{V}\right)=\left(\frac{Q \Delta p}{\pi R^{2} L}\right)=32\left(\frac{u}{D}\right)^{2} \mu_{t}$ 
All parameters used in Eq. (12) are defined in Appendix. Turbulent energy dissipation rate per unit mass, $\varepsilon$, is associated with turbulent eddy viscosity.

$$
\varepsilon=\frac{1}{\rho} \varepsilon_{v}=32\left(\frac{u}{D}\right)^{2} v_{t}
$$

When combined with the kinetic energy $0.5 u^{2}$ and turbulent energy dissipation rate given by Eq. (13), the mixing time $t$ due to turbulent eddy dissipation is seen to be proportional to the square of a length scale, and inversely proportional to eddy viscosity.

$$
t=C\left(\frac{D^{2}}{\left(\frac{\mu_{t}}{\rho}\right)}\right)=C\left(\frac{D^{2}}{v_{t}}\right)
$$

The constant $\mathrm{C}$ in the above equation is a proportionality constant which can be determined by the literature data after a minimum value of eddy viscosity required for complete mixing is determined by Grenville and Tilton's correlation. Their empirical correlation for mixing time is consistent with the Equation (14) presented in terms of length scale and eddy viscosity.

In 1941, A. N. Kolmogorov introduced the idea that the smallest scales of turbulence are universal (similar for every turbulent flow) and that they depend only on $\varepsilon$ and $v$. The definitions of the Kolmogorov microscales can be obtained using this idea and dimensional analysis. Since the dimension of kinematic viscosity is length ${ }^{2} /$ time, $^{2}$ and the dimension of the energy dissipation rate per unit mass is length ${ }^{2} /$ time $^{3}$, the only combination that has the dimension of time is $t_{d}=(v / \varepsilon)^{0.5}$ which is the Kolmorogov time scale. Similarly, the Kolmogorov length scale is the only combination of $\varepsilon$ and $v$ that has dimensions of length.

The Kolmogorov (1941) theory is a mean field theory since it assumes that the relevant dynamical parameter is the mean energy dissipation rate. In fluid turbulence, the energy dissipation rate fluctuates in space and time, so it is possible to think of the microscales as quantities that also vary in space and time. However, standard practice is to use mean field values since they represent the typical values of the smallest scales in a given flow.

Theoretical analysis and experimental studies of mixing processes will result in an increased understanding of the mechanics that may lead to the development of improved mixing devices or mixing indicators. For instance, suppose the order of magnitude of the mixing time that can be achieved is examined. The diffusion length $\lambda_{\text {dif }}$ is given by $\sim \sqrt{D_{m} t}$ where $D_{m}$ is the diffusion coefficient and $t$ is the mixing time. The length scale, $\lambda_{d}$, of the smallest eddies is given by Kolmogorov (1941) as given by Eq. (6). In his equation, $v$ is the kinematic viscosity and $\varepsilon$ is the rate of dissipation of turbulent energy per unit mass. An efficient mixing device will dissipate a substantial fraction of the turbulent energy in the mixing time, so $\varepsilon$ is roughly related to $E / t$ where $E$ is the initial energy of the turbulence. $E$ is basically $u^{2}$ where $u$ is defined in Eq. (13). Sufficient mixing requires that the order of magnitude of $\lambda_{d}$ be at least as small as that of $\lambda_{\text {dif }}$, so the minimum order of magnitude of the mixing time is found by equating $\lambda_{d}$ to $\lambda_{\text {dif. }}$ That is 
$t \approx\left(\frac{v^{3}}{\left(D_{m} u\right)^{2}}\right)=\left(\frac{D_{m}}{u^{2}}\right) S c^{3}$

The dimensionless number in the equation, $S c$, is the Schmidt number, the ratio of momentum dissipation to mass diffusion. When diffusion mixing is achieved for typical operating conditions of the waste tanks at SRS, $D \sim 10^{-9} \mathrm{~m}^{2} / \mathrm{sec}$ and $\mathrm{u} \sim 0.01 \mathrm{~m} / \mathrm{sec}$, the minimum order of magnitude of mixing time $t$ is about 3 hours for a kinematic viscosity of the fluid $v \sim 10^{-6} \mathrm{~m}^{2} / \mathrm{sec}$. It is noted that this time is much longer than the one controlled by the integral length scale in Sec. 4.1.

An example of a turbulent mixing layer is illustrated diagrammatically in Fig. 4 . It is assumed that a uniform irrotational stream emerges from a nozzle into a region where the surrounding fluid is at rest at atmospheric pressure. A sheet of vorticity will be generated at the interface between the moving fluid and the stationary fluid and this leads to the formation of a wedgeshaped turbulent mixing layer. It is observed experimentally that the turbulent mixing layer spreads outwards at a relatively small angle as indicated in the diagram, although it should be noted that the edges of the turbulent zone are intermittent in character like the outer edge of a turbulent boundary layer [Forstall and Shapiro, 1950]. When the turbulent boundary layer equation is applied to the mixing layer along the $x$-direction of the primary water flow as shown in Fig. 5, and the pressure gradient in the $x$-direction is assumed to be zero, the steady-state momentum conservation equation for the boundary mixing region in the $x$ direction is given as

$$
\rho\left(\overline{u_{x}} \frac{\partial \overline{u_{x}}}{\partial x}+\overline{u_{y}} \frac{\partial \overline{u_{x}}}{\partial y}\right) \approx-\rho\left(\frac{\partial\left(\overline{u_{x}^{\prime} u_{y}^{\prime}}\right)}{\partial y}\right)
$$

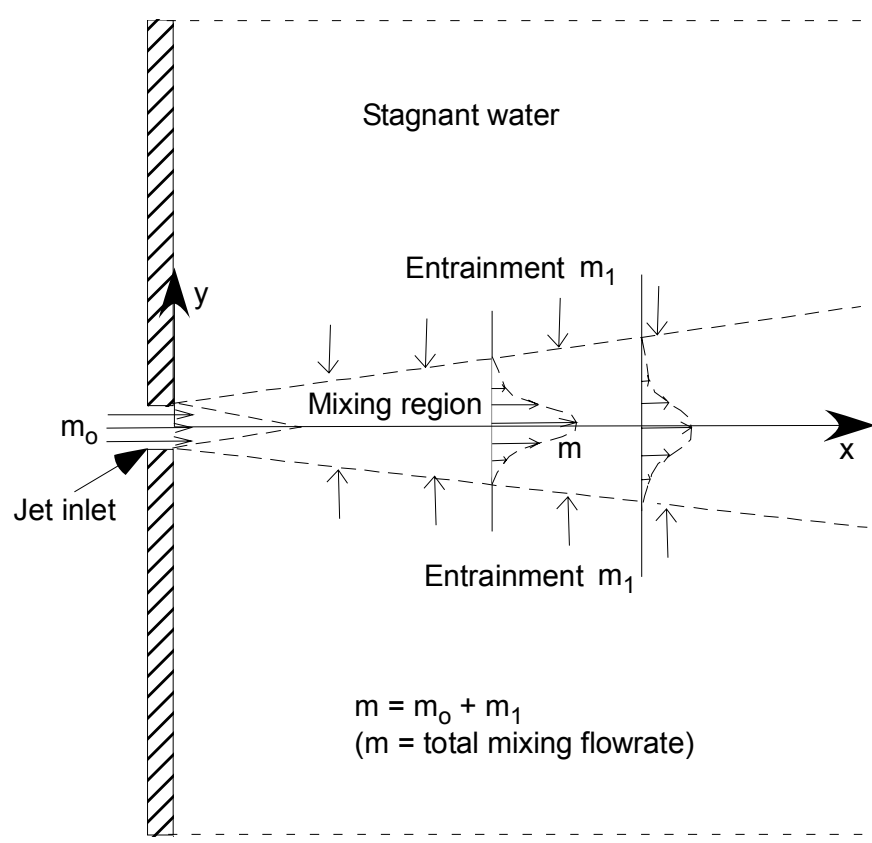

Figure 5. Water entrainment due to turbulent diffusion in three-dimensional turbulent jet under steady-state flow conditions 
Following the literature approach [Kays and Crawford, 1980] regarding the Reynolds stress term on the right-hand side of Eq. (16), it is reasonably assumed that the kinematic eddy viscosity $v_{t}$ should be constant with respect to $y$ over the cross-section of the mixing layer. Using this assumption and the basic hypothesis of the turbulent mixing length, $\lambda$, the righthand side term of the equation can be given in terms of the kinematic eddy viscosity $v_{\mathrm{t}}$, that is,

$$
\left(\overline{u_{x}^{\prime} u_{y}^{\prime}}\right)=-\lambda^{2}\left|\frac{\partial \overline{u_{x}}}{\partial y}\right|\left(\frac{\partial \overline{u_{x}}}{\partial y}\right)=-v_{t}\left(\frac{\partial \overline{u_{x}}}{\partial y}\right)
$$

In Eq. (18) turbulent diffusivity is described by the center-line velocity $U$ at distance $x$, assuming that the eddy viscosity is proportional to the thickness of mixing layer multiplied by the overall velocity difference $U$.

$$
v_{t}=C_{v} U x
$$

From Eqs. (16) and (17), the resulting equation becomes

$$
\left(\overline{u_{x}} \frac{\partial \overline{u_{x}}}{\partial x}+\overline{u_{y}} \frac{\partial \overline{u_{x}}}{\partial y}\right) \approx v_{t}\left(\frac{\partial^{2} \overline{u_{x}}}{\partial^{2} y}\right)
$$

From Eq. (19), the flow momentum driven by the jet is dissipated by turbulent eddy diffusivity, $v_{t}$, leading to the entrainment of the stagnant fluid into the water core region. Thus, the core region will eventually disappear because of the turbulent diffusion. During the turbulent diffusion process, the fluid momentum $M$ should be conserved along the bulk flow direction. When $U$ is local maximum velocity at any distance $x$ from the fluid inlet, the momentum at $x$ becomes

$$
M=2 \pi \rho\left(r_{a}\right)^{2} U^{2} \int_{0}^{1}\left(\frac{\overline{u_{x}}}{U}\right)^{2}\left(\frac{r}{r_{a}}\right) d\left(\frac{r}{r_{a}}\right)=\text { cons tant }
$$

Hence, for a self-preserving flow pattern with profile similarity, Eq. (20) becomes

$$
U r_{a}=U x=\text { cons } \tan t
$$

The total flow rate $m$ at local distance $x$ is given by

$$
m=2 \pi \rho\left(r_{a}\right)^{2} U \int_{0}^{1}\left(\frac{\overline{u_{x}}}{U}\right)\left(\frac{r}{r_{a}}\right) d\left(\frac{r}{r_{a}}\right)
$$

When Eq. (21) is substituted for the local maximum velocity $U$ under a self-preserving velocity profile, Eq. (22) becomes

$$
m=m_{o}+m_{1}=C_{o} r_{a}=C_{1} x \sim \frac{C v_{t}}{U}
$$


In Eq. (23) $m_{o}$ and $m_{1}$ are flowrate at the inlet and total entrainment flow, respectively. The equation shows that the total mass flowrate increases linearly with respect to the distance $x$ from the jet inlet from the stagnant surrounding fluid because of turbulent eddy viscosity at the edge of the boundary layer. This is consistent with test results [Ricou and Spalding, 1961]. As demonstrated by this example, turbulence dissipation due to eddies takes place in the downstream region of jet for large Reynolds number flow. During the momentum decay of the free jet, isotropic turbulent eddies occur since for a large-scale tank there is a large distance from a solid wall.

The viscous shear of an incompressible fluid flow near a solid wall results in the formation of vortex eddies. However, eddies formed by the motion of a solid object such as mechanical impeller are large, and they are not isotropic. As these eddies in a large scale tank decay, they transfer energy to smaller fluid fragments creating smaller eddies. These smaller eddies generated become independent of the solid object geometry. The smaller eddies are considered isotropic, that is, they depend only on the power supplied and on the viscous dissipation. The present work will focus on the mixing evolved by isotropic turbulence.

Most mixing correlations developed by measured data have combinations of physical parameters such as jet diameter, jet velocity, tank diameter, and liquid viscosity as shown in Table 2. They all indicate that the most important parameter to determine mixing time is the momentum flux added to the tank [Fox and Gex, 1956]. They observed a clear effect of the jet Reynolds number on the mixing time except for high Reynolds numbers (larger than $4,500)$. Mixing time was a strong function of Reynolds number in the laminar jet regime, but only a weak function in the turbulent regime.

\subsection{EXAMPLE: VALIDATION OF THEORETICAL CONCEPT}

As the previous review has shown, turbulent flows contain irregular motions over a wide range of length and time scales. The energy spectrum characterizes the turbulent kinetic energy distribution as a function of length scale, indicating the amount of turbulent kinetic energy contained in a specific length scale. Throughout the energy cascade, the turbulent eddy viscosity $v_{t}$ is a primary measure of length scale for momentum dissipation, and it is responsible for most of the mixing [Tennekes and Lumley, 1972]. When a chemical tracer or solid component introduced into the fluid is assumed to be mixed by the process of the turbulent energy cascade, key turbulence parameters such as turbulent dissipation rate and eddy viscosity are expected to provide a good signature or indicator of mixing performance.

The current work will primarily compare the Grenville-Tilton (G-T) correlation (1996) of the jet mixing time with CFD modeling results for their experimental tanks in an attempt to achieve a fundamental understanding of the turbulent jet mixing and to establish the usefulness and application of mixing indicators. These results will be also used to validate the principle of using key turbulence parameters as mixing indicators under three different conditions in a qualitative way. The three modeling conditions considered here are summarized in Table 3. These conditions are provided by the reference [Grenville and Tilton, 1996].

Special care has been taken to explore the representation of the energy dissipation rate and turbulent eddy viscosity as these parameters are the drivers for turbulent mixing. The realizable $k-\varepsilon$ model (RKE) in FLUENT has the option to use a new formulation for eddy 
viscosity, which includes the effect of vorticity transport. The current work is mainly based on the RKE model since the standard $k-\varepsilon$ model is well known to be valid only for very large Reynolds number (i.e., greater than $10^{6}$ Reynolds number). The RKE model uses new improved formulations for eddy viscosity and energy dissipation rate to include the dissipation effect of vorticity transport.

Table 3. Modeling conditions and G-T mixing times for transient CFD calculations

\begin{tabular}{|l|l|l|l|l|l|l|l|}
\hline \multicolumn{1}{|c|}{ Tank } & \multicolumn{1}{|c|}{$\begin{array}{c}\mathrm{D} \\
\text { (Tank dia.) }\end{array}$} & $\begin{array}{c}\mathrm{h}_{\mathrm{l}} \\
\text { (liquid } \\
\text { height) }\end{array}$ & $\begin{array}{c}\text { Inclination } \\
\text { angle of }_{\text {Jet }}^{*}\end{array}$ & $\begin{array}{c}\mathrm{d}_{\mathrm{o}} \\
\text { (jet dia.) }\end{array}$ & $\begin{array}{c}\mathrm{U}_{\mathrm{o}} \\
\mathrm{m} / \mathrm{sec}\end{array}$ & \multicolumn{1}{|c|}{$\mathrm{Re}_{\text {jet }}$} & $\begin{array}{c}\text { Mixing time } \\
\text { by G-T } \\
\text { correlation }\end{array}$ \\
\hline Tank A & $1.68 \mathrm{~m}$ & $1.55 \mathrm{~m}$ & $42.6^{\circ}$ & $9.4 \mathrm{~mm}$ & 2.2 & 20,680 & $758 \mathrm{sec}$. \\
\hline Tank B & $1.68 \mathrm{~m}$ & $1.55 \mathrm{~m}$ & $42.6^{\circ}$ & $26.1 \mathrm{~mm}$ & 19.8 & 516,780 & $30 \mathrm{sec}$. \\
\hline Tank C & $36 \mathrm{~m}$ & 11.16 & $17^{\circ}$ & $50 \mathrm{~mm}$ & 19.5 & 975,000 & $4371 \mathrm{sec}$. \\
\hline
\end{tabular}

Note: *Jet is located at the corner of tank bottom as shown in Fig. 6.

\subsection{Mesh Sensitivity Study}

Basic strategy of the CFD method is to replace the continuous problem domain with a discrete domain using a grid. In this work, grid sensitivity analyses were performed to make sure that the numerical solutions are insensitive to the grid sizes of the entire computational domain. Three different mesh sizes were applied to assess their impact on the flow solutions for two configurations of Tank $B$ and Tank $C$ as shown in Table 3 . The grid was refined based on gradients in the velocity magnitude, with the location of the adapted cells being concentrated around the jet mainstream. The steady flow solutions coupled with the RKE turbulence model were used to determine the regions of highest velocity gradients for the gradient-based adaptation. Each tank was refined two times and the overall mesh size was increased approximately $30 \%$ during each grid refinement. The second grid refinement was based on regions of highest velocity gradients in the previously adapted regions in order to provide further mesh density in the regions surrounding the jet mainstream. Table 4 provides the number of nodes used in each of the grid refinements.

Simulations were performed on two different computational platforms: SUN Enterprise 6900 server with $48 \mathrm{CPUs}(1.5 \mathrm{GHz})$ and $388 \mathrm{~GB}$ of RAM; and SUN Ultra 40 workstation with 4 CPUs $(2.4 \mathrm{GHz})$ and $16 \mathrm{~GB}$ of RAM. To measure the computational performance across all configurations, the total clock time for each simulation $(20,600$ iterations) is normalized per 1 million finite volumes and 4 CPUs. Given these stipulations, simulations using RKE required approximately $50 \mathrm{hrs}$ of clock time on the workstation and $80 \mathrm{hrs}$ on the server.

Appropriate combinations of time step size and iterations per time step were determined by an optimization study. For the baseline Tank B, a time step size of $0.004 \mathrm{~s}$ was used for $0<$ $t<4 \mathrm{~s}$ (1000 time steps), a time step size of $0.04 \mathrm{~s}$ was used for $4<t<8 \mathrm{~s}$ (100 time steps), and a time step size of $0.2 \mathrm{~s}$ was used for $8<t<200 \mathrm{~s}$ (960 time steps). The expected mixing time for this configuration was on the order of $30 \mathrm{~s}$. These numbers were scaled for Tanks $A$ and $C$ based on the relative expected mixing time. For Tank $A$, the incremental time steps sizes were $0.1,1$, and $5 \mathrm{~s}$. For Tank $\mathrm{C}$, the incremental time steps sizes were 0.6 , 
6 , and $30 \mathrm{~s}$. Note that the total number of time steps (2060) and the iterations per time step (10) were kept constant for all simulations. Thus each simulation required 20,600 iterations to go from $t=0$ to a flow time equivalent to 5 times the expected mixing time from Grenville and Tilton $(1996,1997)$.

During the numerical simulation of jet flow in each of the three tanks, nine locations inside the tank were monitored as shown in Fig. 6. The time history of the nondimensionalized velocity magnitudes at point 4 and point 8 for the baseline and two refinement cases of Tank $B$ is shown in Fig. 7. Transient times in Fig. 7 are nondimensionalized with respect to the time estimated by Grenville-Tilton correlation. As can be seen in figure, the point 4 mixing time for the refinement 1 , Adapt 1 mesh, was about 48 seconds while the mixing time for refinement 2, Adapt_2 mesh, was about 51 seconds. The mixing time predicted with the baseline mesh produces an error of less than $10 \%$ as compared to the Adapt 2 mesh. The impacts of the mesh refinements on the turbulent kinetic energy and turbulent viscosity for the Tank B configuration are presented in Figs. 8 and 9. As can be seen in the figures, the turbulent kinetic energy for the refined cases takes longer to settle into its quasi-steady values and exhibits low frequency oscillations about the average equilibrium value for flow times greater than 200 seconds. The sensitivity results for Tank C geometry are also presented in Figs. 10 to 12. Thus, the baseline mesh gives a reasonable estimate of mixing time and the added computational expense of a more refined mesh does not significantly improve the results. The adaptation meshing does result in different initial transient behavior. However, the main concern in determining an appropriate mesh resolution is the effect on the predicted mixing time and the differences in the initial transient behavior are not of primary concern. The primary objective of these studies is to validate the theoretical concept that the eddy viscosity and turbulent dissipation rate can be used as potential measures of mixing performance in a tank. 


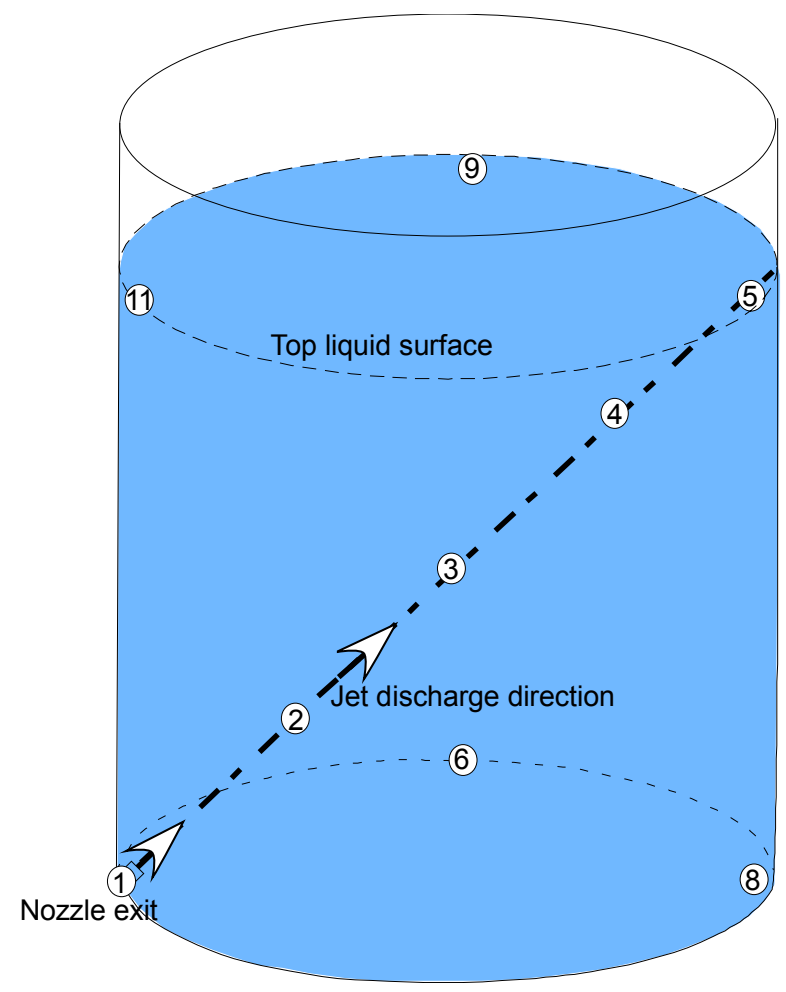

Figure 6. Locations of nine monitoring points in the flow field domain driven by jet mixer inside the tank

Table 4. Number of mesh nodes used in grid sensitivity study for Tank B and Tank C

\begin{tabular}{|c|c|c|c|}
\hline $\begin{array}{c}\text { Tank } \\
\text { configuration }\end{array}$ & $\begin{array}{c}\text { Baseline mesh } \\
\text { (Original) }\end{array}$ & $\begin{array}{c}\text { Refinement 1 } \\
\text { (Adapt_1) }\end{array}$ & $\begin{array}{c}\text { Refinement 2 } \\
\text { (Adapt_2) }\end{array}$ \\
\hline Tank B & 296,000 & 381,000 & 504,000 \\
\hline Tank C & 275,000 & 354,000 & 462,000 \\
\hline
\end{tabular}




\section{Grid size (nodes):}

Original $=296,378$

Adapt_1 $=380,910$

Adapt_2 $=504,164$

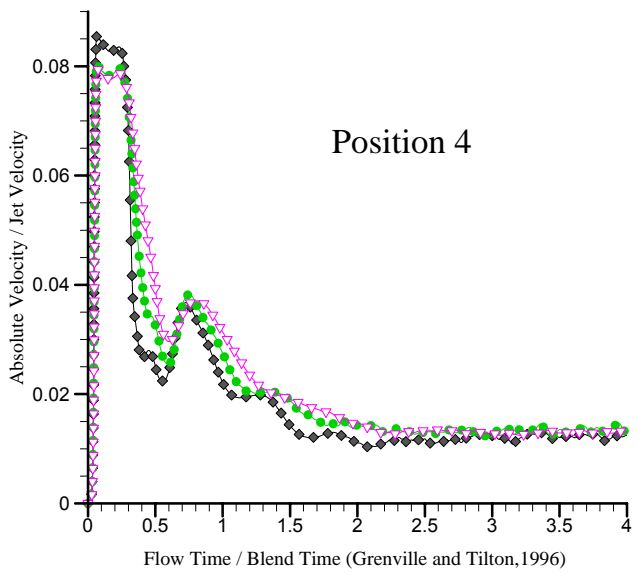

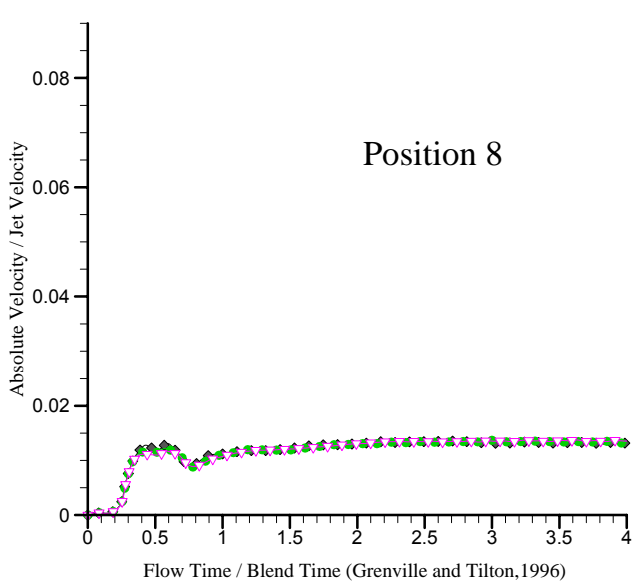

Figure 7. Mesh sensitivity results for transient nondimensionalized velocity magnitudes at two monitoring locations point 4 and point 8 inside Tank B

\section{Grid size (nodes):}

Original $=296,378$

Adapt_1 = 380,910

Adapt_2 = 504,164

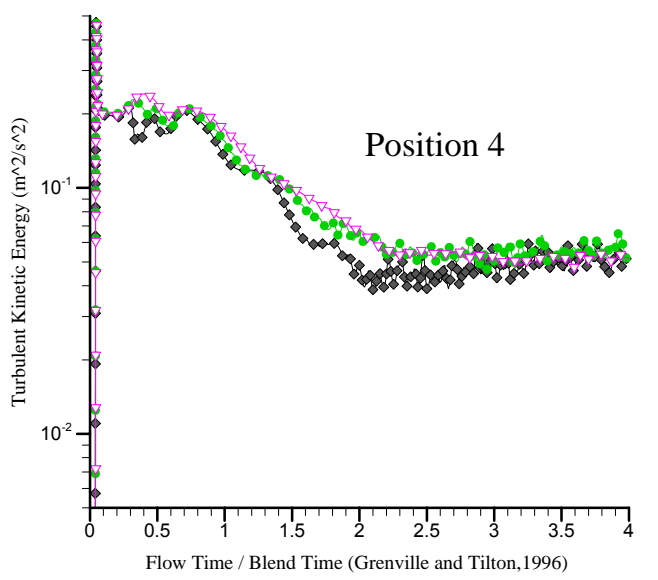

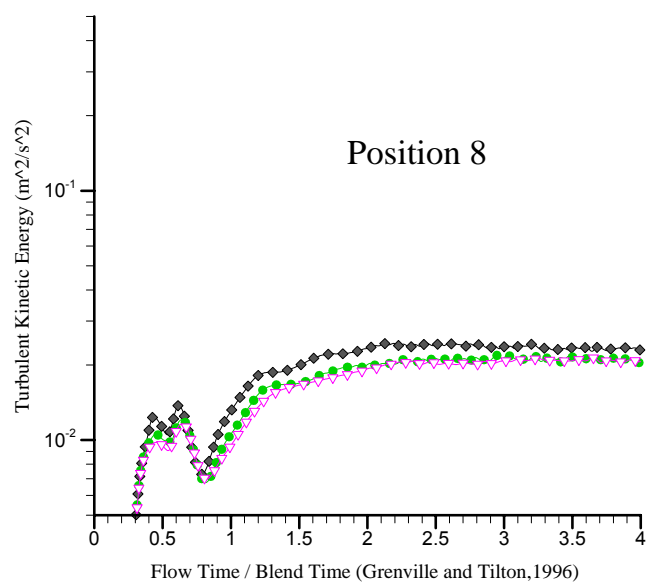

Figure 8. Mesh sensitivity results for transient kinetic energies at two monitoring locations point 4 and point 8 inside Tank $B$ 


\section{Grid size (nodes):}

Original $=296,378$

Adapt_1 = 380,910

Adapt_2 = 504,164
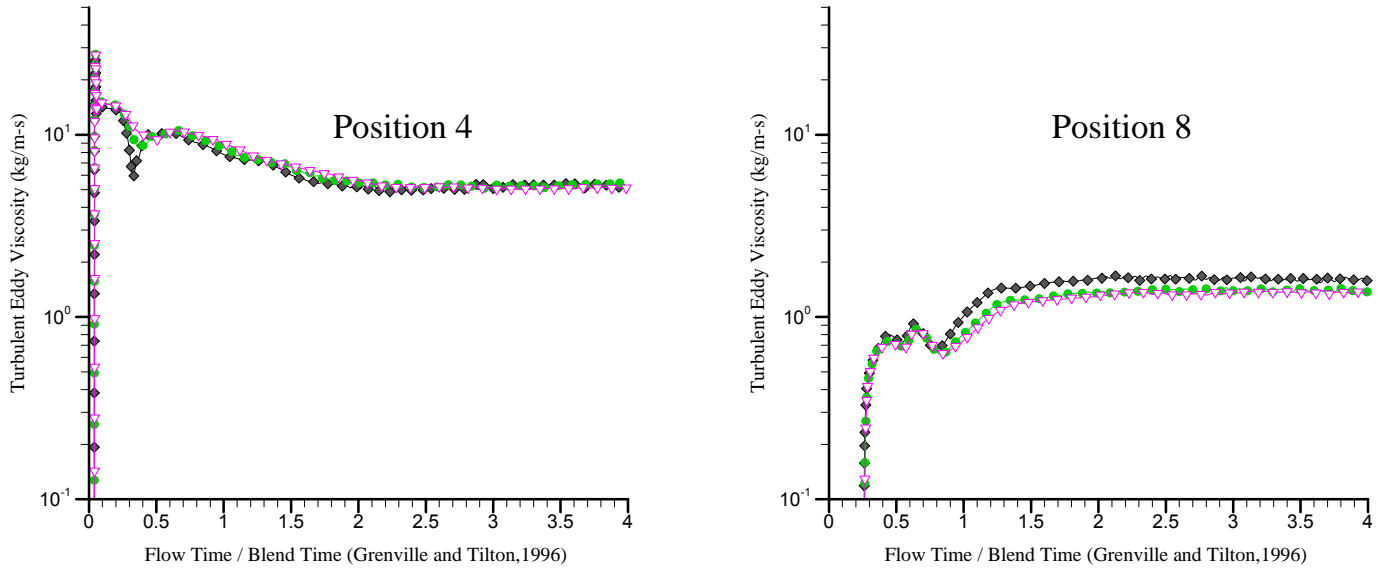

Figure 9. Mesh sensitivity results for transient eddy viscosities at two monitoring locations point 4 and point 8 inside Tank $B$

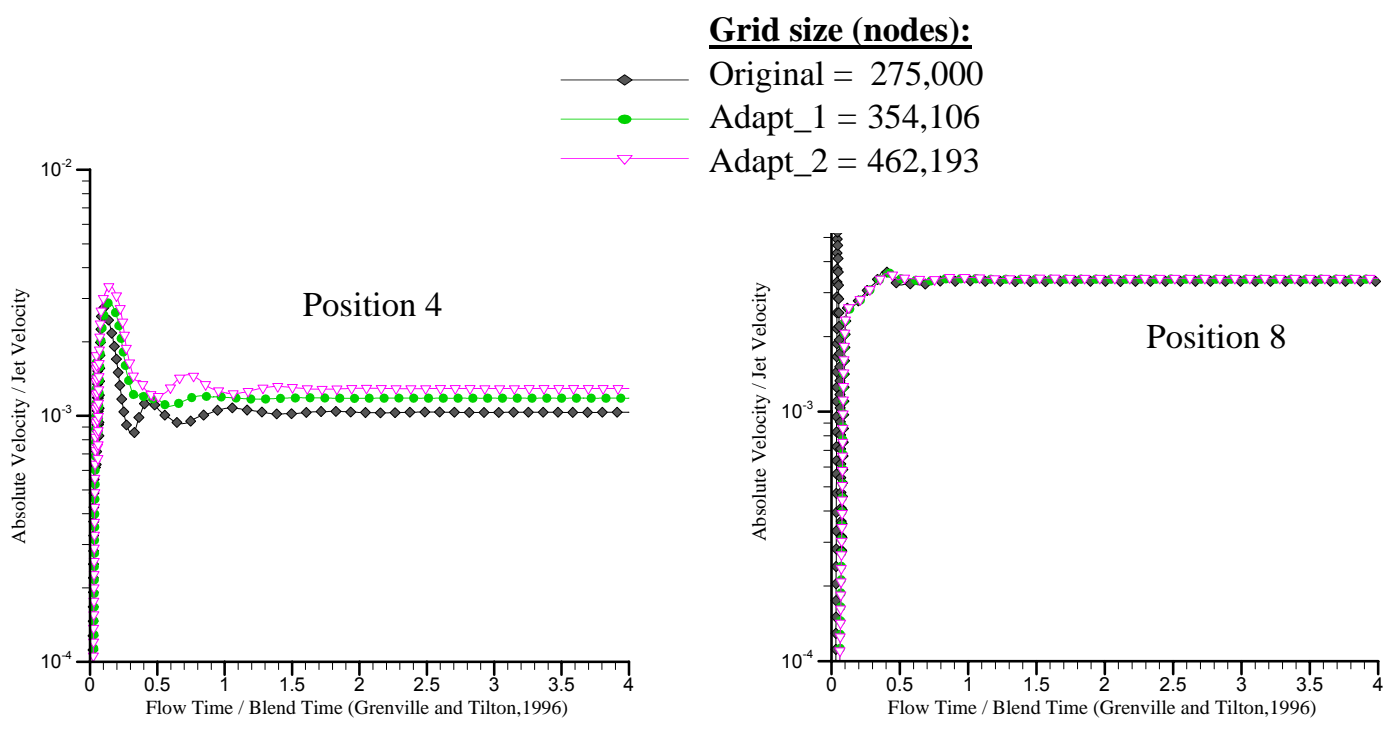

Figure 10. Mesh sensitivity results for transient nondimensionalized velocity magnitudes at two monitoring locations point 4 and point 8 inside Tank $C$ 


\section{Grid size (nodes):}

Original $=275,000$

Adapt_1 = 354,106

Adapt_2 = 462,193
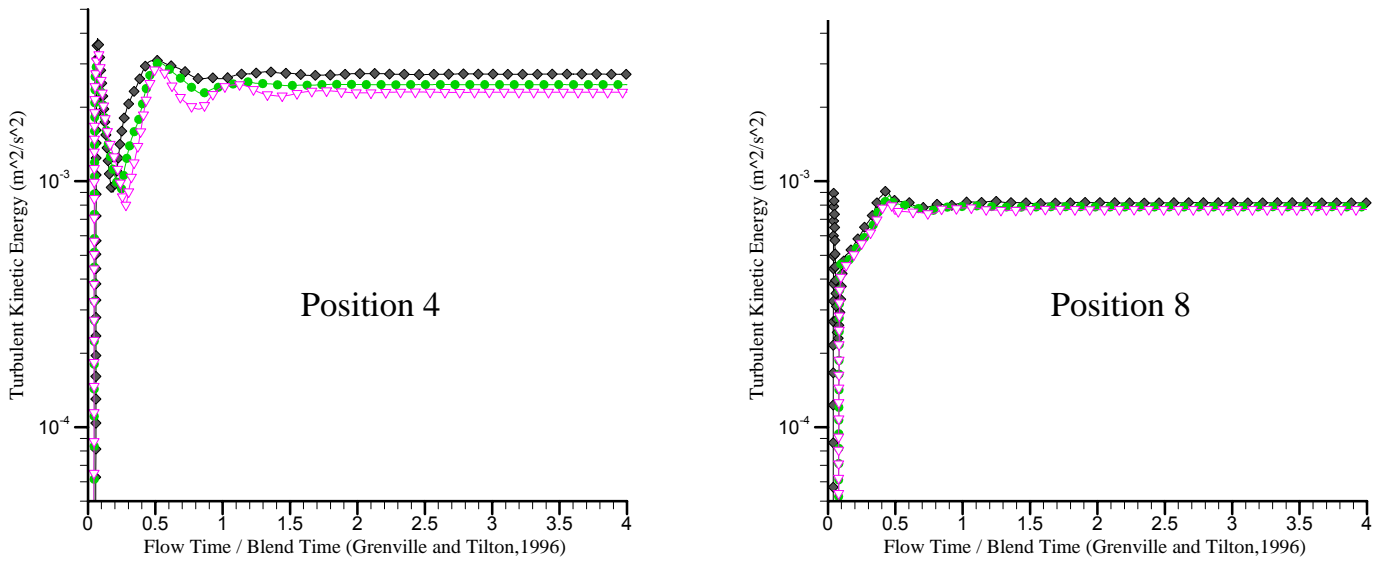

Figure 11. Mesh sensitivity results for transient kinetic energies at two monitoring locations point 4 and point 8 inside Tank $\mathrm{C}$

\section{Grid size (nodes):}

Original $=275,000$

Adapt_1 = 354,106

Adapt_2 = 462,193
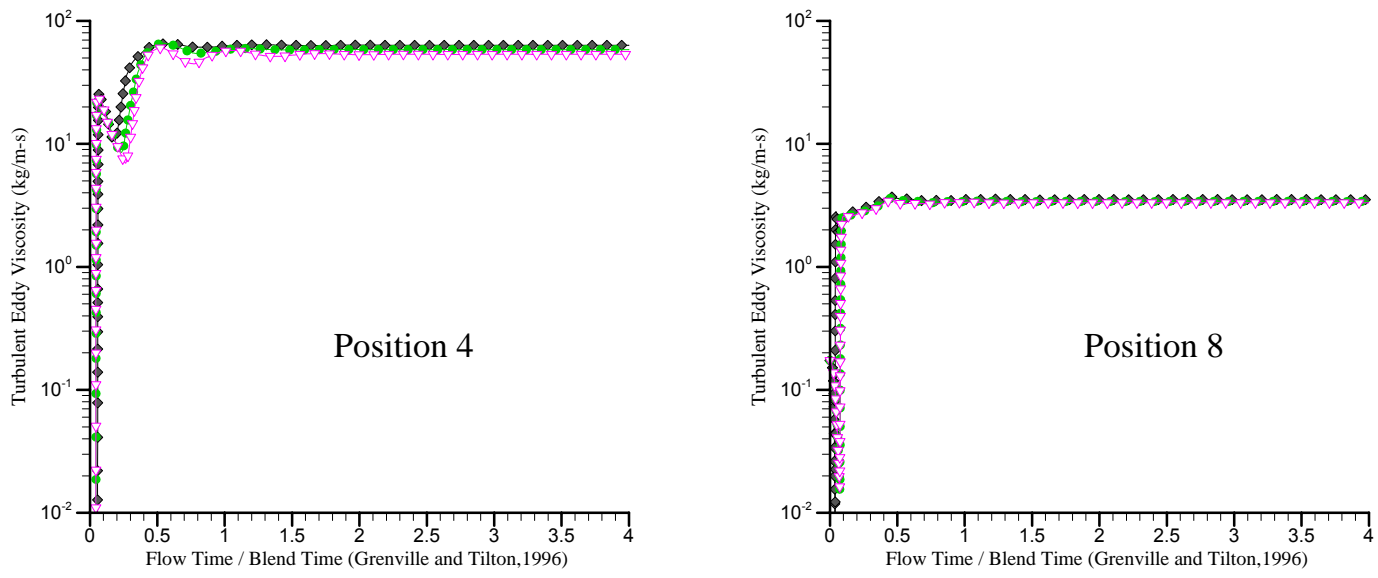

Figure 12. Mesh sensitivity results for transient turbulent viscosities at two monitoring locations point 4 and point 8 inside Tank $C$ 


\subsection{CFD Results against Grenville-Tilton Correlation for Mixing Time}

The prediction of the transient response of submersible jet flows in a quiescent fluid medium is based here on the incompressible continuity and Navier-Stokes (N-S) equation with the RKE turbulence model. Figure 13 shows the transient flow evolution along the principal direction of jet discharge in Tank B. It is noted that local jet velocities along the jet axis decay rapidly by about $80 \%$ of initial jet velocity at a distance of 20 times jet diameter from the jet exit due to the local momentum dissipation into the stagnant liquid. The dissipated momentum induces fluid mixing via liquid entrainment into the jet flow region as illustrated in Fig. 4. Figure 14 shows transient snapshots for the flow evolution in the symmetry plane driven by the jet with a $26.1-\mathrm{mm}$ diameter located at the bottom of Tank B. Transient snapshots of flow evolution in horizontal planes at two different tank elevations, $0.2 \mathrm{~m}$ and $1.2 \mathrm{~m}$ above the jet, are presented in Fig. 15. The results show a transient maximum local velocity at the $1.2 \mathrm{~m}$ elevation occurring in about 30 seconds. While these results show the qualitative development of the jet profile, the quantitative results are questionable and emphasize the need to evaluate the impact of boundary conditions on the flow solution. In this case, the use of a wall boundary to represent the top fluid boundary may be causing unrealistic behavior in the jet development over time. This will be investigated as part of the continuing work.

Transient local velocity magnitudes at two monitoring locations on the principal discharge direction, points 4 and 5 , inside Tank $B$ are shown in Fig. 16. The results show that it takes about 45 seconds for local jet velocity at point 4 (about $1.7 \mathrm{~m}$ from the jet nozzle) to reach quasi-steady state. Their corresponding kinetic energies and energy dissipation rates are presented in Figs. 17 and 18. As discussed previously, eddy viscosity $v_{t}$ is the proportionality constant within the derivative of the Reynolds stress in the N-S equation to describe the rate of energy dissipation. Transient turbulent viscosities at these two monitoring locations on the principal discharge direction inside Tank B are shown in Fig. 19.

The spreading of the jetted fluid is retarded by the interaction with the tank floor and top free surface as shown in Fig. 3, and the inner part of the flow may be expected to show a certain structural similarity to a boundary layer. Entrainment of quiescent fluid occurs near the outer edges of the flow. In this case, sludge solids settled near the edge of the boundary region are entrained into a turbulent zone, and they are suspended and mixed. Figure 20 shows transient local velocity magnitudes at two monitoring locations near the tank floor (point 8 ) and top free surface (point 9 ) inside Tank B. The transient results show that a quasi-steady velocity of about $0.3 \mathrm{~m} / \mathrm{sec}$ is maintained near the tank floor in about 40 seconds after initiation of the jet, resulting in turbulent kinetic energy per unit mass $(k)$ of $0.02 \mathrm{~m}^{2} / \mathrm{sec}^{2}$. The transient turbulent energies at the two remote monitoring points approach a quasisteady value of $\sim 0.02 \mathrm{~m}^{2} / \mathrm{sec}^{2}$ as shown in Fig. 21 . When quasi-steady state is reached, this kinetic energy fed to the fluid medium will be dissipated at a rate of $0.02 \mathrm{~m}^{2} / \mathrm{sec}^{3}$ as shown in Fig. 22. In this case quasi-steady turbulent viscosity is about $1.5 \mathrm{~kg} / \mathrm{m}$-sec as shown in Fig. 23. It is noted that the turbulent viscosity is about 1,500 times higher than molecular viscosity since Reynolds number is in the range of 500,000.

Figure 24 compares transient velocity magnitudes at a monitoring point 4 , Fig. 6 , on the main stream direction of jet discharge for a wide range of Reynolds numbers, $2 \times 10^{4}$ to $10^{6}$. As shown in figure, a quasi-steady condition is reached at the mixing time predicted by G-T correlation. Comparisons of the transient turbulence behaviors for kinetic energy and turbulent viscosity are made for the same range of Reynolds number as presented in Figs. 
25 and 26 . The corresponding results for the remote region, point 8 , are shown in Figs. 27 to 29 .

As shown in the example results, transient behaviors of $k$ and $\varepsilon$ are consistent with turbulent eddy viscosity $v_{t}$. The eddy viscosities were calculated from the RKE turbulence model involving turbulent kinetic energy $(k)$ and its dissipation rate $(\varepsilon)$ coupled with timeand space-averaged N-S equations. The CFD modeling results demonstrate that the time evolution of the turbulent eddy viscosity bears a reasonable similarity to the mixing time based on the G-T correlation.

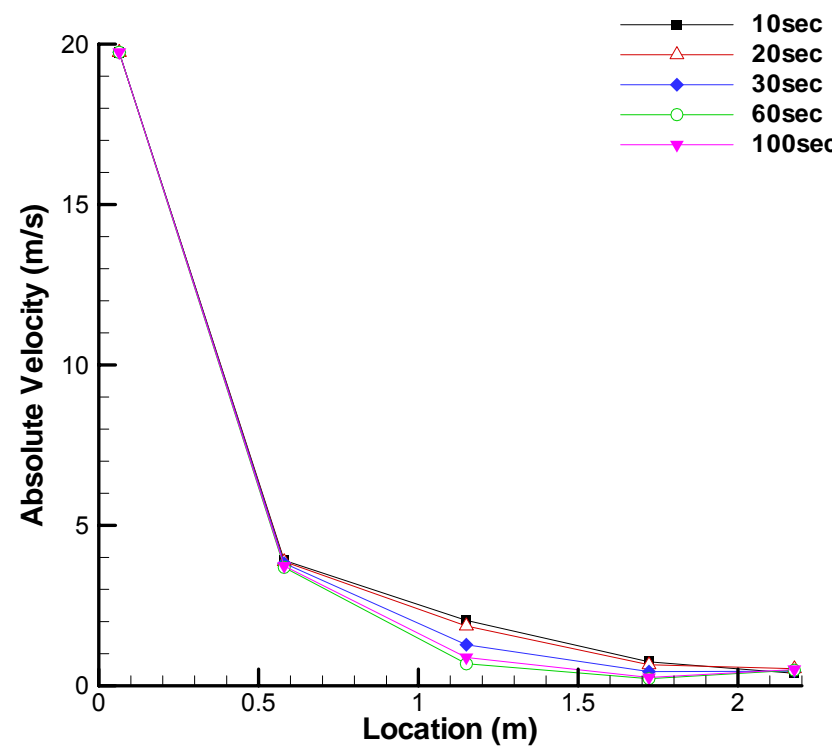

Figure 13. Transient turbulent flow evolutions along the principal direction of jet discharge in tank B 

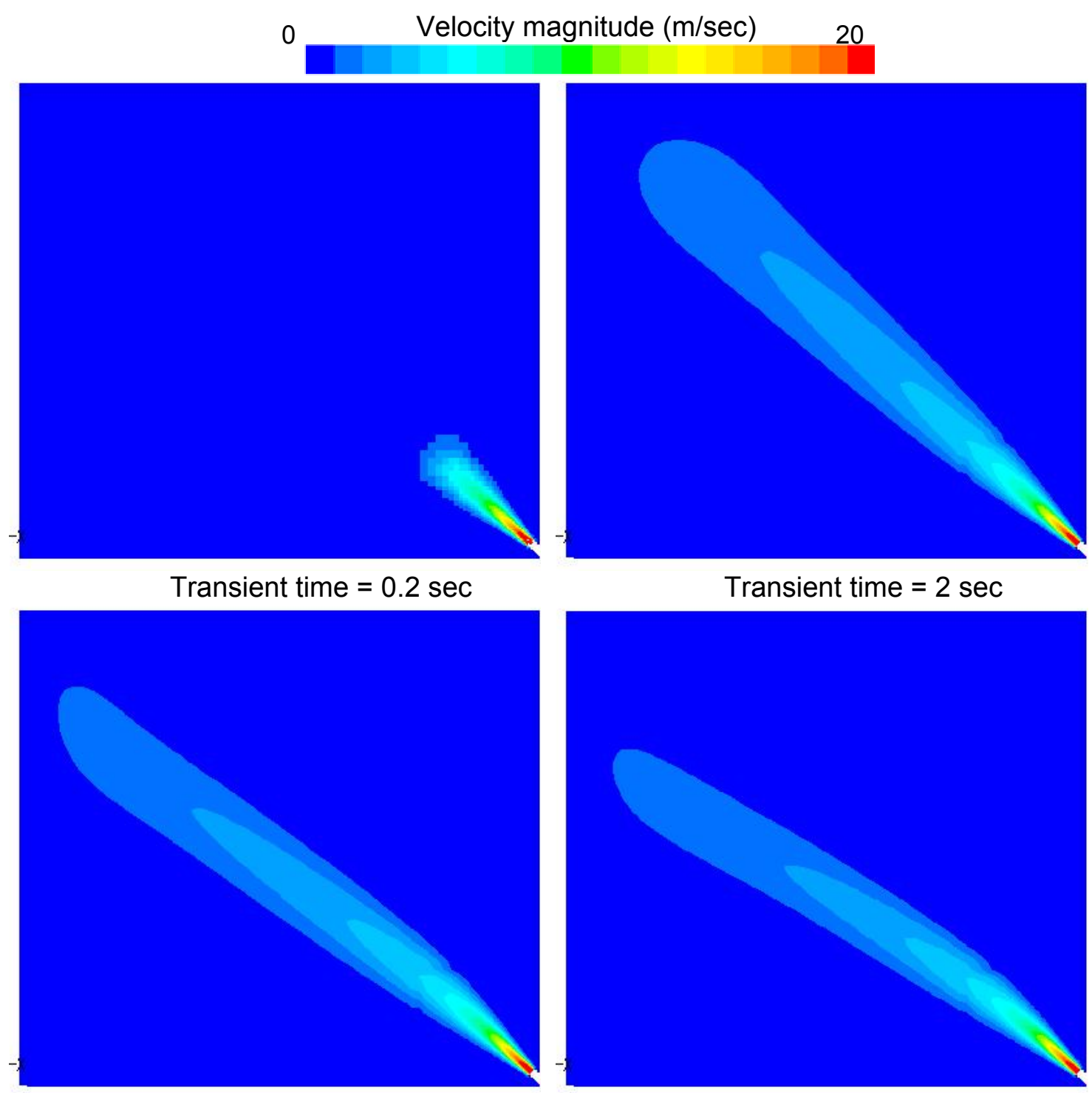

Transient time $=10 \mathrm{sec}$

Transient time $=200 \mathrm{sec}$

Figure 14. Transient flow evolutions at the plane of jet discharge in tank B using RKE turbulence model 


\section{Velocity magnitude color code}

Blue: $0 \mathrm{~m} / \mathrm{sec}$ for 0.2 and $1.2 \mathrm{~m}$ elevations,

Red: $8 \mathrm{~m} / \mathrm{sec}$ for $0.2 \mathrm{~m}$ elevation, $1 \mathrm{~m} / \mathrm{sec}$ for $1.2 \mathrm{~m}$ elevation)

(0.2 m elevation)

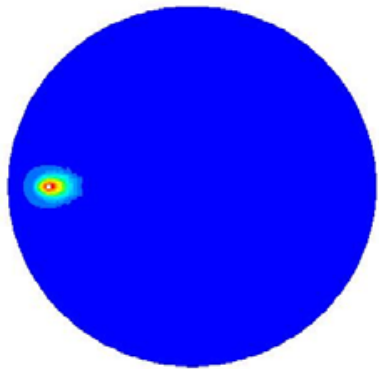

(transient time $=0.2 \mathrm{sec})$

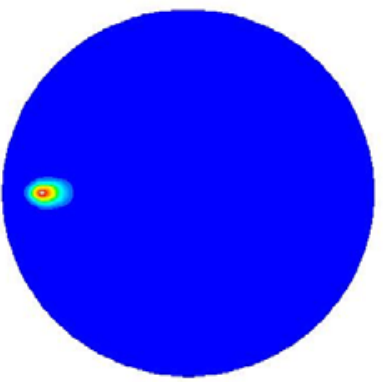

(transient time $=2 \mathrm{sec})$

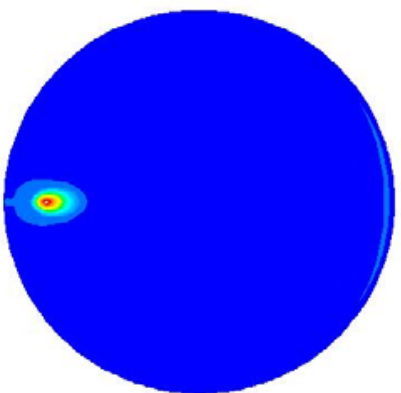

(transient time $=10 \mathrm{sec})$
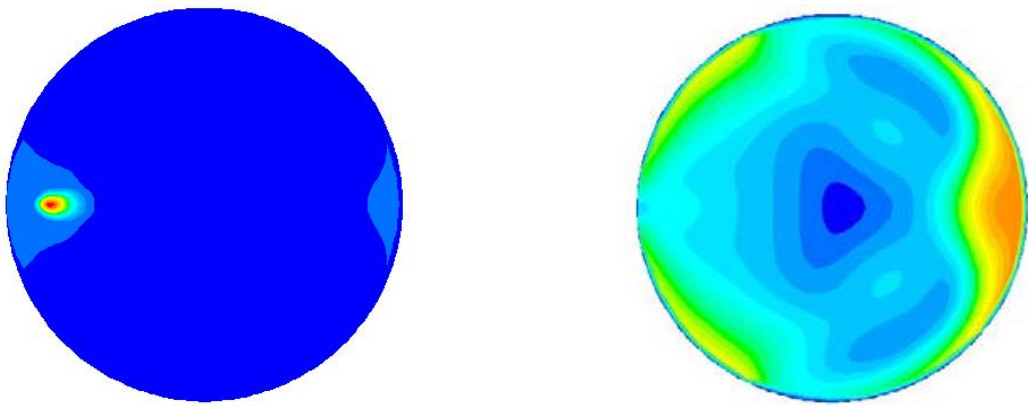

(transient time $=200 \mathrm{sec}$ )

Figure 15. Transient snapshots of flow evolutions at the horizontal planes at two different tank elevations of $0.2 \mathrm{~m}$ and $1.2 \mathrm{~m}$ in tank $\mathrm{B}$ using RKE turbulence model 


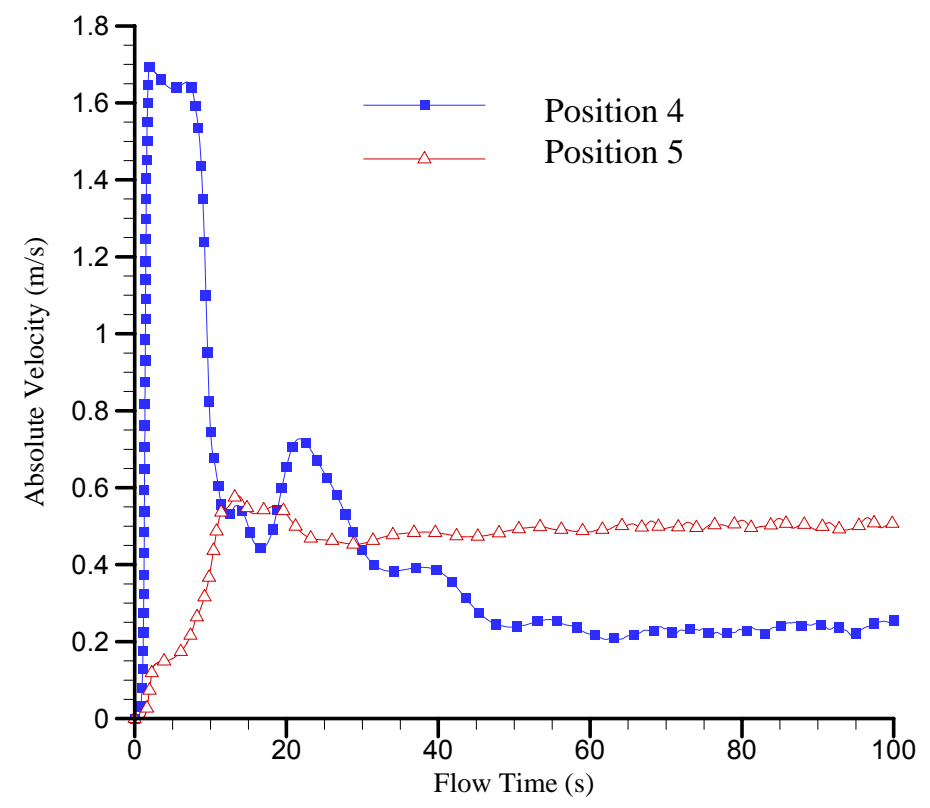

Figure 16. Transient local velocity magnitudes at two monitoring locations on the principal discharge direction inside Tank $B$

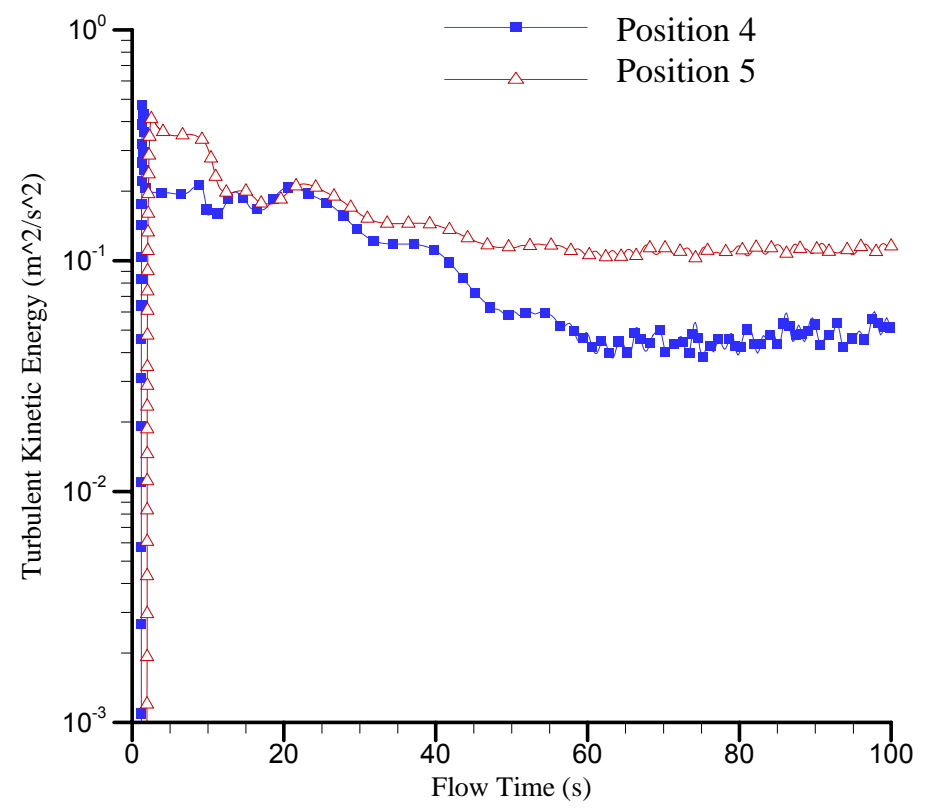

Figure 17. Transient turbulent kinetic energies at two monitoring locations on the principal discharge direction inside Tank B 


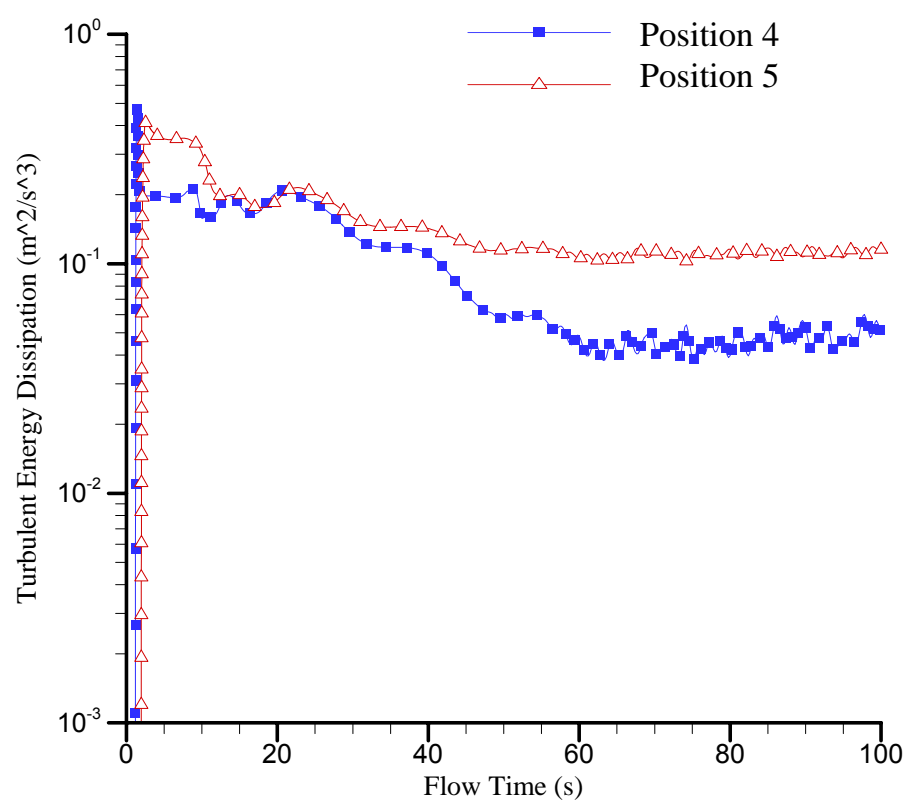

Figure 18. Transient turbulent energy dissipation rates at two monitoring locations on the principal discharge direction inside Tank B

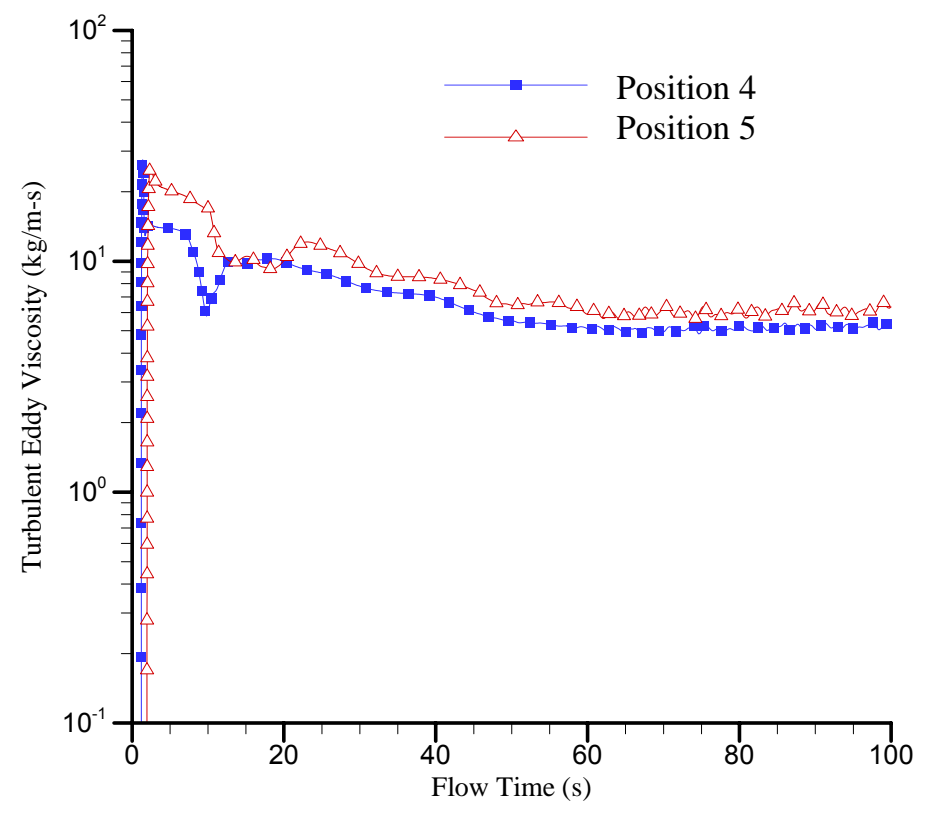

Figure 19. Transient turbulent viscosities at two monitoring locations on the principal discharge direction inside Tank B 


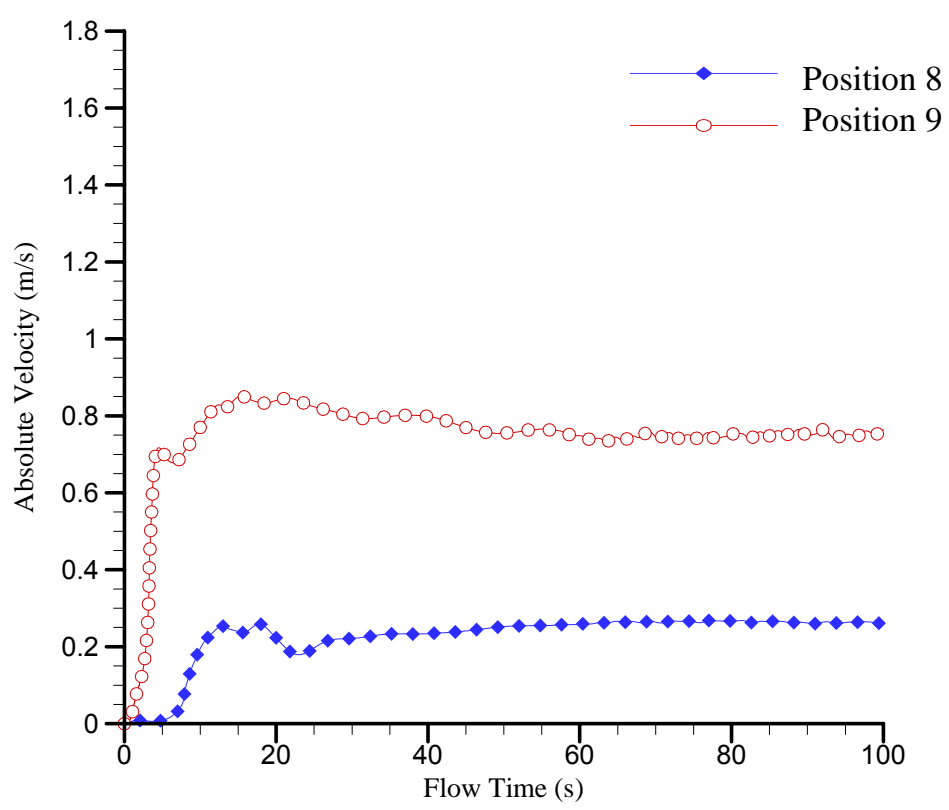

Figure 20. Transient local velocity magnitudes at two monitoring locations far away from the principal discharge line inside Tank B

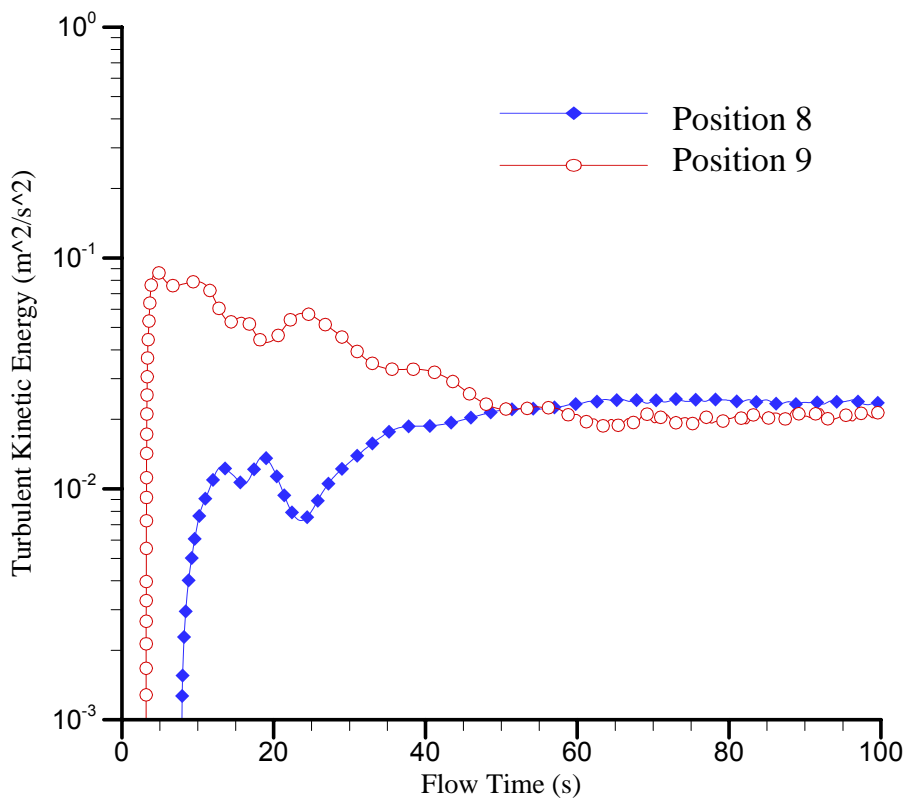

Figure 21. Transient turbulent kinetic energies at two monitoring locations far away from the principal discharge line inside Tank B 


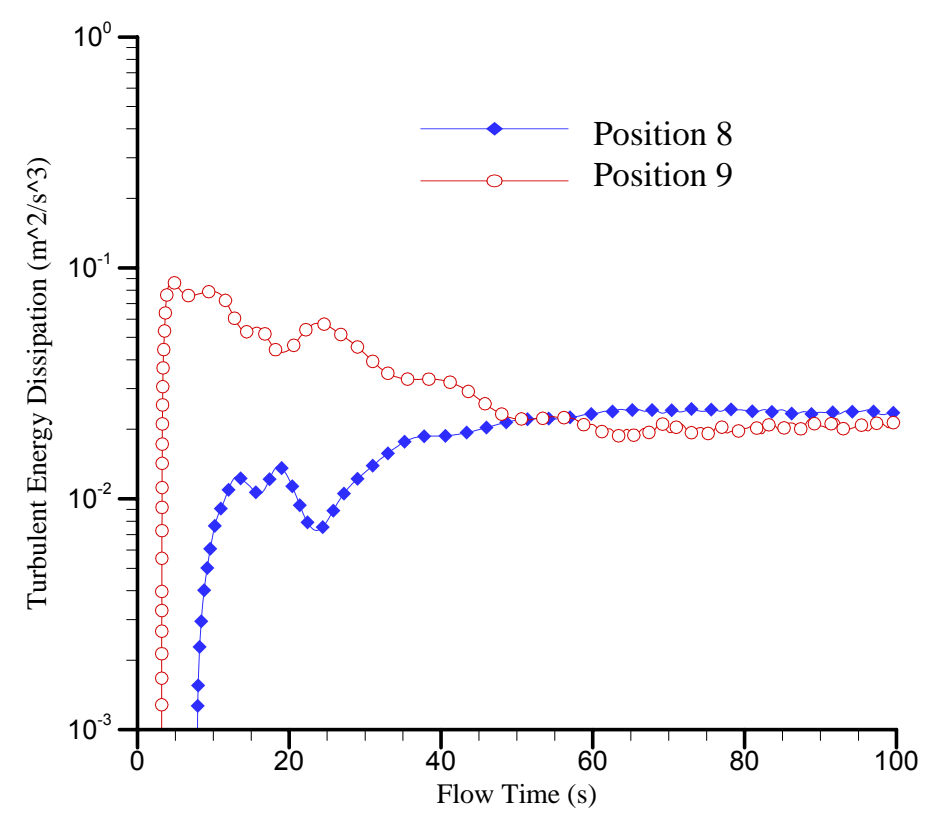

Figure 22. Transient turbulent energy dissipation rates at two monitoring locations far away from the principal discharge line inside Tank B

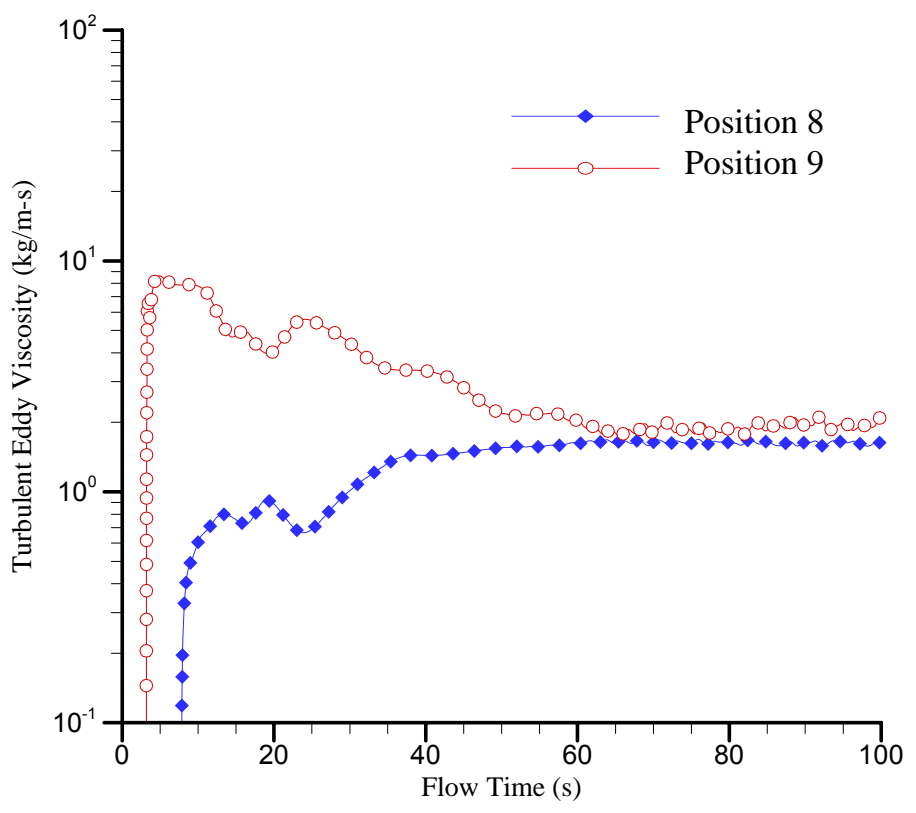

Figure 23. Transient turbulent eddy viscosities at two monitoring locations far away from the principal discharge line inside Tank B 


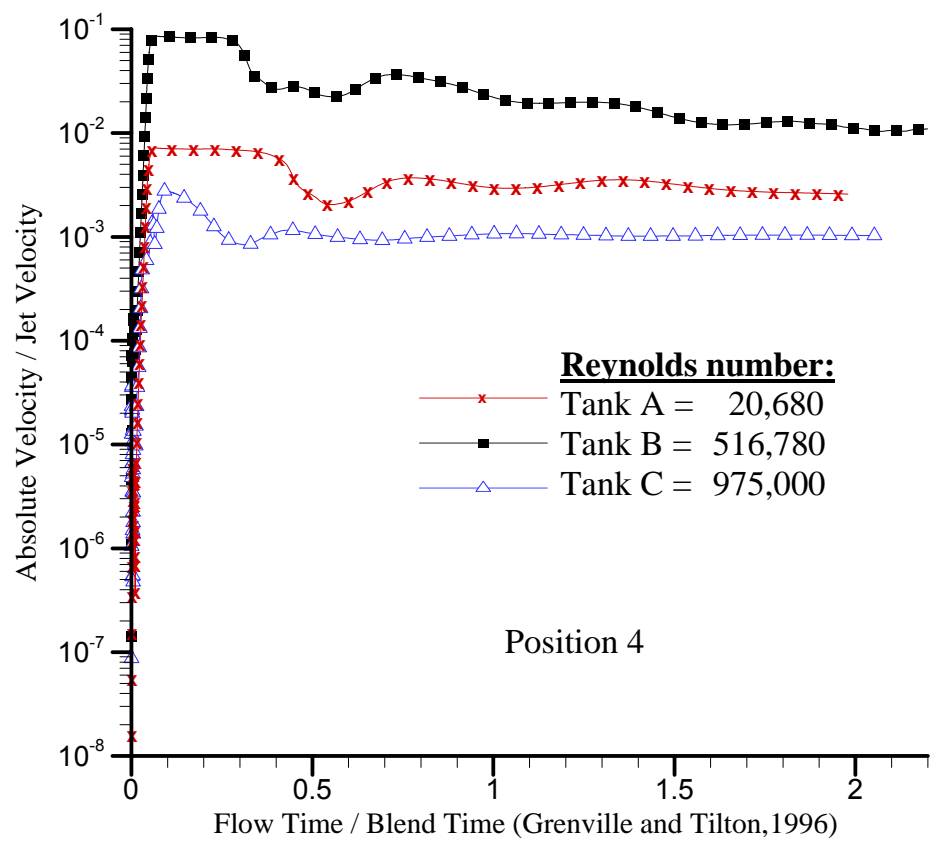

Figure 24. Comparison of transient velocity magnitudes at a monitoring location 4 on the principal discharge line for three different operating conditions (RKE turbulence model)

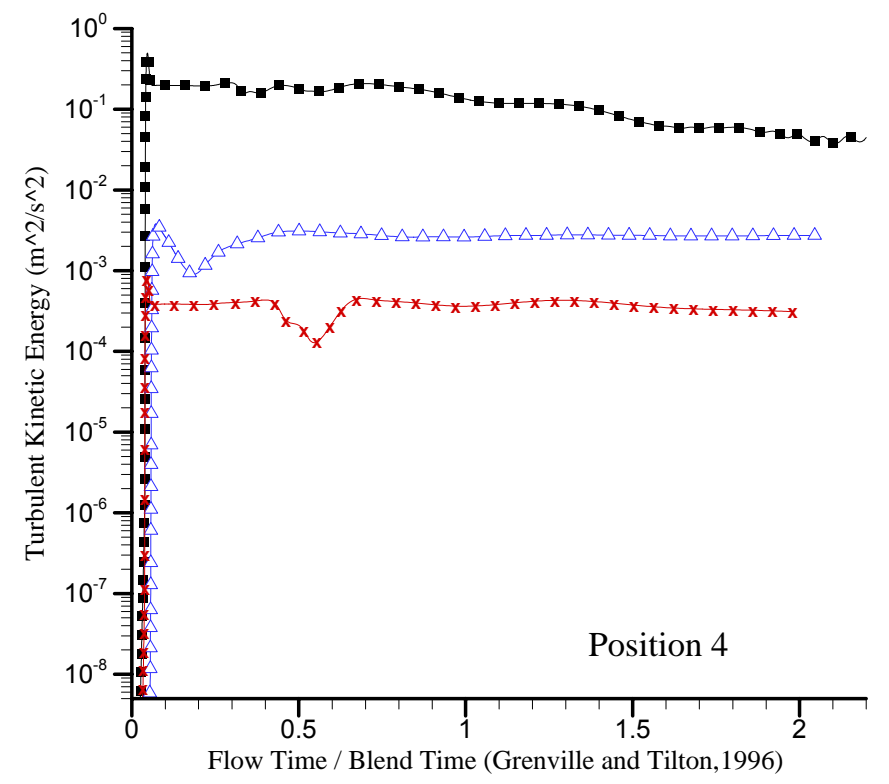

Figure 25. Comparison of transient turbulent kinetic energies at a monitoring location 4 on the principal discharge line for three different operating conditions (RKE turbulence model) 


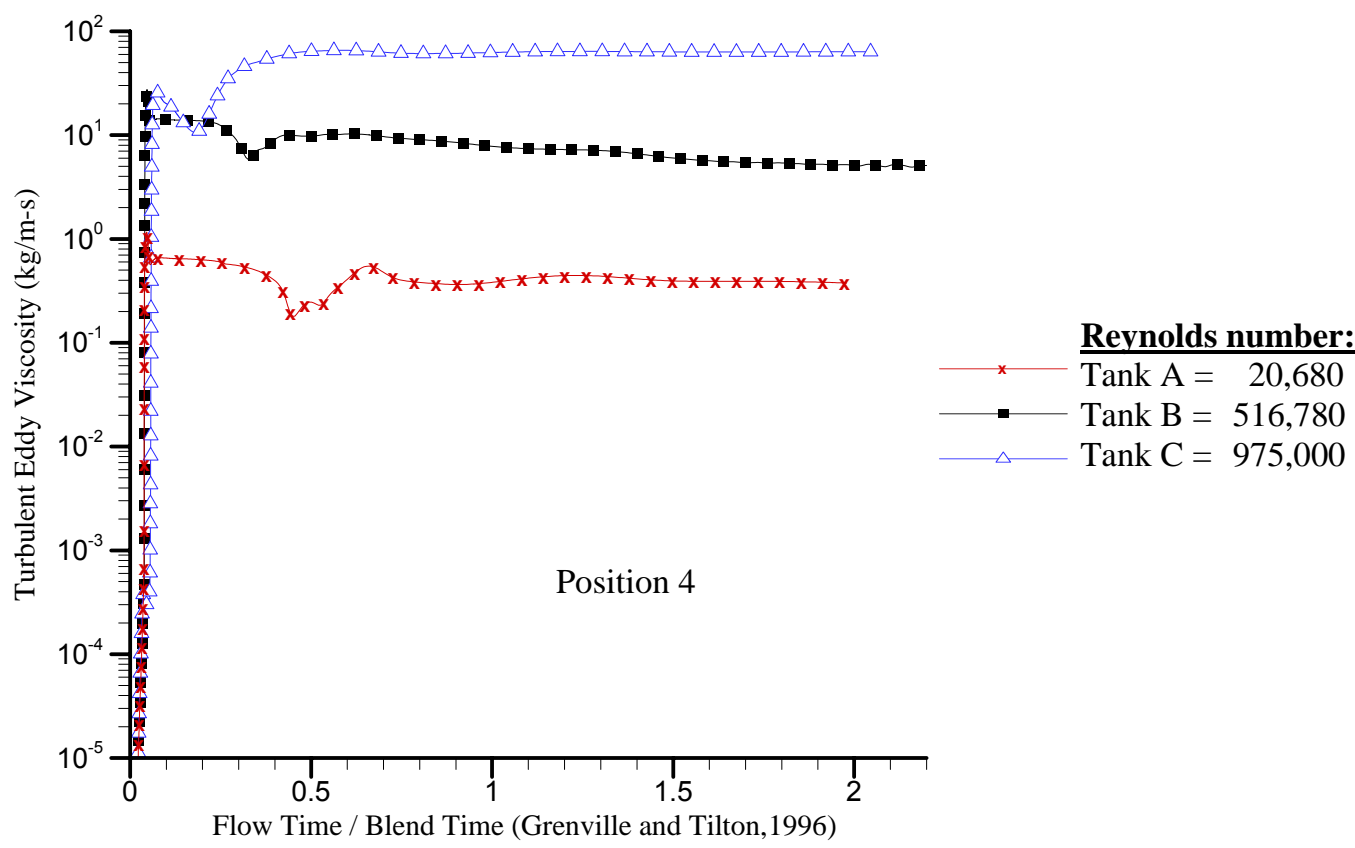

Figure 26. Comparison of transient turbulent eddy viscosities at a monitoring location 4 on the principal discharge line for three different operating conditions (RKE turbulence model)

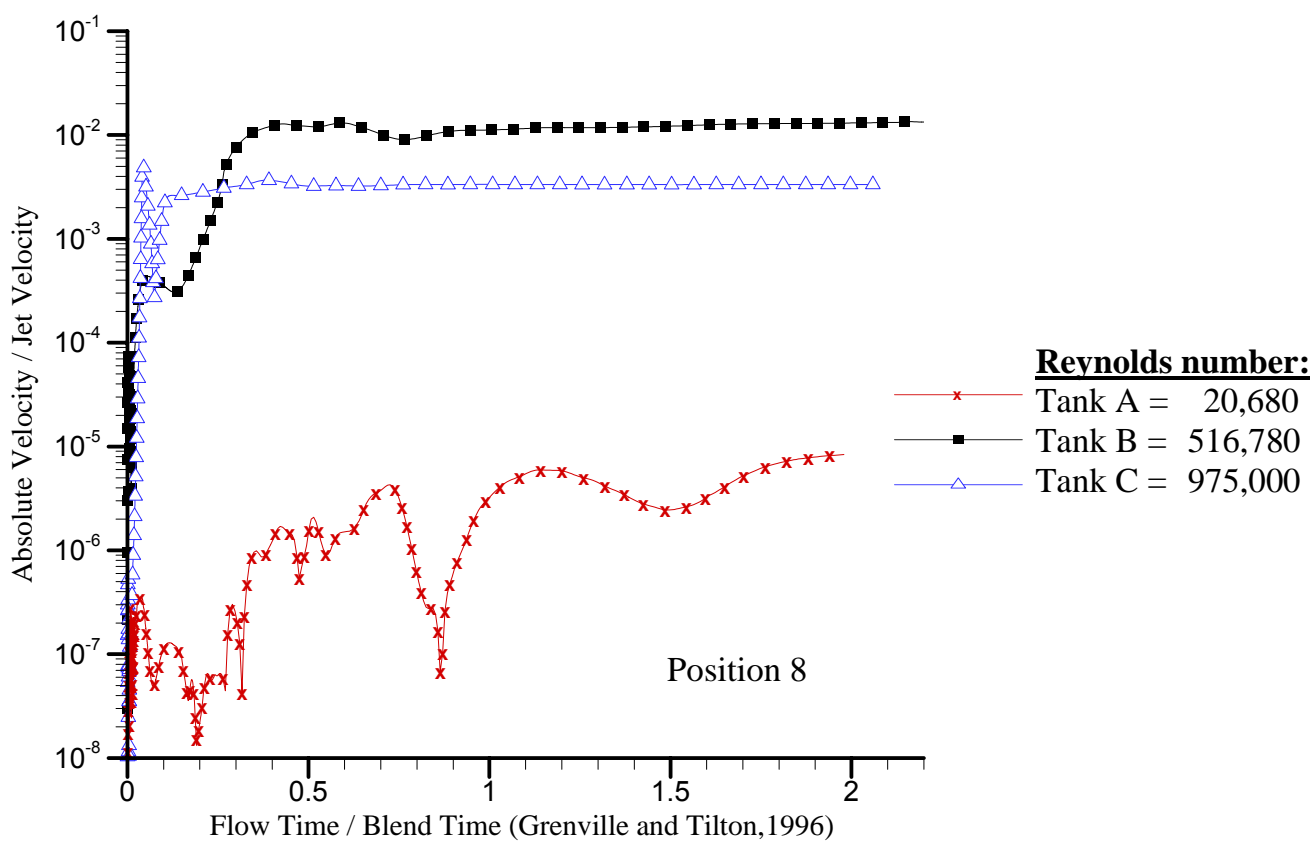

Figure 27. Comparison of transient velocity magnitudes at a monitoring location 8 far away from the principal discharge line for three different operating conditions (RKE turbulence model) 


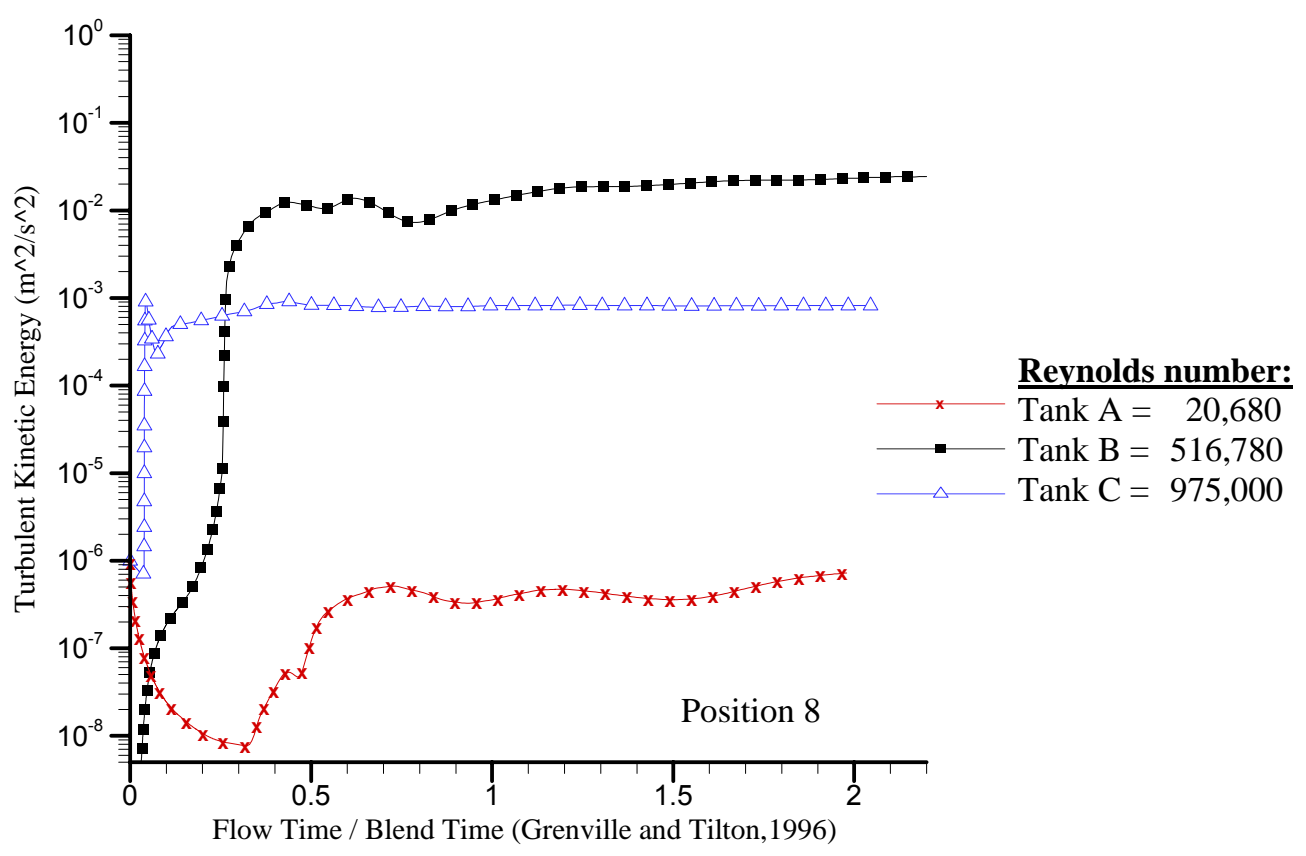

Figure 28. Comparison of transient turbulent kinetic energies at a monitoring location 8 far away from the principal discharge line for three different operating conditions (RKE turbulence model)

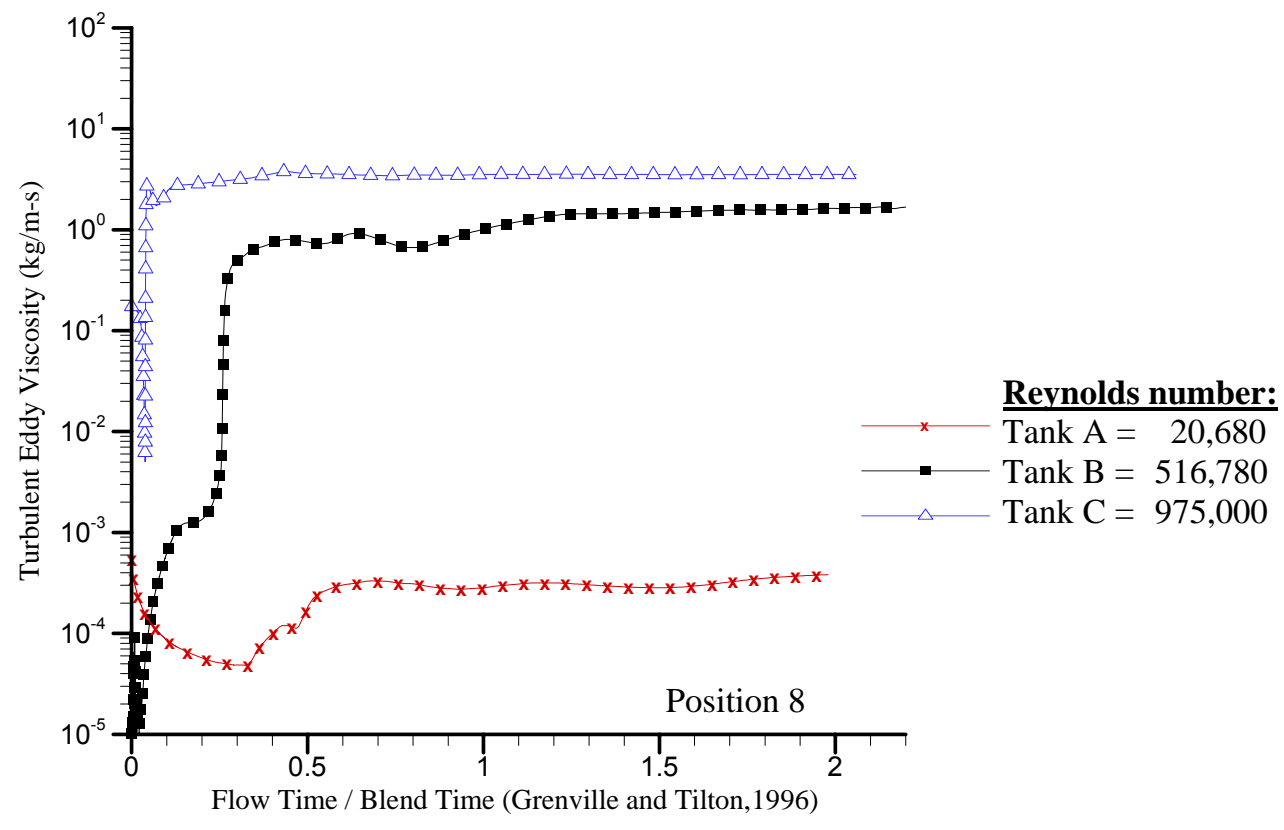

Figure 29. Comparison of transient turbulent eddy viscosities at a monitoring location 8 far away from the principal discharge line for three different operating conditions (RKE turbulence model) 


\subsection{ANALYSIS AND EVALUATIONS}

The present work primarily compares the Grenville-Tilton correlation (1996) of the jet mixing time with CFD modeling results for three experimental tanks in an attempt to achieve fundamental understanding of the turbulent jet mixing and to establish the mixing indicators. These results are used in a qualitative way to validate the theoretical concept of using key turbulence parameters as mixing indicators.

As discussed earlier, there are several important characteristics that all turbulent flows possess. These characteristics include flow fluctuations, rapid eddy diffusion, high levels of fluctuating vorticity, and eddy dissipation of kinetic energy. Figure 30 compares transient jet flow evolutions along the principal discharge direction inside Tank B with steady-state free jet results available in the literature. Flow conditions used in the figure are turbulent in terms of jet Reynolds number. In this case, the two-equation turbulence model, realizable $k-\varepsilon$ (RKE) model, was applied to perform the calculations of jet flow into a stagnant liquid medium for a cylindrical tank.

As shown in Figs. 16 and 20, transient flow behaviors were monitored at the jet and remote regions. The results show that when tank liquid is initially quiescent, the velocity magnitudes increase monotonically from zero to a local maximum and then monotonically decrease during the early transient period. These results were considered questionable and in need of further investigation. Turbulence intensity also increases rapidly and then reaches a quasi-steady value after a transition period of flow fluctuation as shown in Fig. 31. It is noted that when comparing to the mixing time estimated by the G-T correlation, most local mixing takes place during this fluctuating period. Thus, the velocity fluctuations act to efficiently transport momentum, and possibly a second phase solid concentration, over the continuous fluid domain.

The second characteristic of turbulence is a high rate of diffusion due to the flow fluctuations. As shown in Fig. 32, this turbulent transport is significantly more effectively dissipative than molecular diffusion during the early stage of the transient period. In fact, it is common to model the transport due to the fluctuations by defining an effective diffusion coefficient called an eddy or apparent viscosity. While the velocity fluctuations are unpredictable, they possess a spatial structure. A turbulent flow consists of high levels of fluctuating vorticity. Instantaneous vortical motion, called eddies, are present in the flow. These eddies range in size from the largest geometric scales of the flow down to small scales where molecular diffusion dominates. The eddies are continuously evolving in time, and the superposition of their induced motions leads to the fluctuating time records as shown in Figs. 16 and 20.

Turbulent kinetic energy is passed down from the largest eddies to smallest through a process of energy cascade. At the smallest scales, the energy is eventually dissipated to heat by viscous effects. Thus, the last characteristic of turbulent flows is eddy dissipation of kinetic energy. To maintain turbulence, a constant supply of energy must be fed to the turbulent fluctuations at the largest scales from the mean motion.

As shown in Eq. (9), the information of the velocity fluctuations is used to estimate the length scale which provides information on eddy viscosity, $v_{t}$. The constant $v_{t}$ with the derivative of the Reynolds stress in the average N-S equation is essentially a description of the length scale over which the energy quantity is diffused. This length is referred to as the mixing 
length, $\lambda$. The transient length scales corresponding to the energy dissipation at remote locations, point 6 and point 8, are shown in Fig. 33. The results show that eddies lose most of their energy at remote regions inside Tank B with about $100 \mathrm{~mm}$ dissipation scales, and the lost energy will result in local mixing. Thus, the eddy viscosity or diffusivity $v_{t}$ should involve the product of a turbulent mixing scale $\lambda$ and a turbulent velocity scale.

Based on the literature review on turbulent models and mixing mechanisms and completion of an initial set of calculations with the RKE turbulence model, it appears to be very promising that the turbulent eddy viscosity is a primary measure of length scale for turbulent energy dissipation, and it will serve as a good performance indicator in determining the mixing time. Detailed theoretical development and quantitative analysis for turbulent jet mixing characteristics and its indicators will be performed through FY09.

Table 5. Test conditions of turbulent jets used in the present and literature

\begin{tabular}{|c|c|c|c|}
\hline Authors & Jet diameter $(\mathrm{mm})$ & Fluid & Reynolds number, $\mathrm{Re}_{\text {jet }}$ \\
\hline Tank B (present) & 26.1 & Water & 520,000 \\
\hline Kiser (1963) & 9.525 & Water & 35,000 \\
\hline Post (1998) & 10 & Air & 10,000 \\
\hline
\end{tabular}

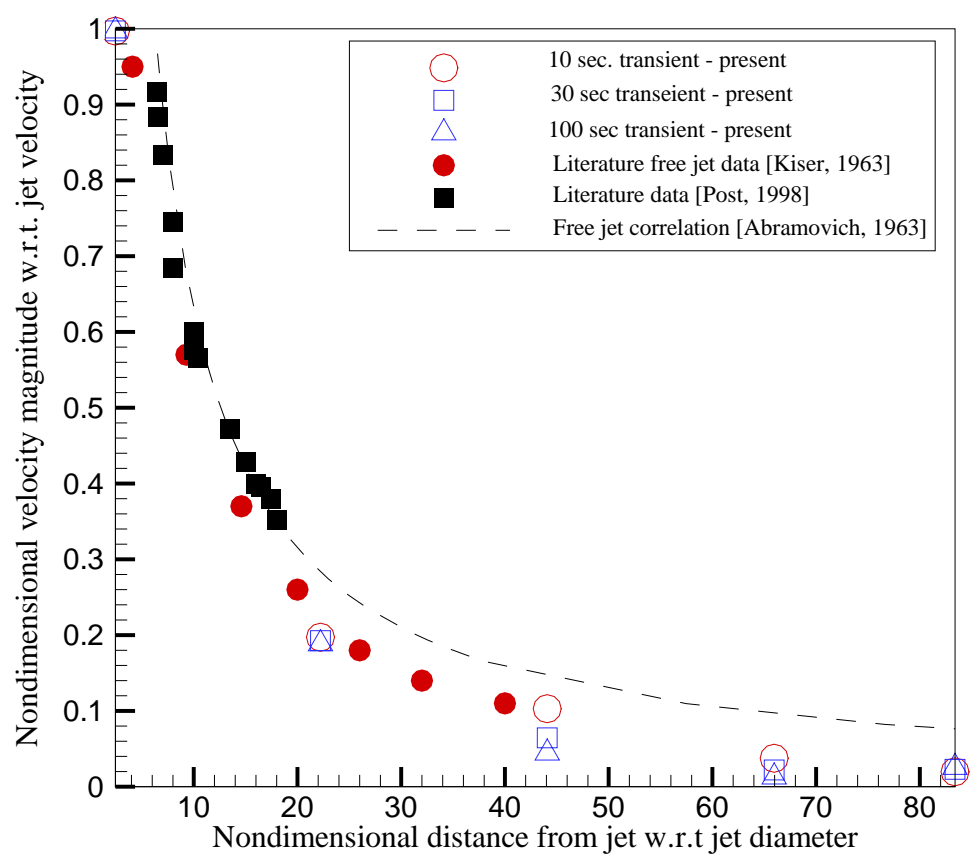

Figure 30. Comparison of transient jet flow evolutions with steady-state literature data along the principal discharge line inside Tank B (RKE model) 


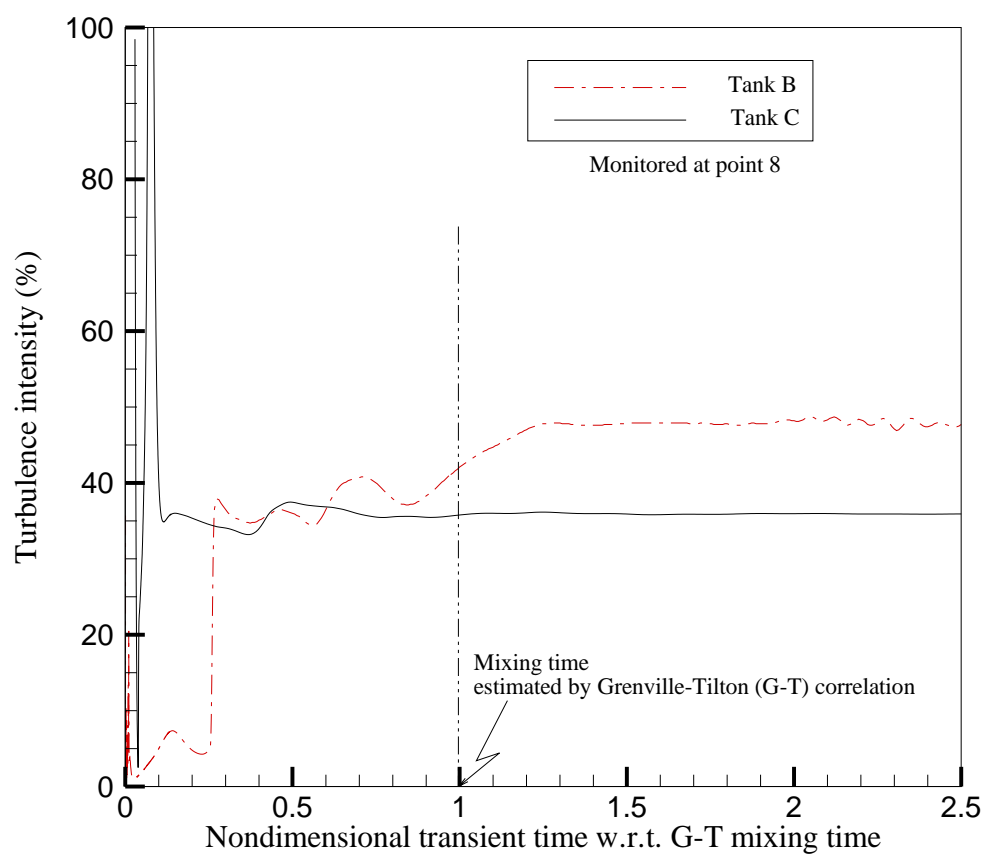

Figure 31. Transient turbulence intensity at remote monitoring point 8 far away from the principal discharge line inside Tank B and Tank C (RKE model)

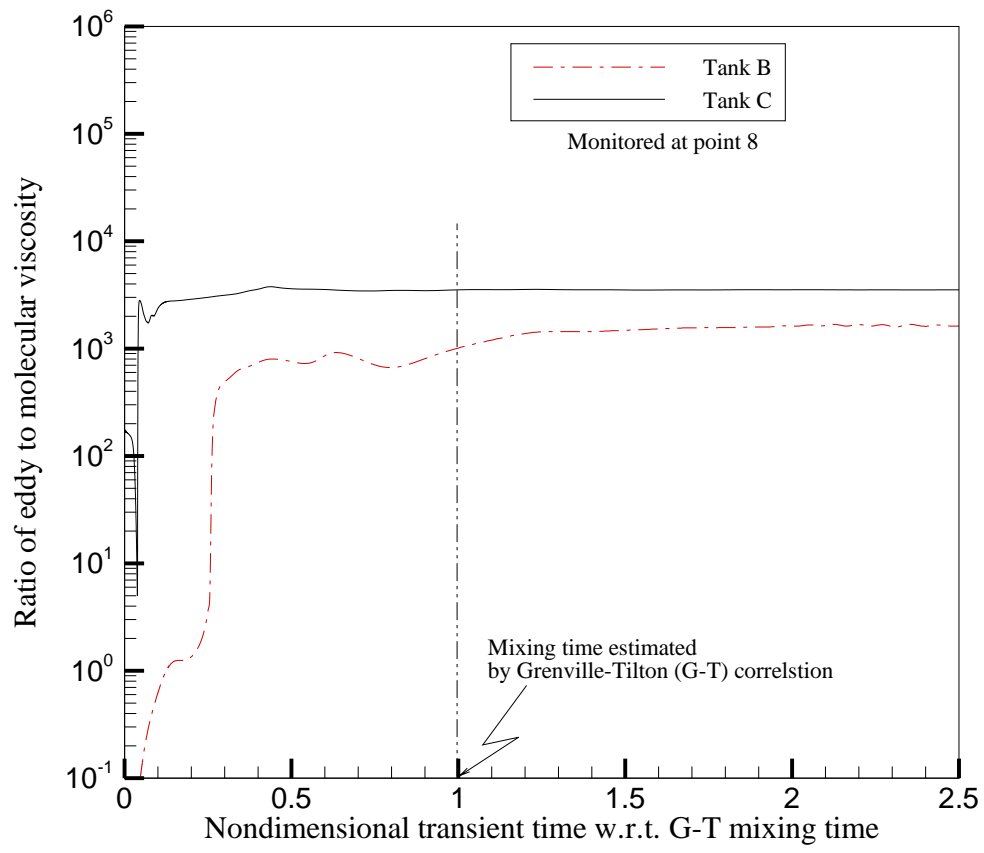

Figure 32. Transient turbulence eddy viscosity at remote monitoring point 8 far away from the principal discharge line inside Tank B and Tank C (RKE model) 


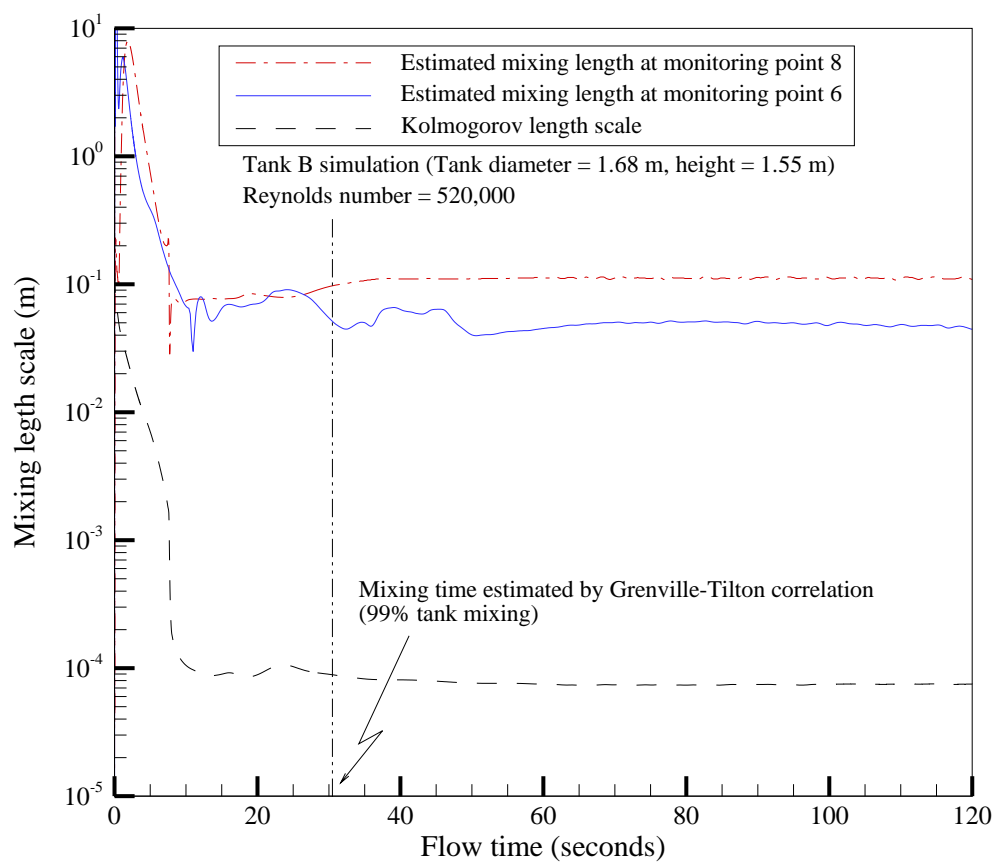

Figure 33. Transient turbulent mixing length scales at remote monitoring locations Point 6 and Point 8 far away from the principal discharge line inside Tank B (RKE model) 


\subsection{CONCLUSIONS AND SUMMARY}

Turbulence parameters identified as potential indicators of mixing within a large tank were identified based on a two-equation turbulence closure model, the RKE model. The parameters selected were the turbulent kinetic energy, the turbulent kinetic energy dissipation rate, and especially the turbulence eddy viscosity. All three were calculated for tank mixing geometries and conditions documented by Grenville and Tilton (1996) and compared against the results of their correlation for mixing time. The results obtained with CFD calculations were qualitatively similar to those observed by Grenville and Tilton, although differences were noted that will require further investigation.

The concept of using the identified mixing indicators to characterize a mixing time was shown to have promise by investigating a range of computational variations including grid sensitivity, time step sensitivity, tank geometries, jet dimensions, and Reynolds number. In all cases, qualitatively similar results were obtained between the calculated flow patterns and the Grenville-Tilton correlation. Based on our present results, recommendations for further investigation, including the development of the theory underlying the use of the mixing indicators, were developed for FY-09.

\subsection{FUTURE WORK / PATH FORWARD}

Work to be accomplished in FY-09 will focus on completing the analysis of mixing in singlephase systems by addressing the following issues:

1. Identify the most applicable turbulence model to calculate the observable parameters.

2. Characterize the impact of using special near-wall models for flow near walls and internal obstructions.

3. Define the observable parameters to be used as mixing indicators. This will include as part of the definition an evaluation of how those indicators should be observed in the computational output, and the impact of using a rotating pump or pumps as the mixing driver on the calculation of the indicators.

While all parameters affecting the calculation of turbulent flow behavior in a vessel will be considered potential variables, two of the most significant ones are grid density and Reynolds number. Both of these will be addressed as key parameters in the mixing evaluation.

Deliverables for FY-09 include:

1. June 30,2009 . Completion of the single-phase evaluation for the geometries described in the Grenville and Tilton reference, including the theoretical basis for the observables. Calculations by PNNL will serve to support and interpret the results obtained by SRNL using Fluent.

2. September 30, 2009. Application of the computational approach to SRS waste tank geometries, including significant internal obstructions in the tanks and the use of multiple, 
rotating pumps. Again, calculations by PNNL will serve to support and interpret the results obtained by SRNL using Fluent.

3. Septemebr 30, 2009. Specify guidelines for performing mixing calculations for a single-phase liquid system, observable parameters to calculate, and guidelines for interpreting those observable parameters to determine whether a tank is mixed.

4. September 30, 2009. Recommendations for continued work in FY-10 to address mixing in two-phase systems.

\subsection{REFERENCES}

1. S. Y. Lee, R. A. Dimenna, R. A. Leishear, D. B. Stefanko, "Analysis of Turbulent Mixing Jets in a Large Scale Tank", ASME Journal of Fluids Engineering, Volume 130, Number 1, pp. 011104, 2008.

2. Abramovich, G. N., "The Theory of Turbulent Jets", The MIT Press, Cambridge, MA, 1963.

3. S. Y. Lee, R. A. Dimenna, R. A. Leishear, and D. B. Stefanko, "Mixing in Large Scale Tanks Part I; Flow Modeling of Turbulent Mixing Jets", HT-FED2004-5622, 2004 ASME Heat Transfer / Fluids Engineering Summer Conference, Charlotte, N. C., July 11-15, 2004.

4. C. Eckart, "An Analysis of the Stirring and Mixing Processes in Incompressible Fluids", J. Mar. Research, vol. 7, pp. $265-275,1948$.

5. D. B. Spalding, "Mixing and Chemical Reaction in Steady Confined Turbulent Flames", $13^{\text {th }}$ International Symposium on Combustion, 649-657, 1971.

6. P. L. Miller, 1991, "Mixing in High Schmidt Number Turbulent Jets", PhD Thesis, California Inst. of Technology.

7. H. B. Fischer, "Longitudinal Dispersion and Turbulent Mixing in Open-Channel Flow", Annual Review of Fluid Mechanics, Vol. 5, pp. 59-78, 1973.

8. J. Baldyga and J. R. Bourne, "A Fluid Mechanical Approach To Turbulent Mixing and Chemical Reaction, Part III Computational and Experimental Results for the New Micromixing Model", CHEM. Eng. Commun., Vol. 28, pp. 259-281, 1984.

9. J. J. Perona, T. D. Hylton, E. L. Youngblood, and R. L. Cummins, "Jet Mixing of Liquids in Long Horizontal Cylindrical Tanks”, Ind. Eng. Res., Vol. 37, pp. 1478-1482, 1998.

10. R. K. Grenville and J. N. Tilton, "A New Theory Improves the Correlation of Blend Time Data from Turbulent Jet Mixed Vessels", Trans. Inst. of Chem. Eng., Vol. 74, Part A., pp. 390-396, April 1996.

11. R. K. Grenville and J. N. Tilton, "Turbulent Flow or Flow as a Predictor of Blend Time in Turbulent Jet Mixed Vessels", Proceedings of $9^{\text {th }}$ European Conf. on Mixing, pp. 67-74, 1997.

12. M. Simon and C. Fonade, "Experimental Study of Mixing Performances Using Steady and Unsteady Jets", The Canadian J. of Chem. Eng., Vol. 71, 1993.

13. Forstall, W., Jr. and Shapiro, A. H., "Momentum and Mass Transfer in Coaxial Gas Jets", Journal of Applied Mechanics, pp. 399-408, December 1950.

14. Ricou, F. P. and Spalding, D. B., "Measurements of Entrainment by Axisymmetrical Turbulent Jets", Journal of Fluid Mechanics, Vol. 11, pp. 21-32, 1961

15. Fossett, H. and Prosser, L. E., "The Application of Free Jets to the Mixing of Fluids in Bulk", J. of Inst. of Mechanical Engineers, Vol. 160, No. 2, pp. 224-232, 1949. 
16. E. A. Fox and V. E. Gex, "Single-phase Blending of Liquids", A.I.Ch.E. Jorunal, Vo. 2, No. 4, pp. 539-544, December 1956.

17. Okita, N. and Oyama, Y., "Mixing Characteristics in Jet Mixing", Chemical Engineering, The Society of Chemical Engineers, Japan, Vol. 1, No. 1, pp. 92-101, 1963.

18. Lane, A. G. C. and Rice, P., "An Investigation of Liquid Jet Mixing Employing an Inclined Side Entry Jet", Inst. of Chemical Engineers, Vol. 60, pp. 171-176, 1982.

19. W. M. Kays and M. E. Crawford, Convective Heat and Mass Transfer, Second Edition, McGraw-Hill Book Company, New York, 1980.

20. Kiser, K. M., "Material and Momentum Transport in Axisymmetric Turbulent Jets of Water", A.I.Ch.E. Journal, Vol. 9, No. 3, pp. 386-390, 1963.

21. Post, S., 1998, "A Computational and Experimental Study of Near-Field Entrainment in Steady Gas Jets," MSME thesis, Purdue University.

22. Bamberger, J.A., L.M. Liljegren, C.W. Enderlin, P.A. Meyer, M.S. Greenwood, P.A. Titzler, and G.Terrones, Final Report: One Twelth-Scale Mixing Experiments to Characterize Double-Shell Tank Slurry Uniformity. PNNL-16859. Pacific Northwest National Laboratory, Richland, Washington, 2007.

23. Bontha, J.R., D.S. Trent, M.D. Johnson, T.E. Michener, and J.M. Bates, Development and Assessment of the TEMPEST CFD Model of the Pulse Jet Mixing Systems. PNWD3261. Battelle Pacific Northwest Division, Richland, Washington, 2003.

24. Fort, J.A., J.A. Bamberger, J.M. Bates, C.W. Enderlin, and M.R. Elmore, 1/12-Scale Physical Modeling Experiments in Support of Tank 241-SY-101 Hydrogen Mitigation. PNNL-8476. Pacific Northwest National Laboratory, Richland, Washington, 1993.

25. Onishi, Y. and K. Recknagle, Tank 241-AZ-101 Criticality Assessment Resulting from Pump Jet Mixing Sludge Mixing Simulations. Pacific Northwest National Laboratory, Richland, Washington, 1997.

26. Onishi, Y. and K. Recknagle, Performance Evaluation of Rotating Pump Jet Mixing of Radioactive Wastes in Hanford Tanks 241-AP-102 and-104. PNNL-11920. Pacific Northwest National Laboratory, Richland, Washington, 1998.

27. Onishi, Y. and K. Recknagle, Simulation of Hanford Tank 241-C-106 Waste Release into Tank 241-Y-102. PNNL-12179. Pacific Northwest National Laboratory, Richland, Washington, 1999.

28. Onishi, Y., K.P. Recknagle and B.E. Wells, Pump Jet Mixing and Pipeline Transfer Assessment for High-Activity Radioactive Wates in Hanford Tank 241-AZ-102. PNNL13275. Pacific Northwest National Laboratory, Richland, Washington, 2000.

29. Onishi, Y., R. Shekarriz, K.P. Recknagle, P.A. Smith, J. Liu, Y.L. Chen, D.R. Rector and J.D. Hudson, Tank SY-101 Waste Retrieval Assessment: Rheological Measurements and Pump Jet Mixing Simulations. PNNL-11352. Pacific Northwest National Laboratory, Richland, Washington, 1996.

30. Onishi, Y., J.M. Tingey, B.E. Wells, J. Liu, G. Terrones, K.P. Recknagle, S.T. Yokuda and M. Quinn, Retrieval and Pipeline Transfer Assessment of Hanford Tank 241-AN-105 Waste. PNNL-14144. Pacific Northwest National Laboratory, Richland, Washington, 2003.

31. Onishi, Y. and D.S. Trent, TEMPEST Code Modifications and Testing for ErosionResisting Sludg Simlations. PNNL-11787. Pacific Northwest National Laboratory, Richland, Washington, 1998.

32. Hinze, J. O., Turbulence, Second Edition, McGraw-Hill, New York, p. 72, 1975.

33. Tennekes, H. and Lumley, J. L., A First Course in Turbulence, The MIT Press, Cambridge, 1972.

34. Onishi, Y., D.S. Trent, B.E. Wells and L.A. Mahoney. 2003. Assessment of Tank 241-S112 Liquid Waste Mixing in Tank 241-SY-101. PNNL-14399. Pacific Northwest National Laboratory, Richland, Washington. 
35. Onishi, Y., B.E. Wells, S.T. Yokuda and G. Terrones. 2003. Feasibility Study on Using a Single Mixer Pump for Tank 241-AN-101 Waste Retrieval. PNNL-14105. Pacific Northwest National Laboratory, Richland, Washington.

36. Onishi, Y., and B.E. Wells. 2004. Feasibility Study on Using Two Mixer Pumps for Tank 241-AY-102 Waste Mixing. PNNL-14763. Pacific Northwest National Laboratory, Richland, Washington.

37. Onishi, Y., S.T. Yokuda and C.H. Majumder. 2002. Optimal Elevation and Configuration of Hanford's Double-Shell Tank Waste Mixer Pumps. PNNL-13913. Pacific Northwest National Laboratory, Richland, Washington.

38. Powell, M.R., Y. Onishi, and R. Shekarriz. 1997. Research on Jet Mixing of Settled Sludges in Nuclear Waste Tanks at Hanford and Other DOE Sites: A Historical Perspective. PNNL-11686. Pacific Northwest National Laboratory, Richland, Washington.

39. Succi, S. 2001. The Lattice Boltzmann Equation for Fluid Dynamics and Beyond, Clarendon Press, Oxford.

40. Trent, D.S., and L.L. Eyler. 1993. TEMPEST: A Computer Program for ThreeDimensional, Time Dependent Computational Fluid Dynamics. PNL-8857, Vol. 1, Pacific Northwest National Laboratory, Richland, Washington.

41. Trent, D.S. and T.E. Michener. 1993. Numerical Simulation of Jet Mixing Concepts in Tank 241-SY-101. PNL-8559. Pacific Northwest National Laboratory, Richland, Washington. 


\section{APPENDIX}

The flow of fluid through a pipe of uniform (circular) cross-section is known as HagenPoiseuille flow. The Hagen-Poiseuille flow is an exact solution of the Navier-Stokes equations in fluid mechanics. The equations governing the Hagen-Poiseuille flow can be derived from the Navier-Stokes equation in cylindrical coordinates by making the following set of assumptions:

- The flow is steady.

- The radial and swirl components of the fluid velocity are zero $\left(u_{r}=u_{\theta}=0\right)$.

- The flow is axisymmetric and fully developed.

Then the second of the three Navier-Stokes momentum equations and the continuity equation are identically satisfied. The first momentum equation reduces to, i.e., the pressure $p$ is a function of the axial coordinate $z$ only. The third momentum equation reduces to:

$$
\mu \frac{1}{r} \frac{\partial}{\partial r}\left\{r\left(\frac{\partial u}{\partial r}\right)\right\}=\left(\frac{d p}{d z}\right)
$$

The solution is

$$
u_{z}=\left(\frac{1}{4 \mu}\right)\left(\frac{d p}{d z}\right) r^{2}+C_{1} \ln r+C_{2}
$$

Since $u_{z}$ needs to be finite at $r=0, c_{1}=0$. The no slip boundary condition at the pipe wall requires that $u_{z}=0$ at $r=R$ (radius of the pipe), which yields

$$
C_{2}=-\left(\frac{1}{4 \mu}\right)\left(\frac{d p}{d z}\right) R^{2}
$$

$u_{z}=-\left(\frac{R^{2}}{4 \mu}\right)\left(\frac{d p}{d z}\right)\left\{1-\left(\frac{r}{R}\right)^{2}\right\}$

$Q=\int_{0}^{R} u_{z} d A=-\left\{\left(\frac{\pi R^{4}}{8 \mu}\right)\left(\frac{d p}{d z}\right)\right\}$

$\mu=-\left\{\left(\frac{\pi R^{4}}{8 Q}\right)\left(\frac{d p}{d z}\right)\right\} \approx\left(\frac{\pi R^{4} \Delta p}{8 Q L}\right)=\left(\frac{\pi R^{4}}{8 Q}\right)\left(\frac{\Delta p}{L}\right)$

This corresponds to laminar flow regime. So, it can be extended to the application of turbulent flow regime since average pressure gradients for both of the flow regimes are closely related to the viscosity for given flow conditions.

$$
\mu_{t} \approx\left\{\left(\frac{\pi R^{4}}{8 Q}\right)\left(\frac{\Delta p}{L}\right)_{t}\right\}
$$

The power $P$ for flow rate $Q$ is

$$
P \approx Q \Delta p
$$


In this case, energy dissipation rate per unit volume, $\varepsilon_{v}$, can be quantified.

$\varepsilon_{V} \approx\left(\frac{Q \Delta p}{V}\right)=\left(\frac{Q}{\pi R^{2}}\right)\left(\frac{\Delta p}{L}\right)_{t}$

Pressure gradient for Eq. (A9) can be expressed in terms of turbulent viscosity $\left(\mu_{t}\right)$ from Eq. (A7).

$\varepsilon_{v} \approx 32\left(\frac{\bar{u}}{D}\right)^{2} \mu_{t}$

Turbulent energy dissipation rate per unit mass, $\varepsilon$, is associated with turbulent eddy viscosity. That is,

$$
\varepsilon=\frac{1}{\rho} \varepsilon_{v}=32\left(\frac{u}{D}\right)^{2} v_{t}
$$




\section{E-Mail Attachment}

\section{"Rector, David" <david.rector@pnl.gov>}

11/12/2008 12:20 PM

\author{
To "richard.dimenna@srnl.doe.gov" \\ <richard.dimenna@srnl.doe.gov> \\ CC \\ Subject Signature
}

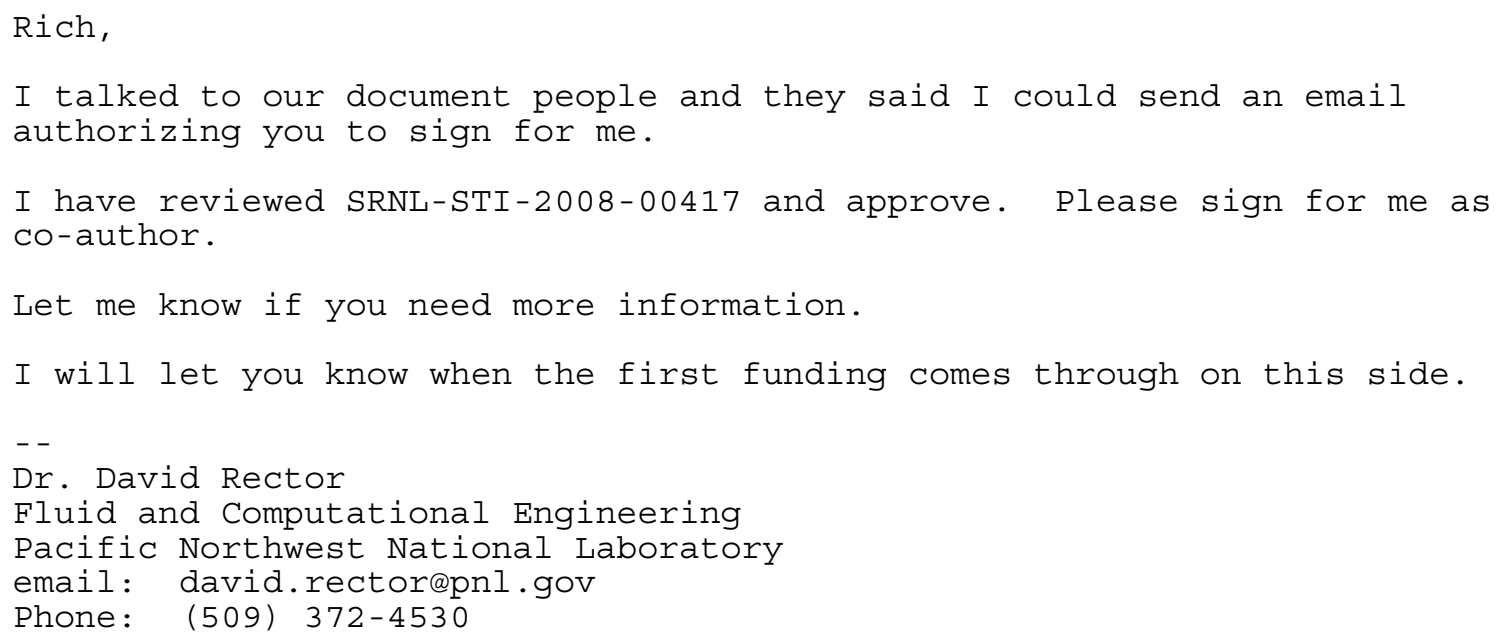

